\title{
Investigating Interactive Biophilic Wearable Objects
}

\author{
by \\ Neda Fayazi
}

A thesis submitted to

the Faculty of Graduate and Postdoctoral Affairs

in partial fulfilment of the requirements for the degree of

Master of Design

in

Industrial Design

Carleton University

Ottawa, Ontario

(C) 2014, Neda Fayazi 


\begin{abstract}
Designers apply different design elements such as form, colour, texture, light, and movement in the design of products. This interdisciplinary study aims to investigate the application of 'biophilic movement' in the design of interactive wearable objects, given that incorporating both natural inspiration (discipline of biology) and physical movement in the design of products can create a pleasurable experience for the users. In order to investigate how designers might incorporate 'biophilic movement' in the design of products, this research draws from the discipline of biology. The study applies inspiration derived from plant and animal movements, which have positive impacts on human psychology. Furthermore, this study takes a user-centered approach by applying different methods: exploring the people's emotional response to different biophilic movements incorporated in designed wearable objects. Based on these emotional responses, this thesis suggests that biophilic movement can potentially create a pleasurable experience and enhance the interaction between people and wearable objects with biophilic movements . The key findings of this study include: 1) Adding biophilic movement can add interest to biophilic wearable objects by engaging the people who interact with it; 2) Identifying and categorizing biologically inspired movements can help designers in the area of biology-to-design; and 3) Presenting a biophilic semantic differential scale that can be used to understand how people interpret movements in biophilic artifacts.
\end{abstract}

Key Words: Interactive Wearable Objects, Biophilic Movement, Design \& Pleasure 


\section{ACKNOWLEDGMENTS}

I am truly indebted to many people for their kind support, care, and encouragement during the time I was conducting this research.

First and foremost, I would like to express my deepest appreciation and gratitude to my dear advisor, Professor Lois Frankel for the continuous support, patience, and knowledge. Her unflagging moral support and invaluable comments, suggestions, and encouragement have been of the greatest help.

I would also like to thank my co-advisor, Dr. Jeff Dawson, for his help and direction with this thesis. I am sincerely thankful to him for his great favours.

I am also thankful to Dr. Ryan Chlebak for his guidance and assistance in designing the mechanism for the flapping prototype.

Moreover, I would like to thank Ben Hopson for dedicating his time to participate in my research study. I would also like to thank my friends, and other individuals who have willingly participated in my study and shared their precious time and experiences during the process of this thesis.

Last, but by no means least, very special thanks to my parents, Soraya and Farhang, for their unending love and support, for always believing in me and giving me the opportunity to follow my dreams and for supporting me in every step of my life, especially my education . I am also thankful to my only sister, Samira and her lovely husband, Mazyar, for always being there for me through everything.

Once again, thank you all! Writing this thesis would not have been possible without your support. 


\section{TABLE OF CONTENTS}

PAGE

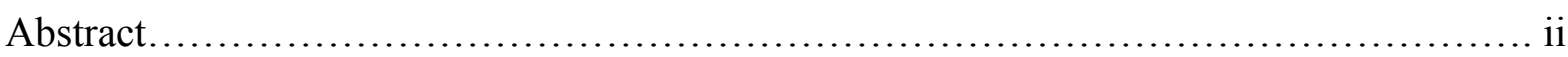

Acknowledgements....................................................... iii

List of Appendices.......................................................... vii

List of Tables................................................................. vii

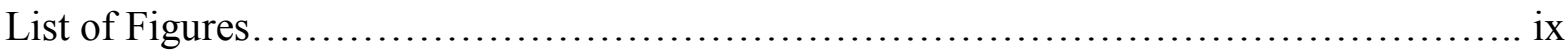

\section{CHAPTER}

1. INTRODUCTION ............................................................

1.1. Purpose of the Study ................................................

1.2. Hypothesis ..........................................................

1.3. Rational for the Research Topic \& Contribution to the Field...................4

1.4. Scope \& Limitations of the Study......................................... 4

1.5. Thesis Structure..............................................................

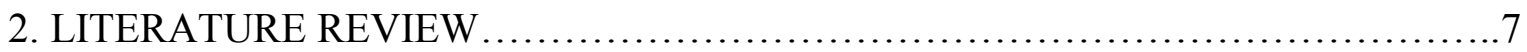

2.1. Experience of Nature...................................................

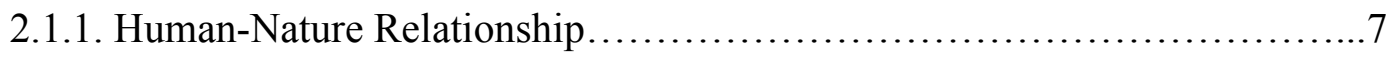

2.1.2. Design Inspired by Nature.......................................... 9

2.1.3. Summary-Experience of Nature.................................. 14

2.2. Wearable Objects................................................... 15

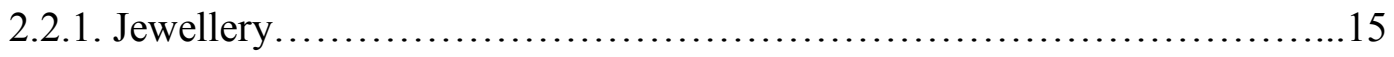

2.2.2. Wearables.................................................... 19

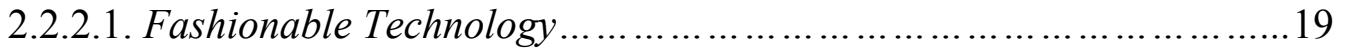

2.2.3. Sensory Experience with Interactive Objects..........................22

2.2.4. Summary-Wearable Object......................................24

2.3. Movement as a Dynamic Element of Design................................24

2.3.1. Qualities and Characteristics of Movement..........................24

2.3.2. Form and Movement...............................................25 
2.3.3. Communication Emotions and Experiences through Movement......... 25

2.3.4. Designing Movement for Products ................................ 28

2.3.5. Summary-Movement as a Dynamic Element of Design................. 30

2.4. Emotional Experience in User-Product Interaction......................... 30

2.4.1. Affect and Core Affect........................................... 31

2.4.2. Enhancing Pleasure through Familiar and Unfamiliar Objects............ 32

2.4.3. Exploring People's Emotions ......................................... 33

2.4.4. Summary-Emotional Experience in User-Product Interaction............ 34

SUMMARY-LITERATURE REVIEW ...........................................

3. PHASE ONE: INVESTIGATING FIELD RESEARCH \& DESIGN PROCESS ...........36

3.1. INTRODUCTION.........................................................

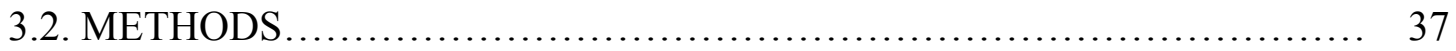

3.2.1. Internet Survey of Videos \& Exhibition Visits..................... 37

3.2.2. Brainstorming Workshop........................................ 38

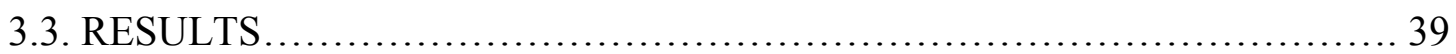

3.3.1. Results of Internet Survey of Videos \& Exhibition Visits................. 39

3.3.2. Results of Brainstorming Workshop.............................. 41

3.4. DESIGN PROCESS.................................................. 42

3.4.1. Idea Generation: Generating Form to Represent Movements............. 43

3.4.2 Prototype Making................................................. 43

3.4.2.1. Prototype A..................................................... 44

3.4.2.2. Prototype B................................................... 46

3.4.2.3. Prototype C.............................................. 47

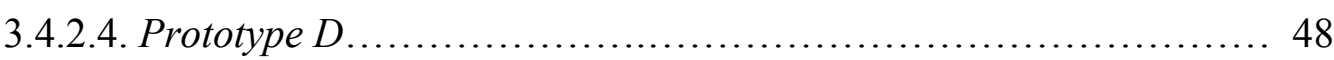

SUMMARY-PHASE ONE................................................... 49 
4. PHASE TWO: EXERCISES............................................... 50

4.1. INTRODUCTION .............................................. 50

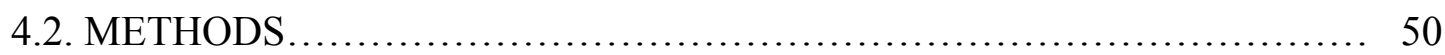

4.2.1. Exercise One................................................ 50

The Setting and Materials...................................... 50

Procedure and Participants..................................... 52

4.2.1.1. Emocards, Multiple-Choice \& Open-ended Questionnaires......... 53

4.2.2. Exercise Two.................................................. 54

4.2.2.1. Polar Adjectives, Card Sorting \& Semantic Differential Scale....... 54

The Settings and Materials........................................55

Participants.............................................56

Procedure.................................................. 56

4.2.2.2. Observation, Verbal Comments ................................. 56

4.2.2.3. Comparative Questionnaire.................................... 57

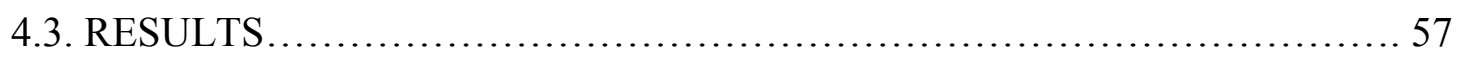

4.3.1. Results of Exercise One......................................... 57

4.3.1.1. Results of Emocards..................................... 57

4.3.1.2. Results of Multiple-choice questionnaire ........................... 58

4.3.1.3. Results of Open-ended Questionnaire............................. 59

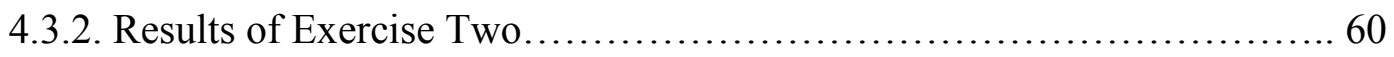

4.3.2.1. Result of Polar Adjectives,

Card Sorting \& Semantic Differential Scale.........................60

4.3.2.2. Results of Observation \& Verbal Comments.........................67

4.3.2.3. Results of Comparative Questionnaire.......................... 70

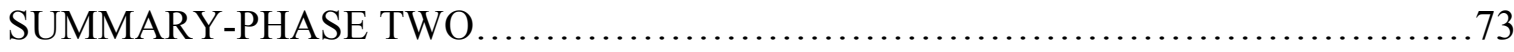

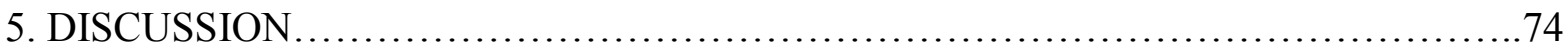

5.1. Creating Pleasure through Interactive Biophilic Wearable Objects................ 74

5.2. Design Guidelines................................................... 76

5.3. Implications and Contribution of the Study............................. 78 
5.4. Limitations of the Study........................................... 78

6. CONCLUSION \& SUGGESTIONS ........................................... 81

6.1. Conclusion........................................................... 81

6.2. Suggestions for Future Research................................... 82

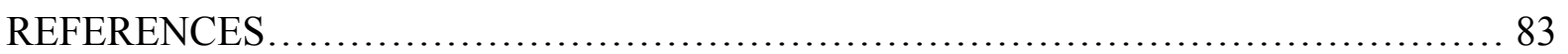

APPENDICES

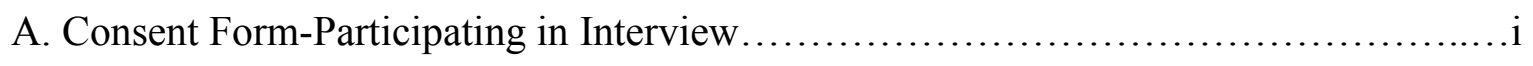

B. Expert Interview Questions................................................ii

C. Internet Survey of Videos \& Exhibition....................................... iv

D. Consent Form-Participating in Workshop......................................

E. Workshop Hand out........................................................

F. Consent Form-Participating in Exercise One..................................viii

G. Exercise One: Emocards \& Multiple Choice Questionnaire.........................

H. Consent Form-Choosing the Adjectives for SDS .................................

I. Form-Choosing Adjectives......................................................

J. Consent Form-Participating in Exercise Two..................................xiv

K. Exercise Two: Semantic Differential Scale....................................xvi

L. Exercise Two: Comparative Questionnaire.....................................

M. Exercise Two: Observation Chart...........................................

N. Exercise Two: Semantic Differential Scale Analysis............................xxviii

O. Exercise Two: Comparative Questionnaire Analysis............................xx

P. Ethics Approval Form........................................................... 


\section{LIST OF TABLES}

Table 1. Different Approaches to the Application of Nature in Industrial Design......... 11

Table 2. Examples of Ancient Jewellery from Various Cultures..................... 12

Table 3. Classification of Biophilic Movements.................................. 40

Table 4. Results of Emocards................................................... 58

Table 5. Participants' Comments-Exercise One.................................. 59

Table 6. Top Adjectives.................................................... 61

Table 7. Chosen Adjectives................................................. 61

Table 8. Polar Adjectives.......................................................... 62

Table 9. Facial and Verbal Expressions-Exercise Two........................... 68

Table 10. Reasons for Choosing Each Prototype.................................... 73

Table11. Kinetic Wearable Object and Usability-Design Considerations................. 77 


\section{LIST OF FIGURES}

Figure 1.Indirect Experience of Nature, Necklace (c. 28,000 BC) ......................... 13

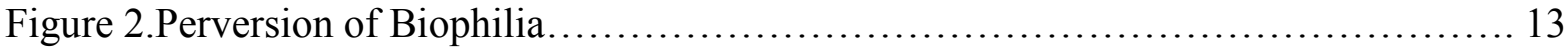

Figure 3. 'Necklace' \& 'Ring Bean................................................ 14

Figure 4. 'Tomato and Gold ring' \& 'Pepper and Found Ring' ................................ 14

Figure 5. 'Bubble Bath Neckpiece' \& 'Bracelet' .......................................... 14

Figure 6.Family Necklace (for the Schobinger family), Gerd Rothman, 1998.............. 17

Figure 7.Interactive Object: Watering Instrument Brooch (2001)....................... 18

Figure 8.Kinetic Bracelet by Friedrick Becker.................................... 18

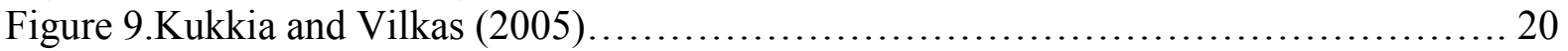

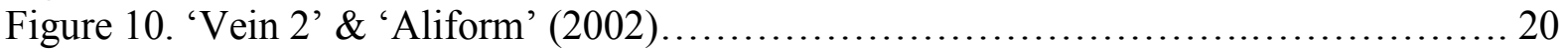

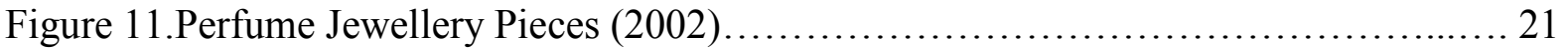

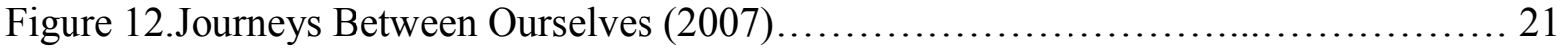

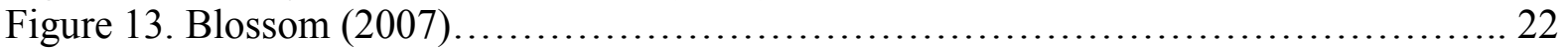

Figure 14.Virtual Dress and Test Results.......................................... 26

Figure 15. Proposed Kinetic Product Features and Meaning of Movement Model.......... 27

Figure 16. Proposed Emotion-Movement Relationship Framework......................... 27

Figure 17.Vacuum Cleaner Attachment Concept....................................... 29

Figure 18. New Product Concept for Kitchen Faucet................................... 29

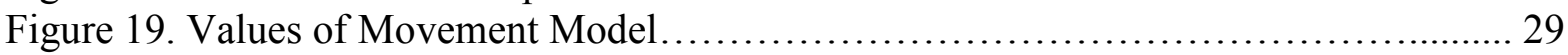

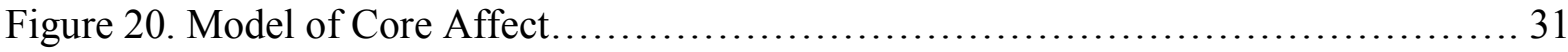

Figure 21. Carleton University's ‘Annual Butterfly Show' ................................................ . 37

Figure 22. Models Developed in the Brainstorming Workshop.......................... 39

Figure 23. Same Movement (Translational), Different Forms......................... 42

Figure 24.2-Dimensional \& 3-Dimensional Sketches.................................. 43

Figure 25. Prototype A............................................................. 45

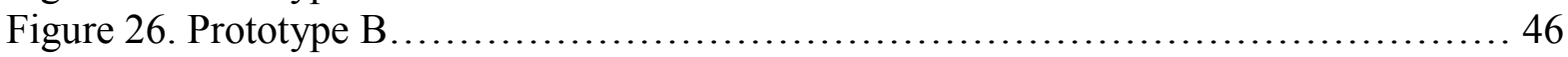

Figure 27. Prototype C....................................................... 47

Figure 28. Prototype D...................................................... 48

Figure 29. Exercise One: Brooch A (Worn) ....................................... 51

Figure 30. Location-Exercise One............................................... 51

Figure 31. Eight Emotional Categories and Emocards................................ 53

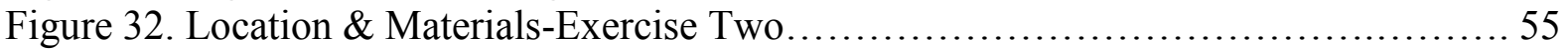

Figure 33. Emocard Analysis...................................................... 58

Figure 34. Factors Involved in Perceiving the Movement............................................. 58

Figure 35. Degree of Enjoyment from Viewing Kinetic Wearable Object................. 59

Figure 36. Prototype A Characteristics.......................................... 63

Figure 37. Prototype B Characteristics.......................................... 64

Figure 38. Prototype C Characteristics............................................ 66

Figure 39. Prototype D characteristics ........................................ 67

Figure 40. The Most Engaging Prototype during the Interaction....................... 70

Figure 41. The Most Enjoyable Prototype during the Interaction........................ 71

Figure 42. The Most Appealing Movement during the Interaction...................... 71

Figure 43. The Prototype You Choose to Wear..................................... 72 


\section{CHAPTER 1}

\section{INTRODUCTION}

Humankind has always been searching for pleasure and many people find pleasure in nature and the natural environment. They find joy from the touch of the sun on their face, or the beauty of a landscape, the feel of rain, watching animals in the wild, the warmth of a summer breeze, or the cool shade in a forest. People are also derive pleasure from the artifacts surrounding them. Norman (2004) concurs, "We become attached to things if they have significant personal association, if they bring to mind pleasant, comforting moments" (p. 48).

From the earliest time, humankind has been attached to nature and has built a strong emotional bond with nature and its surroundings. Edward O. Wilson's 'biophilia hypothesis' explores this bonding with nature (1984). He defines biophilia as "an innate human urge to have contact with other species, to spend time in natural environments, surrounded by animals and other living things" (as cited in Flannery, 2008, p. 34). This biophilic urge can inspire a biologically-based need for humans to create, associate, and co-exist with nature and the natural world (Kellert \& Wilson, 1993). A close connection with nature can have a positive impact on human well being, both physically and psychologically (Kellert, 2008; Shepard, 1996; Kaplans, 1989).

Different disciplines apply adaptations and inspirations from nature such as 'bio-inspired design', 'biomimicry', 'bionics', ‘biognosis', and 'biomimesis' (Vincent, 2007). A biophilic design - for example a building entrance where a small waterfall is surrounded by lush green plants - creates a positive atmosphere that connects people and nature in a built enivronment (Kellert, 2005). Symbolic experiences of nature provide a passive form of contact with nature through representation of the natural world such as images, videos, metaphors, dried flowers, statues, and even jewellery with a focus on nature (Kellert, 2008; Flannery, 2005). A sense of 
well-being and pleasure is often the result when people are presented with symbols and representations of nature. (Flannery, 2008; Shepard, 1996; Ulrich, 1979; Ulrich et al., 1991; Kaplans, 1989).

Objects, such as jewellery, can be mediums for creating pleasure. Jewellery is "an unusual and particular form of object: intimate, human-relational, acting as a conduit to other times, places and experiences and as such often having a strong role within our developing sense of self" (Wallace, 2007, p. 13). Jewellery can also be meaningfully and emotionally significant for the wearer. People become attached to the objects because they have "some profound and sustained meaning to [them]" (Desmet \& Hekkert, 2007, p. 61).

Nature has characteristics that can be applied in bio-inspired design. Some of these features include form, movement, growth and development, as well as complexity (Heerwagen, 2003). A design may be inspired by nature in terms of form, material, structure, mechanics, and dynamics (Volstad \& Boks, 2012). In the design of wearable objects, designers may be inspired by natural forms and shapes, as well as natural materials. Natural organic forms can bring about enhanced pleasure for customers when incorporated in designed objects (Wu \& Chang, 2007, p.1). Other aspects of nature can inspire designers in the field, such as dynamics, which includes movements and motions found in nature. Incorporating physical movement in the design of products can enhance the emotional value of the object (Nam, Lee \& Park, 2007). Hopson (2009) mentions that designing movement in objects is as important an aesthetic factor as other design elements such as form, colour, or material. Physical movement in objects can result in more exciting and creative products, contributing to commercial success (Hopson, 2008).

This thesis looks at how designers can create pleasurable experiences for users by integrating plant and animal movements in the design of interactive wearable objects. 


\subsection{PURPOSE OF THE STUDY}

This study aims to explore the emotional response of people to the application of 'biophilic movement' in the design of interactive wearable objects. It looks at how incorporating both natural/biological inspiration and physical movement in the design of wearable objects can show the potential to create pleasurable experiences by engaging people who interact with it. 'Biophilic movement' is a term developed for this research. It refers to natural movements produced by plants and animals that have a positive impact on human psychology. Biophilic movement can be designed into an interactive wearable object and applied as an output for the interactive device. The type of wearable object that this research focuses on is interactive or digital jewellery'. This research contributes to the development of digital jewellery by providing information about the value of movement, which would most likely be digitally or technically activated.

There is an input as well as an output in digital jewellery that works with sensor technology. The output of an interactive device could stimulate a visual, tactile, olfactory, or auditory sense. Digital jewellery embraces different meanings from the viewpoint of a contemporary jeweller and industrial designer. Nonetheless, the dynamic design element of physical movement can be applied as an output for a piece of jewellery, no matter how the jewellery is used. This element, like any other elements of design — such as form, colour, and texture - can be a way of enhancing the interaction between user and object. Adding natural elements to a designed object may strengthen people's emotional bond with nature and can act as a reminder of the natural world. It may also satisfy people's biophilic desires, while bringing pleasure and fun to experiences with the product.

\subsection{HYPOTHESIS}

Jewellers have been using biophilic forms for centuries, mostly as a static representation. Recently, miniaturized technologies have allowed jewellers to add movement to jewellery. 
Therefore, the hypothesis of this study is that the incorporation of biophilic movement in interactive wearable objects can create a positive emotional response.

The main question driving this research is: How can designers incorporate biophilic movements into designing interactive wearable objects in order to potentially enhance the userproduct interaction?

\subsection{RATIONALE FOR THE RESEARCH TOPIC \& CONTRIBUTION TO THE FIELD}

Most of the time, designers do not know if their interactive wearable object will be pleasant or unpleasant for the wearer and their viewers. In fact, designers often do not know how people feel toward the jewellery pieces they create. Often, their "art" pieces are expressions of their own ideas, feelings, and emotions (Meilach, 2003; Snyder, 2008). Therefore, this research takes a user-centred approach, which offers useful information for contemporary jewellers, fashion designers, and industrial designers about designing movement for interactive wearable objects. Furthermore, the study provides some insights into possible emotional responses to kinetic wearable objects. The results of the study may assist designers in deciding how to choose specific biophilic movements for wearable objects in order to engage users through the element of movement. A study of people's perceptions and emotional responses to different qualities of movement can provide valuable inspiration for the design of interactive wearable objects.

\subsection{SCOPE \& LIMITATIONS OF THE STUDY}

This research investigates interactive biophilic wearable objects to explore how people interact with and respond emotionally to them. In order to explore the issue, the study first looks into the meaning of 'biophilic movement' with the purpose of applying it in this research. Many different types of biophilic movements could have been investigated, however, this research focused specifically on four types of biophilic movements. It explored people's emotional responses to four interactive wearable objects, each incorporating different movements. 
In this investigation it was hard to separate movement from form. Therefore, in order to explore people's emotional responses toward a specific kind of movement, form was considered as a representation of movement. Form is the factor that affects people's emotional response toward the specific type of movement.

In this study, biophilic movement was incorporated into "looks-like" and "works-like" prototypes of jewellery pieces manually, and activated by the researcher to explore the emotional responses of people toward wearable objects with moving parts. If the prototypes had been more interactive (using Arduino and sensor technologies), the results might have been more realistic and come much closer to the purpose of this research. As a result, this study should be considered a preliminary investigation.

For the purposes of this study, movement is defined as the actual or apparent translation or rotation of an object. Movement may be perceived by an observer as having different qualities including speed, rhythm, continuity, direction, and changes in volume or size. Change in each of these qualities can result in a change in the viewer's emotional response. This research considered only the quality of direction. Other qualities were not taken into account. Using sensor technology may have provided more control over the speed of the objects and different results would have been obtained.

\subsection{THESIS STRUCTURE}

This thesis includes six chapters, as follows:

This first chapter introduces the thesis topic and includes the purpose of the study, why this research topic should be investigated, and its contribution to the field, followed by the hypothesis, the main question, and limitations of the study.

The second chapter provides a literature review related to the topic of 'Interactive Biophilic Wearable Objects'. The chapter is divided into four sections: Experience of Nature, 
Wearable Objects, Movement as a Dynamic Element of Design, and Emotional Experience in User-Product Interaction, respectively.

Chapter three describes phase one of the study: the methods used followed by the results. Since this was an exploratory study, the results from the first methods described in chapter three led to the next steps, which are Design Process and Prototyping followed by Phase Two (Exercises). Thus, the two phases of this research are each described in a separate chapter: Phase one (Investigative Field Research followed by Prototyping \& Design Process) and Phase two (Exercises). Chapter four explains phase two (Exercises) of the research: the methods applied followed by the results. In the methodology section, the subjects who participated in the study, the setting in which the research took place, the tools that were used to run the exercise, and the methods used for collecting and analysing the data are discussed. The 'results and findings' section pertain to qualitative results achieved from the investigation and data analysis.

Chapter five discusses and interprets the results of this study. This chapter explains the role of 'biophilic movement' in the design of interactive wearable objects. The chapter goes through the research questions in relation to the findings. It proposes design suggestions for eliciting emotional responses when incorporating biophilic movements in interactive wearable objects. This chapter also explains the contributions and limitations of the study.

Finally, chapter six is the conclusion where the main findings and results of the research are summarized. This chapter also makes suggestions for future research. 


\section{CHAPTER 2}

\section{LITERATURE REVIEW}

This literature review addresses different areas related to interactive biophilic wearable objects that lead to the research questions. The first section addresses the human-nature relationship and design inspired by nature. The second section focuses on jewellery and fashionable technology, including sensory experiences with interactive objects. The third section discusses the meaning of movement and the value it adds to user-product interaction. The fourth section addresses the emotional experience in user-product interaction.

\subsection{EXPERIENCE OF NATURE}

In order for designers to be inspired by nature, they can try to understand the relationship between humans, nature, and the impact of different natural elements on people's experiences. This study focuses only on the aspects of nature that are known to have positive impacts on people since these positive impacts can enhance the value of a design. However, the natural environment is also filled with dangers like snakes or height that create fears, stress, and “biophobic" responses (Heerwagen \& Hase, 2001).

\subsubsection{Human-Nature Relationship}

History reveals that humankind has always been both intrigued by nature and a desire to preserve it. The term biophilia was coined to describe this (Flannery, 2008). According to biologist Edward O.Wilson, (1984) 'Biophilia' describes “an innate human urge to have contact with other species, to spend time in natural environments, surrounded by animals and other living things" (as cited in Flannery, 2008, p. 34). Wilson (1989) defines biophilia as the "innate tendency to focus on life and lifelike processes" (Kellert \& Wilson, 1993, p. 4).

Contact with nature can provide positive impacts for human beings (Kellert, 2008; Shepard, 1996; Kaplans, 1989). Kaplan's research (1989) reveals that contact with nature at the 
workplace can decrease job stress and increase job satisfaction. Moreover, it improves the physical, emotional, and intellectual well-being of workers at the workplace (Kellert, 2005). For example, being exposed to a fish aquarium can result in positive changes in diastolic blood pressure, overall leisure satisfaction, and the relaxation states of people (Katcher et al., 1984; Riddick, 1985).

Contact with nature can be achieved through active (gardening, and walking) or passive (observation) interactions (Heerwagen, 2009). Kellert (2008) describes direct, indirect, and symbolic ways of interacting with nature. Direct experience includes contact with the natural environment, such as daylight, plants, animals, natural habitats, and ecosystems. Indirect experience refers to "contact with nature that requires ongoing human input to survive such as with a potted plant, water fountain, or aquarium" (Ibid, 5). Designing indirect experiences of nature requires the manipulation of environmental elements such as vegetation, animal life, light, air, water, and materials (e.g., stone, wood, cotton, hides, wool, leather) (Kellert, 2005). Symbolic or vicarious experiences of nature involve "no actual contact with real nature, but rather the representation of the natural world through image, picture, video, metaphor, and more" (Ibid, 6).

Ulrich (1984) investigates the impact of the visual perception of nature on people. Viewing nature, even in a passive form such as videos, or photographs, increases positive feelings and reduces stress (Ulrich, 1979; Ulrich et al., 1991). Heerwagen and Orians (1986) observe that employees with windowless offices tend to use more visual materials from natural settings instead of urban environments. Shepard (1996) also points out the role of flora and fauna photographs as reminders of the living world and natural settings. Flannery (2001) discusses the importance of nature and natural representations in the interior design of homes and living areas. In this century, people live most of their time away from natural environments. Even a minimum amount of interaction with nature — in the form of representations and reminders such as dried flowers, images, statues, and jewellery with a nature focus — can act as 
a medium for satisfying people's biophilic desire for nature (Flannery, 2005). The history of bioinspired jewellery indicates that the use of flora and fauna in jewellery is often symbolic. It is not obvious that using symbolic organisms in the design of jewellery is solely for satisfying biophilic desire, but Flannery (2007) notes, “I don't think the use of organisms as symbols is evidence against the significance of biophilia” (p. 44). Flannery, (2008) who applies biophilia to jewellery, says "Jewellery depicting flora and fauna could play a role in building mental wellbeing" (p. 41).

In short, designing symbolic representations and reminders of nature, such as in jewellery with a nature focus, can be effective in creating positive psychological feelings.

\subsubsection{Design Inspired by Nature}

Similar words and phrases imply copying, adaptation, or derivation from biology, such as 'biologically inspired design', 'biomimesis', 'biomimicry', 'bionics', and 'biognosis' (Vincent, 2007). It is important to understand the features, characteristics, forms and sensory attributes of nature that attract, repel, and affect people in order to create bio-inspired design (Heerwagen, 2003). As mentioned by Heerwagen (2003), the general characteristics of nature, which define it as a candidate for bio-inspired design, are described below:

1. Movement. All living organisms and life supporting systems of nature have movement. Movement is generated by the organism itself or generated with the aid of wind, water, or attachment to a moving organism. Katcher and Wilkins (1993) believe that some movement patterns are associated with safety and tranquillity, such as the soft movement of grasses in a light breeze or movement of fish in an aquarium. Other types of movements are associated with danger and erratic, sudden movements, such as birds fleeing from a hawk (as cited in Heerwagen, 2009).

2. Growth and Development. All living organisms show developmental patterns that grow over time from simple to a more complex form. Patterns of development are viewed in life-like processes, such as storms and daily light cycles. 
3. Complexity. Complex design or adaptive complexity can be viewed in all organisms and life-like processes. This complexity may not be initially clear, but is discovered through sensory exploration.

4. Fractal Patterning. Fractal growth can be seen in the forms and patterns of living organisms, systems, and natural processes. These types of patterns are similar at different scale levels, but are not exact replicas of one another. In contrast, many patterns designed by humans repeat the same form in different colours and sizes.

5. Organic Shapes. Natural forms consist of curvilinear and organic shapes rather than rectilinear ones. Studies show that people have a positive attitude toward organic shapes and curvilinear spaces in buildings, landscapes, and artifacts (Heerwagen 2003). The term, 'Bios form' is the synonym of 'biomorphic', 'organic', and 'freeform' (Patton, 2005 cited in Wu \& Chang, 2007). Bios forms are often applied in design to improve the value of the products for the consumer market (Wu \& Chang, 2007). Results of a study conducted by $\mathrm{Wu}$ and Chang (2007) reveal that products with less abstract forms and with life-like animal features are more attractive for consumers and evoke more pleasure.

6. Multi-sensory. Living organisms and life supporting processes (e.g. fire, water, and sun) are sensory rich as they can communicate information to all human senses: sight, sound, touch, taste, and odour.

7. Abstract Informational Characters. Kaplan and Kaplan (1989) indicate different visual qualities for environments that have high psychological attraction (appeal) and are essential for information processing: coherence, legibility, complexity, and mystery (Heerwagen, 2003).

Different art and design disciplines, such as architecture, decorative art, product design, fashion design, and jewellery design incorporate natural elements. In built environments, the connection between people and nature is called positive environmental impact or 'biophilic design' (Kellert, 2005, p. 143). A biophilic design creates environments filled with naturally agreeable and appealing positive emotional experiences (Kellert et al., 2008). 
Biomimicry is "the act of learning from nature, borrowing designs and strategies that have worked in place for billions of years" (Benyus, 2008, p. 28). The practice of biomimetic invention can proceed from biology-to-design or from design-to-biology.

In the design-to-biology approach, the designer starts with a human design challenge, identifies the core function, and then reviews how various organisms or ecosystems achieve that function but in the biology-to-design approach, this application consists of using form/shape language from nature to create aesthetically pleasing products. It is used in design projects with a strong artcomponent (Volstad \& Boks, 2012, p. 193).

In the field of jewellery design, biophilic representations - like floral brooches or rings — are derived from nature. This traditional or classic approach is an example of a biology-todesign approach.

The table below reveals applications of nature in the field of industrial design. Thus, a design may be biomimetic in terms of form (what it looks like), material (what it is made out of), structure (how it is made), mechanics (how it works), or function (what it is able to do).

Table 1. Different Approaches to the Application of Nature in Industrial Design

(Volstad \& Boks 2012, p.193)

\begin{tabular}{|l|l|}
\hline $\begin{array}{l}\text { Materials } \\
\text { material science }\end{array}$ & Approach 1 \\
\hline $\begin{array}{l}\text { Mechanineering } \\
\text { general engineering, locomotion }\end{array}$ & Approach 2 \\
\hline $\begin{array}{l}\text { Structure } \\
\text { structural engineering, architecture }\end{array}$ & Approach 2 \\
\hline $\begin{array}{l}\text { Form } \\
\text { architecture and art }\end{array}$ & Approach 3 \\
\cline { 1 - 2 }
\end{tabular}

The qualities mentioned in Table 1 can be inspired by nature and integrated in product design to enhance the value of the object. Historically indirect and symbolic experiences of nature have been applied when designing jewellery pieces by presenting forms, shapes, and the 
materials of flora and fauna. Examples of ancient jewellery from various cultures reveal the long history of natural representations in body ornaments (Table 2).

Table 2. Examples of Ancient Jewellery from Various Cultures

\begin{tabular}{|c|c|}
\hline Jewellery Piece & Description \\
\hline & $\begin{array}{l}\text { "Sumerian court jewellery from Ur (2500 BC), made principally of gold, lapis lazuli } \\
\text { and cornelian, including Queen Pu-abi's headdress of gold flowers and other jewels } \\
\text { from her tomb" (Phillips, 1996, p.11) }\end{array}$ \\
\hline & $\begin{array}{l}\text { "A Minoan gold repousse pendant, said to be from the island of Aegina }\left(17^{\text {th }} \text { century }\right. \\
\text { BC). It shows a Nature god standing on a field with lotuses, holding in either hand a } \\
\text { water-bird. The two curved objects behind him are probably composite bows" (Trait, } \\
\text { 2008, p. 38). }\end{array}$ \\
\hline & $\begin{array}{l}\text { "Pectoral ornament found in the tomb of Tutankhamun, c. 1336-1327 BC. The motifs } \\
\text { include the udjat eye, winged scarab, cobras crowned by sun-discs, and lotus flowers } \\
\text { and buds" (Phillips, 1996, p.18). }\end{array}$ \\
\hline & $\begin{array}{l}\text { "Dress-pins from Luristan, in the western part of modern Iran (c. 1000-700 BC).The left } \\
\text { one is the shape of a winged monster, while the disc shaped head of right one is } \\
\text { decorated with a pattern of arcaded buds and pomegranates" (Trait, 2008, p. 54). }\end{array}$ \\
\hline & $\begin{array}{l}\text { "Korean earrings of the } 5^{\text {th }}-6^{\text {th }} \text { century AD. The single earing is decorated with } \\
\text { granulation. The pair of earrings consists of openwork roundels hung with small leaf- } \\
\text { shaped pendants, with another large leaf-shaped pendant below" (Trait, 2008, p. 119). }\end{array}$ \\
\hline & $\begin{array}{l}\text { "Russian bouquet of brilliant-cut diamond flowers and emerald stems, 1760" (Philips, } \\
\text { 1996, p. 110). }\end{array}$ \\
\hline
\end{tabular}

Through an indirect experience of nature, natural materials can be applied in the design of jewellery. Before people were able to shape metal or carve stone, they adorned their bodies with natural materials and objects such as berries and shells in a form of simple beads (Phillips, 1996, see Figure 1).

Attraction to nature and other species can lead to killing organisms instead of preserving them. Manipulation of natural materials to satisfy people's desire for nature can damage the organism itself. Flannery (2008) refers to this as perversion of biophilia. To fulfil their indirect 
experience of nature, people kill organisms and make deer-head trophies, tiger-skin rugs, sheep skin coats, and fur jackets, thereby keeping nature close (Figure 2).

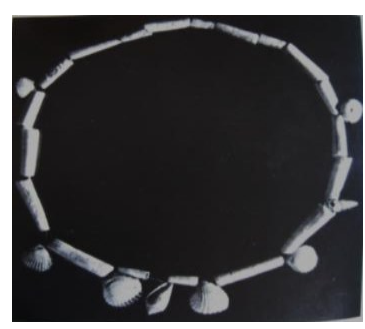

Figure 1.Indirect Experience of Nature, Necklace (c. 28,000 BC), Fossilized shells strung together as beads (Phillips, 1996, p. 8)

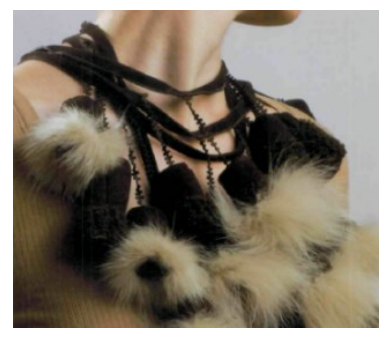

Figure 2.Perversion of biophilia, Beige Mink Hanging Neckpiece by Tina Rath, 2001 (Flannery, 2008, p. 39)

Designers apply natural forms and shapes as well as natural materials in the design of wearable objects. There are other aspects of nature that can be inspired by designers in the field. One of these aspects is the mechanics, dynamics, approach 2 (Table 1, p.11). In contemporary times, the fields of social robotics, robotic art, puppetry, choreography, and automata benefit from the element of motion and kinetic forms in functional and perceptual areas (Parkes, Poupyrev \& Ishii, 2008). Here is an opportunity for designers of wearable objects to get inspiration from the movements found in nature. Some designers have attempted to simulate animal or human forms and movements in different design disciplines. The examples of early kinetic art, automata, and robotic art that are mimetic of living things reveal the power of motion as a medium for engaging, fascinating, and creating an interactive conversation between the object and user (Parkes et al., 2008).

Three examples of modern jewellers' works are presented here to illustrate the incorporation of nature in the designed objects (Astfalck, Broadhead \& Derrez, 2005).

Nana Akashi’s jewellery uses natural forms such as flowers, chilis, and beans. She believes that jewellery should have the capacity to stimulate the viewer's senses and incorporates movement and sound in her work. In her chili whistle (2003), the piece acts as both a necklace and a musical instrument (Figure 3, left). From the same collection, a ring bean (2003) rattles as it moves on the fingers (Figure 3, right). 


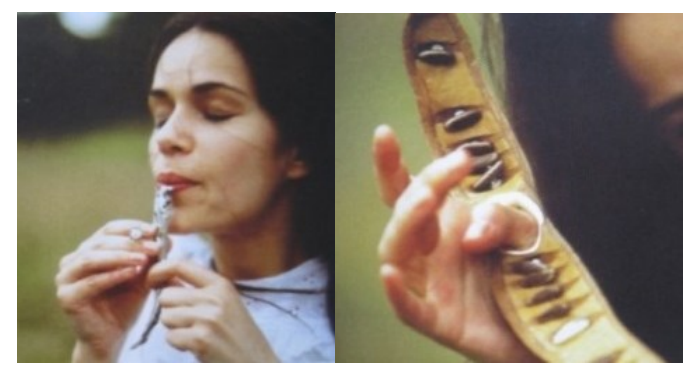

Figure 3.'Necklace' \& 'Ring Bean'

Hilde De Decker pushes the boundaries between jewellery and nature by playing with materials, techniques, and appearances. As shown in the figure below, the vegetable wears the jewellery in one and the jewellery wears the vegetable in the other. De Decker presents a tomato set as a stone on a ring, demonstrating unusual colours, textures, and forms (Figure 4, left). She also placed a bejewelled ring squeezed into a paprika as it grew (Figure 4, right).

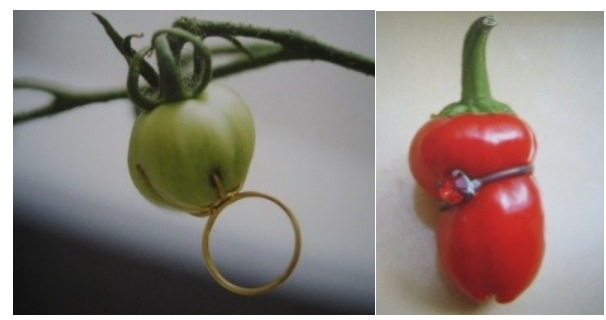

Figure 4. 'Tomato and Gold ring' \& 'Pepper and Found Ring'

Use of organic forms can also be viewed in Nora Fok's works. She calls her works 'wearable sculptural objects'. Her jewellery is based on the organic fluidity of life (Figure 5).

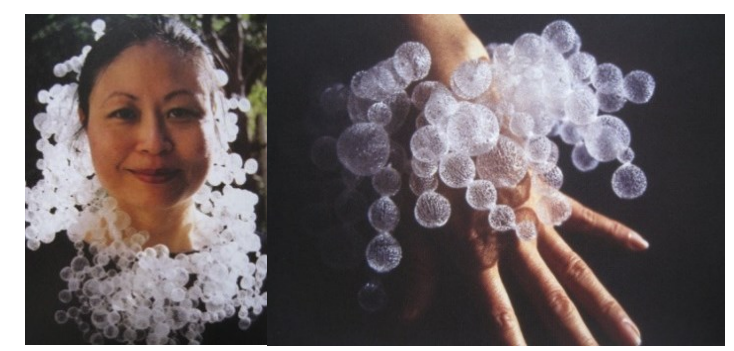

Figure 5. 'Bubble Bath Neckpiece' \& 'Bracelet'

\subsubsection{Summary_Experience of Nature}

Contact with nature has a positive effect on people's emotional state. Nature and the natural environment are often a great source of pleasure for humans (Jordan, 2000). Designers 
apply natural forms and materials in the design of wearable objects. Symbolic interaction with nature such as bio-inspired jewellery, through interacting with objects that focus on nature, is effective in satisfying people's desire for nature. Other aspects of nature, such as dynamics, can also be inspired by designers in the field. This raises the question: In order to enhance the interactions between humans and objects, can natural movements, in addition to forms and shapes, inspire the design of wearable objects?

\subsection{WEARABLE OBJECT}

This section discusses the meaning of 'wearable object', whether digital or non-digital. It looks into different realms of jewellery, fashionable technology, and the meaning of wearable objects from the perspective of traditional and contemporary jewellers.

\subsubsection{Jewellery}

Both men and women have been wearing forms of jewellery since ancient times. "Jewellery is an intensely personal art form... [it] allows the wearer an opportunity to celebrate an occasion or key moment in life and encapsulates the spirit of an emotion forever" (Galton, 2012, p. 10). In early times, people decorated their bodies to satisfy their wishes for selfadornment (Trait, 2008, p. 11). Friesen (2011) states that "humans have proven their attraction towards ornamenting themselves - as an expression of love, an enhancement of beauty, a show of pride, status or wealth, religious affiliations, everything from a simple statement of belief to a show of hierarchy and power" (p. 64). According to Derrz, "Jewellery could be a statement, a mass-produced product, an accessory, a DIY kit, a clothing addition, a photographic prop, wearable sculpture, a costume or stage pieces" (2005, p.12). Kuhn and Stiner (2007) point out, "Body decoration is a kind of information technology for transmitting social information about the wearer. It tells the viewer who we are, and how we might relate to them or other people around us" (p. 41). Today, people can communicate from a distance while walking down the street, long before verbal communication takes place, They communicate through body decoration through tattoes, body piercings, and personalized styles of clothing. By wearing a 
certain kind of decoration, non-verbal messages are commuicated and transmitted to others who pick up the non-verbal signals. (Kuhn \& Stiner, 2007).

While traditional jewellery has been used to symbolise wealth, social status, and cultural positioning, contemporary jewellery is a medium for designers to communicate their beliefs, fashion trends, concerns, attitudes to society, cultural viewpoints, and rituals (Cheung, 2006, p. 12). According to Snyder (2008), “Art jewellers have a facility for engaging the senses, inspiring emotions, and producing wearable art that will complement the human form while making a statement" (p. 7).

People wear jewellery for different reasons. One receives jewellery as a gift, or a piece might contain stories, personal histories, and associations with loved ones or significant life events. The meanings behind the object transform it from 'traditional' jewels into jewellery (Cheung, 2006). People identify metaphors and assign certain kinds of meanings, personality, and expressive qualities to products. Desmet and Hekkert (2007) define this product experience as a level or experience of meaning. This level involves cognitive processes such as interpretation, memory recovery, and association. Products such as jewellery can contain deep emotional meaning, and a person's experience of that meaning can bring about attachment.

Jewellery is an object that might be emotionally significant for the wearer just because it connects the user to loved ones, family, other people, or places. The jewellery acts as a memento and builds a very strong attachment with the wearer based on meaning and emotional experience. Norman (2004) mentions:

We become attached to things if they have a significant personal association, if they bring to mind pleasant, comforting moments... Our attachment is really not to the things, it is to the relationships, to the meanings and feelings the thing represents (p. 48). 
As well, due to the close relationship between jewellery and the human body, jewellery is a special object that can signify deep social, personal, and cultural meanings. Broadhead (2005) states:

When objects are active at the boundary of the body-jewellery in its widest sense - there is the potential to explore identity and meaning... Objects that are used in a close relationship to an individual can indicate a personal history, declare a relationship to others, and raise issues of identity and status (p. 25).

Examples indicate the emotional bonds between the wearer and the piece of jewellery. In one example, a wearer says that she cannot take her rings off because her children gave them to her. Another example — Gerd Rothman's piece, "Family Necklace” (Figure 9) — consists of small, gold discs randomly marked with fingerprints of her family. The wearer believes that, "when I wear it, my family is with me". Therefore this piece demonstrates the importance of personal meaning, like love, commitment, and family values (Figure 6).

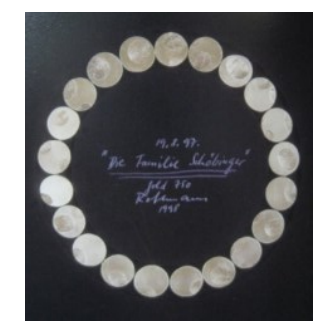

Figure 6. Family Necklace (for the Schobinger family), Gerd Rothman, 1998

Jewellery can act as an interactive object. According to Kluszczynski (2010):

An interactive artwork takes on the shape of an event. An artist does not make a final, completed piece of art, instead produces an area of activity for the receivers, whose interactive actions bring to life an artwork-event (p. 1).

Jewellery can serve as an interactive element to evoke a sense of play and pleasure for the wearer or to create a private joke that can be shared with others. It can also be carried around all day to invite wearers and viewers to laugh. An example of this can be viewed in the work of Sigurd Bronger, called "Watering Instrument" (Figure 7). This playful interactive object creates 
a new form of pleasurable interaction between the wearer (the person wearing a piece of jewellery), the object, and viewer (the person observing the wearer with his or her piece of jewellery). Jordan (2002) defines this type of pleasure as socio-pleasure, which is a type of pleasure and enjoyment derived from relationships with other people, and society as a whole. He points out that products such as a piece of jewellery may facilitate social interaction by attracting people's comments.

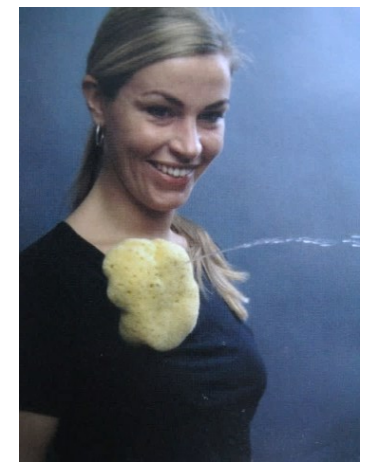

Figure 7. Interactive Object: Watering Instrument Brooch (2001)

In another example, the element of movement is incorporated into the design of interactive jewellery pieces created by Friedrich Becker (1922 - 1997), the creator of kinetic jewellery (Figure 8). His desire was to develop kinetics on a miniature scale with jewellery as well as on a large-scale with sculptures. Becker benefited from his knowledge of aeronautical engineering and combined it with craftsmanship ("The Artistic Work," n.d.).

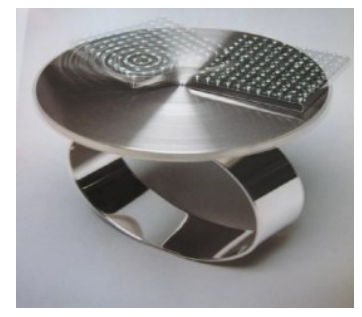

Figure 8. Kinetic Bracelet by Friedrick Becker (Dormer and Turner, 1994)

Thus, designers incorporate different elements — such as water in the work of Sigurd Bronger or movement in the work of Friedrich Becker — in the design of interactive wearable objects to communicate with people. 


\subsubsection{Wearables}

Garments with embedded sensors are developed and employed for interactive entertainment, sport, military, medicine, exercising, connecting people to others, and other networked activities (Frankel, 2007; Carpi \& DeRossi, 2005; Helmer et al., 2008). One fundamental component of wearable electronic systems is the sensor. Sensor technology can be integrated into garments for the purpose of capturing physiological data such as body temperature, heart rate, skin conductivity, etc. (Tang, 2007). Sensors can also gather data from the environment as well as the wearer (Seymour, 2009). There are several areas of wearable technology such as wearable computers, second skin (or memory-rich clothing), digital jewellery, and personal area networks (PANs) (Owens, n.d.).

\subsubsection{Fashionable Technology}

Today, many designers in the area of fashion and contemporary jewellery are incorporating sensor technology in their works to express different ideas, values, and meanings (Seymour, 2009; Wallace, 2007). The new interactive approach to the design of wearable objects is called "Fashionable Technology", a term coined by Sabine Seymour. It refers to an emerging field in which fashion, ubiquitous computing, design, science, and wearable technologies intersect (Seymour \& Beloff, 2008). Fashionable wearables are 'designed' garments, accessories, or jewellery that combine aesthetics and style with functional technology (Seymour, 2009, p. 12).

Sensor-enabled technology devices have both inputs and outputs. With the help of actuators, electrical signals can be transformed into physical phenomena that can then be transformed into a form of output whether audio, visual or tactile (Tang, 2007). There are two kinds of inputs; active and passive. Active inputs can be consciously controlled by a wearer with a tactile or acoustic feedback system. Passive inputs can be biometric data gathered from the body or the environment (Seymour, 2009). 
This realm takes advantage of natural inspiration in the design discipline. The example below is a kinetic electronic garment named "Kukkia and Vilkas, 2005", by Joanna Berzowska. The Kukkia flowers are behavioural kinetic sculptures that frame the face, opening and closing slowly over time (Seymour, 2009). In this work, the designer was inspired by the form and movement of the flower and applied it in the design of behavioural sculptures (Figure 9).

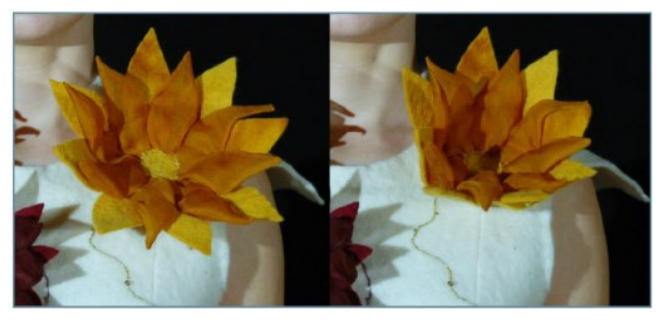

Figure 9. Kukkia and Vilkas (2005)

Jewellery can be a medium for expressing one's emotions and feelings. Sompit Moi Fusakul (2005) investigated the relationship between jewellery and its wearer by making ornamental objects that responded to human emotions. In the piece named "Vein 2", the colour changed as the wearer's heartbeat increased (Figure 10, left). "Aliform" is a piece that responds to the heartbeat by changing shape (Figure 10, right).

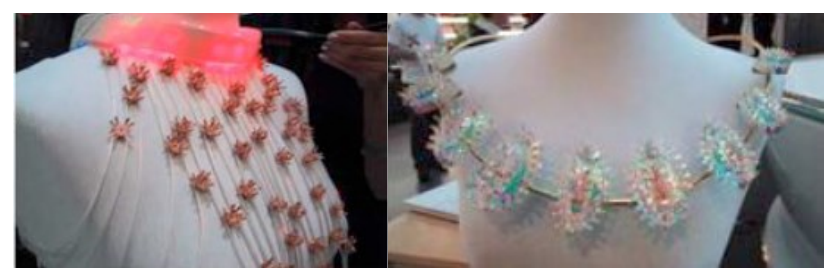

Figure 10. 'Vein 2' \& 'Aliform' (2002)

With the help of sensor technology, jewellery can also be a vehicle for expressing people's emotional feelings for each other. In the work of Stijn Ossevort, "Perfume Jewellery Pieces (2002)", two lovers can communicate with each other through a piece of necklace they each wear. When one of the lovers blows against the piece, the first piece activates and sends a radio-transmitted signal to the other person's (remote) jewellery piece. In turn, the second jewellery piece releases a small amount of perfume (Seymour, 2009). The output of the second piece of jewellery stimulates the sense of smell as a way of communicating (Figure 11). 


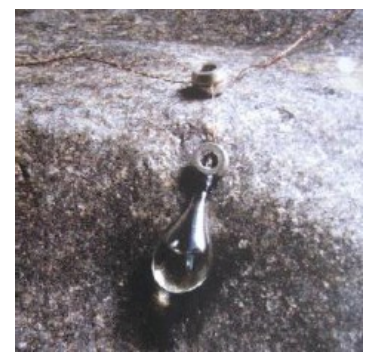

Figure 11. Perfume Jewellery Pieces (2002) by Ossevort

Jayne Wallace believes that pieces of jewellery have the potential to operate in an emotionally significant way connecting people to other individuals, places, or experiences. Wallace (2007) attempts to present people's feelings about concepts such as family relationships, love of nature and communication in her works. In her piece, "Journeys Between Ourselves (2007)" two neckpieces, which were custom made for a mother and daughter, are responsive to touch (Figure 12). The touch of one causes the second one to tremble. This tactile echo reveals their feelings for each other (Wallace at al., 2007).

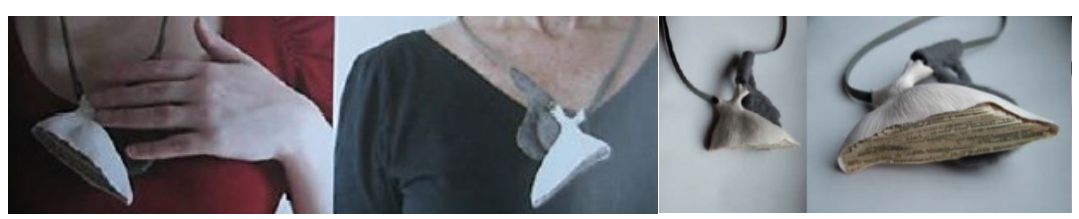

Figure 12.Journeys Between Ourselves (2007)

By Jayne Wallace (in Collaboration with Dan Jackson, Cas Ladha, Patrick Plivier, Andrew Monk, Peter Weight and Mark Blythe)

In the piece named "Blossom (2007)" (Figure 13), the form and digital capability of the piece illustrates the participant's love of nature, precious relationships with her grandmothers, and connections to family and family land in Cyprus. This piece was created with the goal of connecting human relationships within a specific location. The jewellery object located in the participant's home in London is connected to a rain sensor planted on the participant's family land in Cyprus. As soon as the rain sensor has recorded a determined quantity of rain in Cyprus — which may take months or even years - a signal is sent to the jewellery object and the mechanism is activated by gently opening the petals like a flower blossoming. The piece maintains the flower metaphor by blossoming only once (Wallace et. al., 2007). In this jewellery 
piece, the wearer has an emotional bond with the object that reminds her of her love of nature and relationships with loved ones.

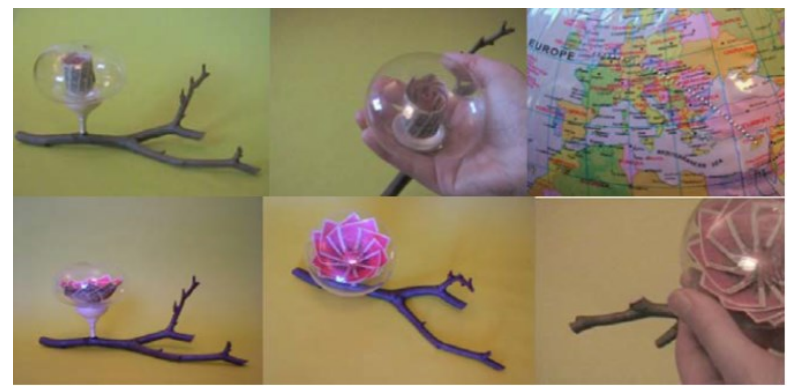

Figure 13. Blossom (2007) By Jayne Wallace

In summary, various outputs are applied in the design of fashionable technology wearables to express different concepts. The outputs include light, movement, scent, etc. that engage people's senses. The element of movement engages people's visual sense (as seen in "Blossom" \& "Aliform") as well as sense of touch (in "Journeys Between Ourselves"). One important aspect is the effect of these outputs on people's emotions. Jordan (2000) mentions that people want products with appropriate functionality that can be easy to use. More than that, people desire products that offer something extra; products that bring emotional benefits.

Therefore, it is important to apply a user-centered approach in the design of interactive wearable objects and explore the user's emotional response to the outputs of the interactive objects. There is an opportunity here to investigate people's emotional responses to the element of movement as an output of the interactive object.

\subsubsection{Sensory Experience with Interactive Objects}

The output of interactive wearable devices results in different sensory experiences. Many studies have mentioned that the more senses engaged while interacting with a product, the richer one's experience will be (Bahrick \& Lickliter, 2000; Spence, 2002; Stein \& Meredith, 1993, cited in Schifferstein \& Spence, 2008, p. 133). Sight, taste, touch, smell, hearing, balance, and movement arouse sensations that all shape the aesthetic appreciation of an object (Macdonald, 2002). 
Visual perception of an object depends on properties such as colour, size, or shape. Each colour or shape can evoke different emotional responses. Movement can also be recognized as a visual element that communicates emotion (Ugur, 2013). Movement can stimulate our vision, as well as our tactile and auditory senses. Moving garments can be activated by shape-memory metals such as Nitinol or with the help of mechanical actuators (Ugur, 2013).

Hodgson (2001, cited in Sonneveld \& Schifferstein, 2008) notes that during tactual experiences with a product, people may have different motivations for interacting with it. Interaction with an object may be for practical, functional use such as the tactual experience of using a camera to take pictures or using scissors to cut paper. The objects may also be used for play, rather than functional reasons, such as tennis rackets and yo-yos (interaction to play). Objects are used for personal care, for example, brushing one's teeth, or supporting someone a coat can keep a person warm (interaction to care for and to be taken care of). When something is new and unknown, people want to explore how it feels. Even familiar objects are touched just to have contact with them (interaction to explore). Another way to familiarize objects is by carrying them in a pocket, on one's back, in one's hands, etc. (interaction to carry). Sitting on or bumping into something by accident is another type of tactual experience (interaction by accident, by coincidence).

Auditory output in fashionable wearables, such as the sound made during a particular movement in a piece of interactive jewellery, can arouse different emotions (Ugur, 2013). Ozcan and Van Egmond (2009) describe two types of sounds in products: consequential and intentional. Consequential sound is emitted by the product as a result of its function, such as the sound of a propeller turning in a fan, while intentional sound is designed and implemented by a sound engineer in order to convey specific types of messages, such as an alarm that goes off at a specific time. 


\subsubsection{Summary-Wearable Objects}

A wearable object is both meaningful and emotionally significant to the wearer. Jewellery has the capability to act as an interactive tool in order to facilitate the interaction between wearer, viewer, and the object by creating socio-pleasure. Designers incorporate different outputs in the design of interactive wearable objects in order to communicate with wearers and their audiences. The outputs can include light, movement, scent, etc. to engage people's different senses. However, creating an aesthetically pleasant movement to an object is an aspect that is often neglected by designers in the field (Young et al., 2005; Hopson, 2009). It is equally important to apply a user-centred approach that explores the user's emotional response when incorporating different types of movements as the output in interactive wearable objects.

\subsection{MOVEMENT AS A DYNAMIC ELEMENT OF DESIGN}

This section looks into the meaning of movement and the values that this design element brings about for user-product interaction.

\subsubsection{Qualities and Characteristics of Movement}

It is important to understand the qualities and characteristics of movement in order to design kinetic products. Through a number of animation studies, Vaughan (1997) defines qualities of movement as Path (the line the object movement creates), Area (the use of space by the object), Direction (the direction of the animation), and Speed (the speed and tempo of the animated object). Bacigalupi (1998) notes that Kepes (1965) in "The Nature and Art of Motion" and Moholy-Nagy (1947) in "Vision in Motion" classify the formal qualities of movement as Rhythm (result of the change in temporal space between one movement and the next movement), Time/Beat (rhythmic flow or pace of rhythm), Continuity (related to both rhythm and time), and Direction. When an object has continuous movement, it always moves in space and this is when direction forms. In addition, route, volume (change in size), and speed are other qualities of movement (Bacigalupi, 1998). 
There are also expressive qualities that consist of empathic and kinetic movement. Empathic movement refers to the emotional qualities that a person attributes to the movement of an object. For example, the rhythmic pulse of ocean waves or the slow movement of the sun as it sets elicit recognition and identification, while communicating emotional states such as joy, happiness, sorrow, or etc. (Bacigalupi, 1998). As mentioned by Bacigalupi (1998), kinetic movement refers to "how the quality of movement is expressed as it supports the communication of a particular emotion" (p. 177). This quality of movement defines which formal qualities of movement such as rhythm, tempo, sequence, and direction are employed to move through space.

\subsubsection{Form and Movement}

When designing movement for a product, the form of the object and the capabilities of performing its designed movements should be considered first (Young et al., 2005). Effective movement design requires that the designer understand the product's form and correctly associates the context of movement with that form (Young et al., 2005).

Separating form from movement is a daunting task. It is important to understand whether the viewer of a kinetic objects is influenced more by movement or the form of an object. Young et al. (2005) show that when movement occurs at low speeds, people notice the form more than the movement, whereas at fast speeds the movement is more noticeable than the form. Hopson (2013) also does not define movement as something separate from form. He mentions, "form and movement are going to marry at the end" (Interview with Ben Hopson, December, 2013).

\subsubsection{Communicating Emotions and Experiences through Movement}

Research has shown it is possible to understand how a designed movement might affect the viewer. In a study conducted by Ugur (2013), a virtual dress was designed and tested in order to analyse how the different direction of the dress's movements can communicate various emotions and experiences. For example, as shown in figure 14, Spreading to two sides is mostly 
associated with positive emotions — being self-confident and energetic — while Enclosing from two sides signifies fear and stress. (Ugur, 2013).
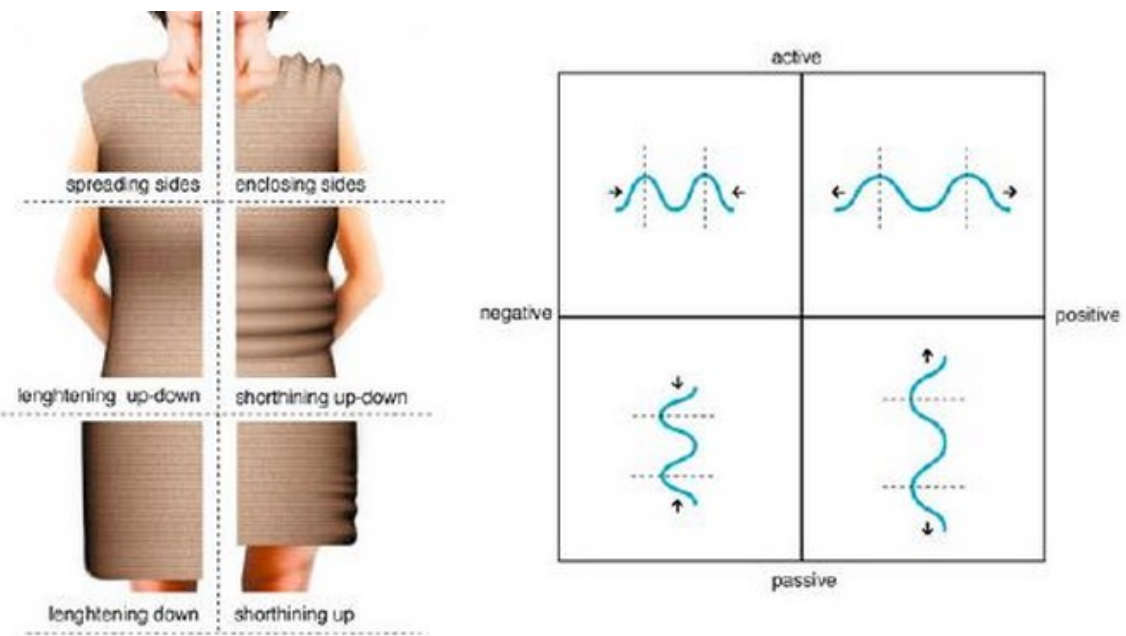

Figure 14.Virtual Dress and Test Results (Ugur, 2013, p. 83)

As mentioned before, products can communicate a range of emotional, social and cultural messages through functionality, form, colour, material, sound, and movement (Hekkert \&Van Dijk, 2011). Therefore, when movement is incorporated into the design of a product through its features, it can communicate with the user and elicit certain kinds of emotions. Young et al. (2005) called the effects of motion on peoples' emotions as 'E-motive'.

Different factors attribute characteristic meaning to a movement such as the movement itself, the user, the product (colour, shape, etc.), and context. Context can be defined as circumstances or events that form the environment with which something exists or takes place (Young et al., 2005). In relation to human beings, a product derives meaning and has certain sensory, functional, and behavioural properties (Hekkert \& Van Dijk, 2011). Elvin Karana (2010) developed the Meanings of Materials Model (MoM), which describes the dynamic action between a user and a material where the material obtains its meanings. Fayazi and Frankel (2014) adopted this model in order to depict the features of a product with movement (Figure 15). The model reveals features and qualities of a kinetic product and the importance of each of the features in the meanings attributed to the product. 


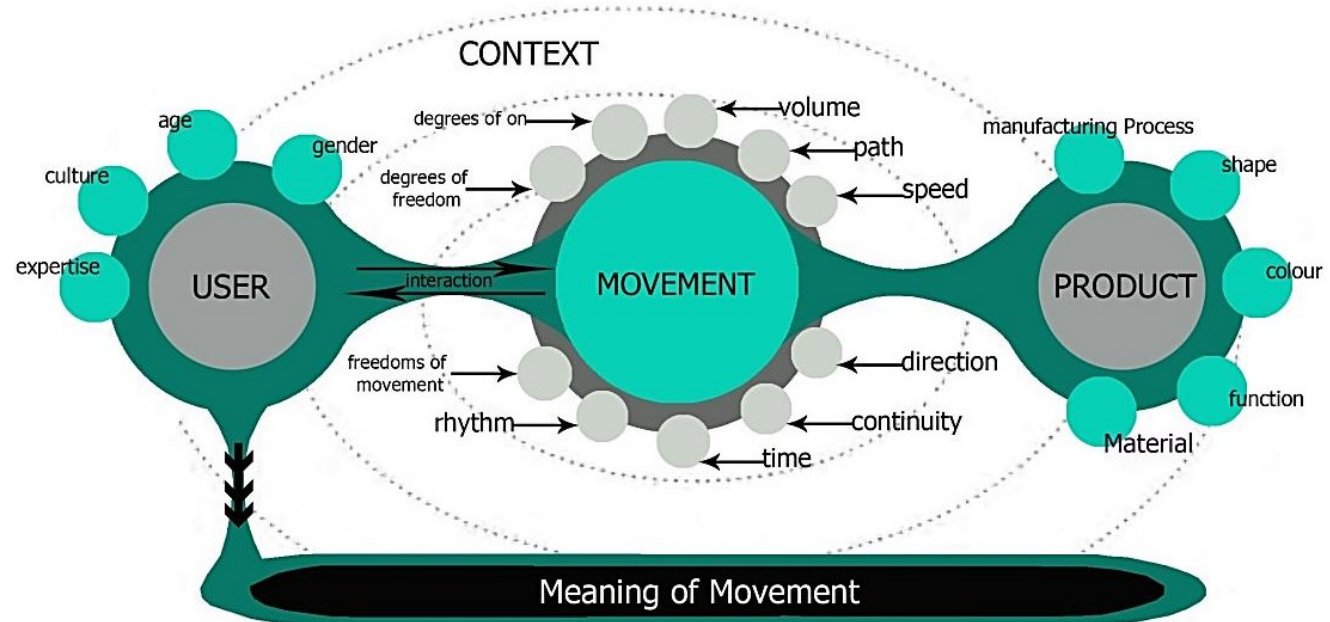

Figure 15. Proposed Kinetic Product Features and Meaning of Movement Model, (Fayazi \& Frankel, 2014)

Expressing emotion through movement has been somewhat overlooked in the realm of industrial design. Incorporating physical elements of movement in the design of products can enhance the emotional value of the objects (Chao, Cimen, Lancee, Offermans, \& Veenstra, 2004). Nam, Lee, and Park (2007) also mention, "One of the ways to enhance emotional interaction is to use dynamic attributes as a way of expressing functional or emotional states of products" (p. 1). Based on a literature review and the field research, Nam et al. (2007) presented a framework that represents the relationship between emotional expression and physical movement. This framework is based on Russell's circumplex model (Figure 16).

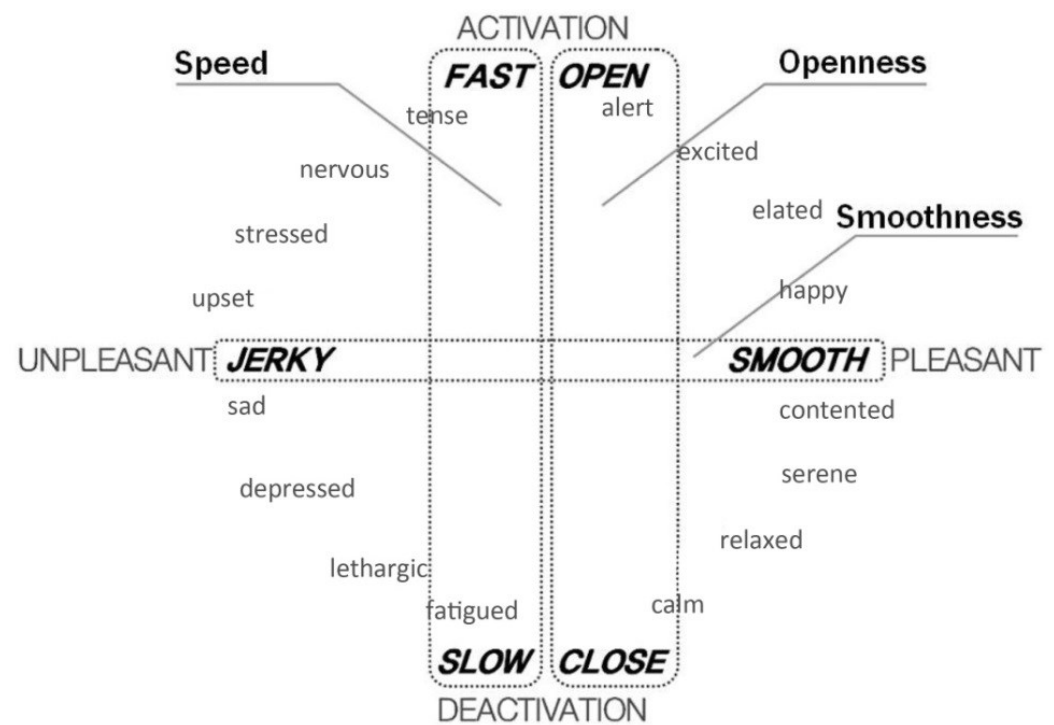

Figure 16. Proposed Emotion-Movement Relationship Framework (Nam et al., 2007) 
Based on this framework for expressing emotion, certain features and elements of movement are needed. These features are: speed, openness, and smoothness. Unchanging rhythm or beat is related to the fastness, which is in the category of 'speed'. 'Smoothness' includes continuous or irregular rhythm, which could be smooth predictable movement or unpredictable movement. 'Openness' includes contraction and expansion, which is related to directionality or volume of the movement. These three features - speed, smoothness, and openness - can be related to the 'activation' and 'pleasantness' properties in the circumplex model.

\subsubsection{Designing Movement for Products}

“Movement has not historically been designer's territory. It's really been engineers' territory" (Interview with Ben Hopson, December, 2013). Hopson drew attention to the newness of the field of kinetic design and the importance of providing tools and guidelines for designers in order to create movement.

Hopson (2009) mentioned that designing movement in objects is an aesthetic factor, a design element as important as form, colour, or material. Hopson (2009) described the importance of choreographing the forms' movements as follows:

Designers are not just form-givers, they are whole object creators and experience designers. By incorporating the creative and experiential notions of Kinetic Design into their vocabulary, designers will produce more exciting, more unified products, which will in turn lead to greater commercial success (Kinetic Design \& the Animation of Products, Para. 5).

According to Hopson (2009), kinetic design can be useful in two different ways. First by improving the function of existing products (Figure 17). Second, movement can create a new aesthetic dimension for existing products and result in the invention and development of new product concepts (Figure 18). 


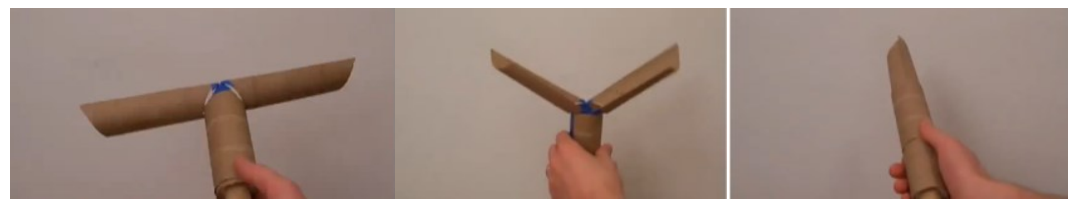

Figure 17.Vacuum Cleaner Attachment Concept, A movable floor brush can change shape and reach tight areas without the need to replace the vacuum cleaner attachment http://www.benhopson.com/?page id=88

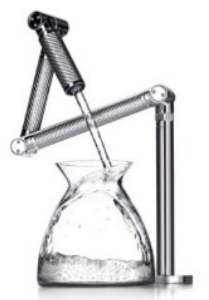

Figure 18. New Product Concept for Kitchen Faucet, the faucet handle moves in a more interesting way. Not only is it fascinating and engaging for the user, but it may also be more functionally appropriate.

http://www.benhopson.com/?page_id=88

Based on Hopson's kinetic ways to enhance products, the model below was developed (Fayazi, Frankel 2014) to reveal the values that movement may create for user-product interaction (Figure 19).
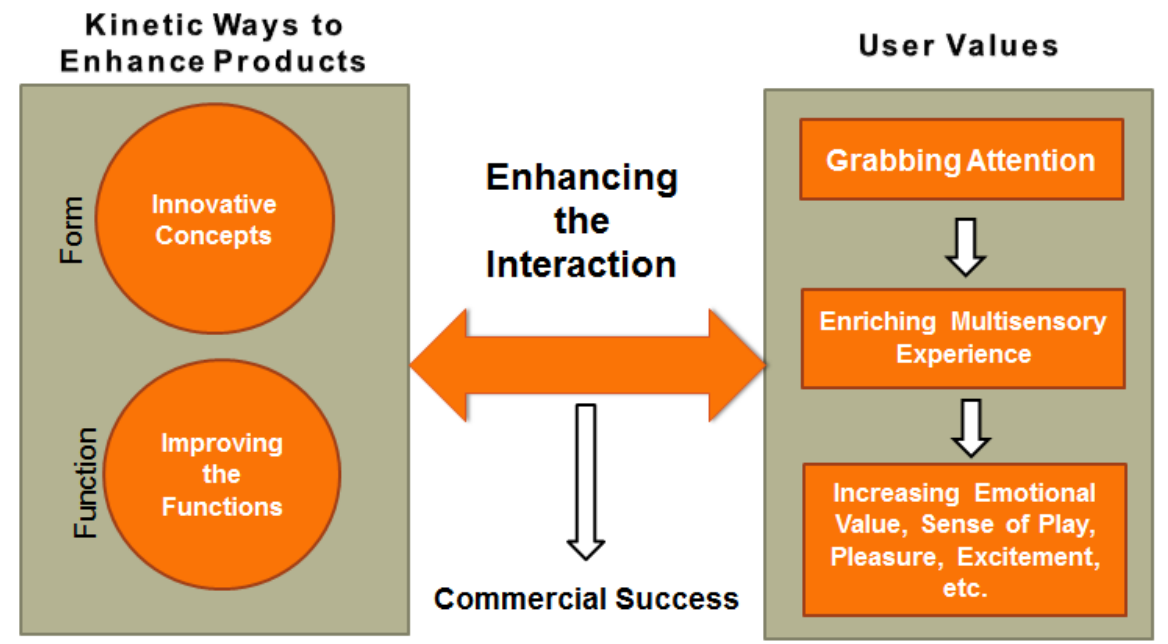

Figure 19. Values of Movement Model (Fayazi \& Frankel, 2014)

The model indicates that adding movement can enhance the value of products and lead to innovative concepts and improved product functionality. Movement grabs the user's attention, enriches multisensory experiences, and increases the sense of play and pleasure. All these values 
enhance the interaction between the user and product, which can lead to commercial success (Fayazi \& Frankel, 2014).

Hopson (2013) mentioned that designing movement for a piece of jewellery or any other object is the same. The main challenge when designing movement for a jewellery piece is usability, since the piece is in a close relationship with the human body (Interview with Ben Hopson, December, 2013).

\subsubsection{Summary-Movement as a Dynamic Element of Design}

The dynamic design element of movement can be incorporated in designed objects to enhance product experiences. Movement communicates with the user and elicits certain kinds of emotions through its unique qualities. The qualities of movement include time or beat, speed, direction, continuity, path, rhythm, etc. Incorporating movement can enhance the emotional and aesthetic value of the object. It can also result in new product concepts and improved functionality. It can create multisensory experiences by engaging visual, tactile, and auditory senses. These values transform 'movement' to attractive and pleasurable aspects of the design elements that contribute to commercial success.

\subsection{EMOTIONAL EXPERIENCE IN USER-PRODUCT INTERACTION}

People experience products on three levels. These levels include aesthetic experience (the degree to which all our senses are gratified), experience of meaning (the meanings we attach to the product), and emotional experience (the feelings and emotions that are elicited) (Hekkert, 2006, p. 160). This section describes the aspects at the emotional level of user experience. 


\subsubsection{Affect and Core Affect}

The concept of 'affect' refers to all the different psychological states such as emotions, feelings, moods, sentiments, and passions. These affective states differ in duration, impact, and eliciting conditions. Frijda (1986, cited in Desmet \& Hekkert, 2002) mentions:

Of these states, emotions are most relevant for product experience because only they imply a one-to-one relationship between the affective state and a particular object: one is afraid of something, angry at someone, happy about something, and so on (p. 62).

Core affect is the neurophysiological state consciously accessible as the simplest raw (non-reflective) feelings evident in moods and emotions (Russell, 2003, p. 148). James Russell first introduced the model of 'core affect' in 1980 noting, "Core affect is a single integral blend of two dimensions" (Russell, p. 148). The horizontal dimension represents valence ranges from pleasure to displeasure, and the vertical dimension represents arousal ranges from calm to excitement (Russell, 2003, Figure 20).

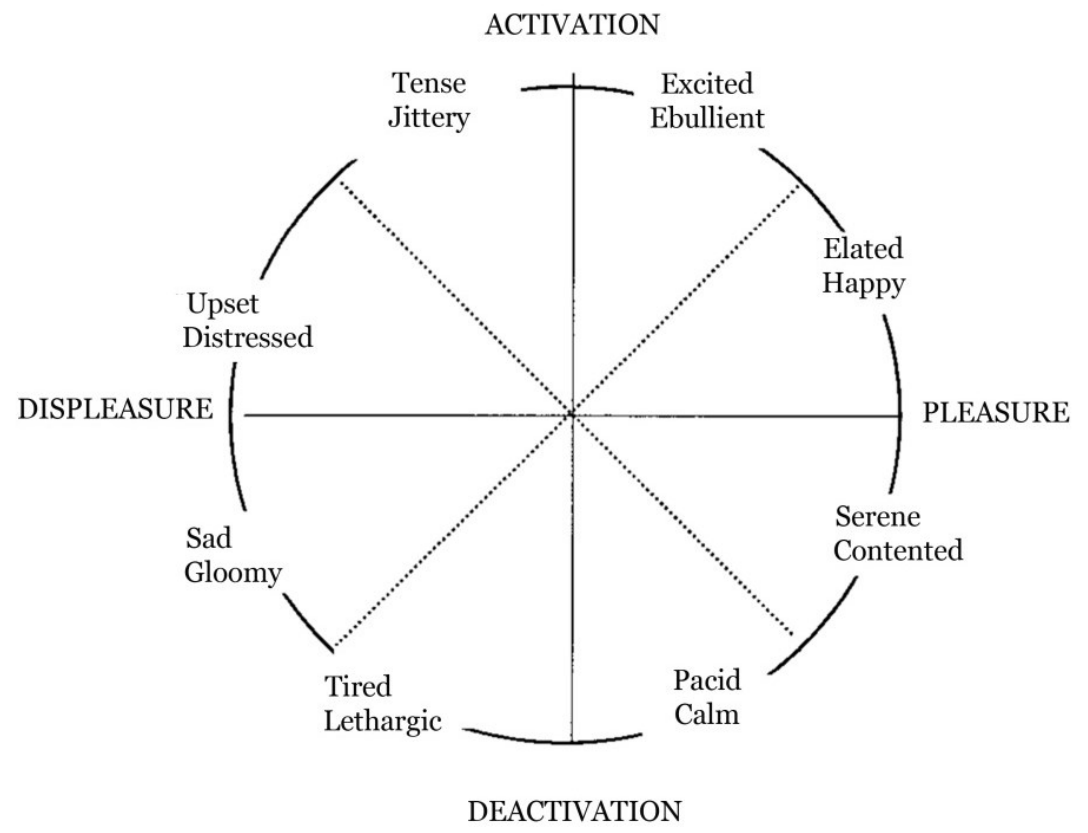

Figure 20. Model of Core Affect, Adapted from Russell, 2003 
People experience core affect in every moment of their lives and with every product interaction. Every moment of people's affective responses, as their emotions change, are located on this diagram (Desmet \& Hekkert, 2007).

\subsubsection{Enhancing Pleasure through Familiar and Unfamiliar Objects}

Macdonald (1998, cited in Suri, 2002) states that experience is a complex phenomenon that depends on reactions to various attributes of a design. People find one product more enjoyable or attractive than another, one interaction more exciting or pleasurable, and another depressing. Van Gorp and Adams (2012) note that when a person interacts with objects or experiences that are similar to positive situations that he or she has encountered before, the person associates the two. This familiarity can be enough to create pleasurable emotions for the user.

In the nineteenth century, William James and Gustav Fechner assumed that 'familiarity breeds liking'. Robert Zajonc's findings in 1968 discuss why people often like people they know, feel more comfortable in their homes, and like the brand of car they own. Because familiarity breeds liking, a generally accepted recommendations for creating objects that people like is to design products that people are familiar with. As mentioned by Reber et al. (2004, cited in Hekkert \& Leder, 2008), "repetition or familiarity makes perceptual and cognitive processing easier and somehow more fluent, and this fluency is intrinsically pleasant" (p. 268).

In contrast, Biederman and Vessel (2006, cited in Hekkert \& Leder , 2008 ) mention that new and unfamiliar objects can evoke a sense of pleasure when the new object is not terrifying. Unusual and innovative products often fascinate people (Veryser \& Hutchinson 1998, cited in Hekkert \& Leder, 2008). Encountering unfamiliar and new objects evoke people's pleasure due to the "Experience of Wow". The concept of 'Wow' is described as a combination of fascination, pleasant surprise, and desire. The approach of 'design for wow' concentrates on the emotions that constitute a wow-experience. Therefore, researchers argue that "products that excite customers will be more successful than those that do not" (Millard 2006, cited in Desmet, 
Porcelijn, \& Van Dijk, 2007, p. 141). According to Desmet et al. (2007), “The focus on excitement is basically a focus on surprise by newness, and a feature that excites today will inevitably stop being exciting tomorrow - or the day after tomorrow" (p. 142). The element of surprise is one of the exciting features that can be incorporated in the design of products that enhance pleasure.

\subsubsection{Exploring People's Emotions}

There is not abundant information about how people respond emotionally to products and what features of design elicit emotional responses (Desmet, 2005). It is not easy to explore emotion since various factors may affect people's experience with products. Moreover, it is difficult to find relationships between the design features and emotional responses. Desmet and Overbeeke (2001) argue that there is no one-to-one relationship between design features and emotional responses because mostly emotions are not elicited by the products, but rather by meanings derived from the products. Product users find it difficult to express what they feel and why they feel that way. There are several reasons for this. The first reason is the complexity in verbalizing emotions, specifically low intensity emotions elicited by products (Desmet \& Hekkert, 1998, cited in Desmet \& Overbeeke, 2001). The second reason is that the expression of emotions by users of any product requires cognitive involvement, which might have an effect on the response itself.

However, it is possible to identify emotion through verbal and non-verbal reports. Verbal report measures are usually in the form of verbal protocols or a set of rating scales that ask respondents to report their emotions (e.g., Likert Scale and Semantic Differential Scales). Nonverbal report measures involve methods in which participants select a visual presentation of an emotion in order to communicate their feelings while interacting with the object (e.g. SAM, FACS, PrEmo, Emocards) (Agarwal \& Meyer, 2009). This research applies both verbal and non-verbal methods to explore the emotional response of participants to wearable objects with 
biophilic movement. There are also physiological and behavioural measures which are beyond the scope of this research.

\subsubsection{Summary_Emotional Experience in User-Product Interaction}

In order to design products that fit the emotions of users, designers should understand people's emotional responses. Although understanding people's emotions is not easy, there are some tools to assist designers in identifying people's emotions.

James Russell's core affect model reveals that people's affective responses change every moment as their emotions change (Desmet \& Hekkert, 2007). Different factors affect people's experience with a product. Familiarity and unfamiliarity in designed objects can create pleasurable experiences for people, depending on their emotional responses.

\section{SUMMARY - LITERATURE REVIEW}

Contact with nature provides positive impacts on people's emotional states. Passive interaction with nature through representations or reminders of nature can be effective in increasing positive feelings and satisfying biophilic desires for nature. A biology-to-design approach is traditional in the area of jewellery design where static representations of nature are common. Therefore, an interactive and symbolic experience of nature in the form of jewellery may have a positive effect on a person's psychological behaviour.

Jewellery is a special form of object that is in a constant relationship with the human body. It can be both meaningful and emotionally significant for the wearer. Wearable objects have the potential to communicate emotions and thus connect people to other times, places, people, and experiences more than any other objects. This is due to both the emotional experience and the experience of meaning that is shaped during interaction with these sorts of objects. Moreover, jewellery has the capability to act as an interactive tool for socio-pleasure in order to facilitate the interaction between wearer (the person wearing a piece of jewellery), 
viewer (the person observing the wearer with his or her piece of jewellery on), and the object (the piece of jewellery).

Designers apply natural forms, and shapes as well as natural materials in the design of wearable objects. There are other aspects of nature, such as dynamics, that are inspired by designers in the field. Movement as a dynamic element of design can be incorporated as an output in the design of interactive wearable objects in order to enhance the product experience. In fact, movement can also communicate with the user and elicit certain kinds of emotions through the qualities and features it represents. Qualities of movement include time or beat, speed, direction, continuity, path, rhythm, etc.

In order to design products that positively engage users through pleasurable emotions, designers should understand people's emotional responses. By taking a user-centered approach in the design of interactive wearable objects it may be possible to explore the user's emotional response to the element of movement as an output of the interactive object. There is an opportunity here to investigate how designers can incorporate the movements found in nature referred to as 'biophilic movement' in this study — in the design of interactive wearable objects. A user-centred, biophilic movement approach to design may enhance the interaction between the object and people. Therefore, this research aims to answer these sub-questions:

\section{How is it possible to elicit people's emotional responses through the incorporation of} biophilic movement in wearable objects?

2. How is it possible to develop design suggestions about incorporating biophilic movement in wearable objects? 
CHAPTER 3: PHASE ONE

\section{INVESTIGATING FIELD RESEARCH \& DESIGN PROCESS}

\subsection{INTRODUCTION}

This exploratory study is comprised of a multi-phased methods design. This study applies a mixed methods approach and a qualitative approach. The methods applied in phase one (Investigative Field Research and Design Process) along with the derived results from these methods help determine the best research design and data collection methods for phase two of the study (Exercises), described in chapter four.

This chapter aims to investigate the meaning of 'biophilic movement' and how it can be applied in designed objects. The research focuses on exploring the movements of marine creatures and insects such as butterflies. The literature review discusses the importance of an aquarium in the built environment. It points out the positive effects of interaction between humans and nature, such as how people like having an aquarium in their homes as a way of relaxing and eliciting positive feelings. Through conversation with biology Professor Jeff Dawson, the researcher also learned about the positive impact on people's emotional state of interacting with insects such as butterflies. Therefore marine creatures and flying insects were chosen as inspirations for the study in this phase of the research.

This chapter starts with investigative field research that includes an internet survey of videos, museum and exhibition visits, followed by a workshop description. The results from these initial methods inform the next steps: idea generation and prototyping. The study applies the method of Internet survey to observe and explore plant and animal movements. The workshop session method is to understand how people create movements in three-dimensional form. Finally, idea generation and prototyping are used to present the concept of 'biophilic movement', making this concept manageable to test. Four types of prototypes are presented at 
the end of this chapter, which are later tested through the methods applied in chapter four (phase two).

\subsection{METHODS}

Initial methods applied in this phase are discussed here in detail. The methods include Internet Survey of Videos \& Exhibition Visits and Brainstorming Workshop.

\subsubsection{Internet Survey of Videos \& Exhibition Visits}

In order to design biophilic movement for wearable objects, the meaning of 'biophilic movement' is explored more precisely by first looking into the science of biology. The primary objective of this section was to gain more knowledge about the different types of plant and animal movements. The researcher studied nature through observation while in natural settings, as well as observing plants and animals in videos, museums, and exhibitions (see Appendix C for details). Through interactions with the department of biology and with Professor Dawson, the researcher became familiar with the movements of different creatures, specifically insects (Professor Dawson is an expert in the area of flying insects). The researcher also attended Carleton University's 'Annual Butterfly Show' at the department of biology. In this show, butterflies are released into the greenhouse. Visitors bring fruit to entice butterflies, and they land on people's hands, clothes, etc (Figure 21).

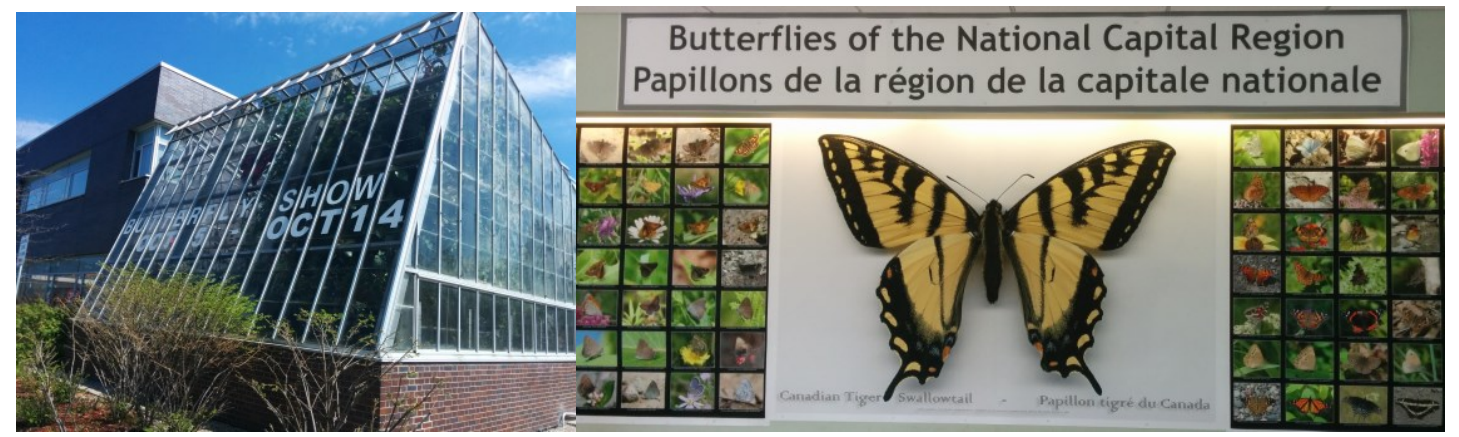

Figure 21. Carleton University’s ‘Annual Butterfly Show’ 
Through attending the Insectarium, Botanical Garden in Montreal, the researcher also observed different insects and their behaviours.

Moreover, the researcher visited the American Museum of Natural History and the special exhibition on marine animals. The researcher looked into the life of sea creatures and different types of marine creature movements identified through observing videos and visiting museums.

\subsubsection{Brainstorming Workshop}

A brainstorming workshop was held on Wednesday, November 13, 2013 to help the researcher understand how people might create three-dimensional kinetic models with simple materials such as paper, beads, wire, coloured paper, cardboard, and foam. Another aim of this workshop was to give the researcher ideas about how to create forms that incorporated moving parts. Since the participants' background was not a controlling factor, the researcher chose Carleton University students from different fields (Convenience Sample). Students were asked to sign a consent form for this participation (Appendix D). This two-hour workshop had three sections: introduction, working session, and a sharing session.

In the first section, the researcher explained the procedure of this workshop. Participants were asked to design different movements using the given materials. If a participant did not have any movement in mind, they were asked to just start making different moving forms. In the working session six participants, including the researcher, created different forms that incorparated a range of movements. In the final section, participants discussed their model/models, how it/they move, and the source of inspiration for that type of movement. Figure 22 shows the models created by participants in the session (see Appendix E for the details on the workshop instructions). 


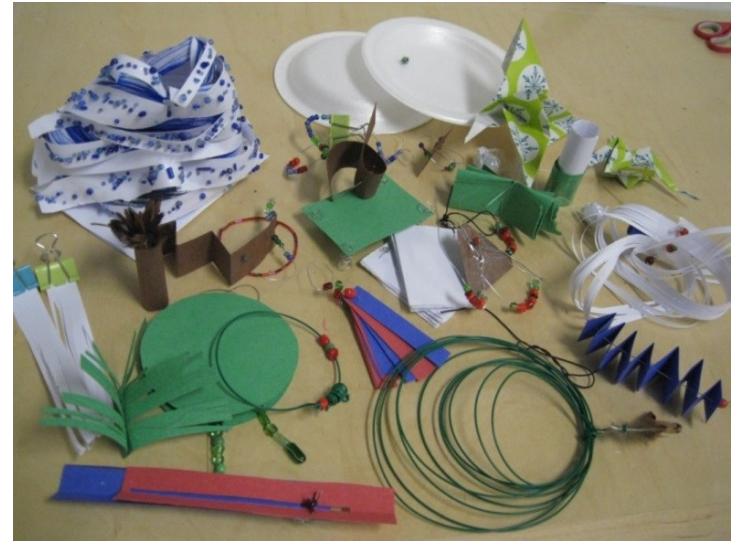

Figure 22. Models Developed in the Brainstorming Workshop

\subsection{RESULTS}

The researcher reached the following conclusions based on the methods described above. These results helped fulfil the next steps of the research.

\subsubsection{Results of Internet Survey of Videos \& Exhibition Visits}

After observing many different types of movements, the researcher identified similar patterns of movement in different animals or plants and classified these movements in groups based on their similarities (see Table 3). After the researcher identified the directions of movement in each of the creatures, through a card sorting technique, each of the creatures with a specific type of movement were located in a specific category. Some of the identified movements were placed in more than one group, since they have multiple patterns of movement. In order to create these nomenclature categories, the researcher consulted with biology Professor, Jeff Dawson at Carleton University. 
Table 3. Classification of Biophilic Movements

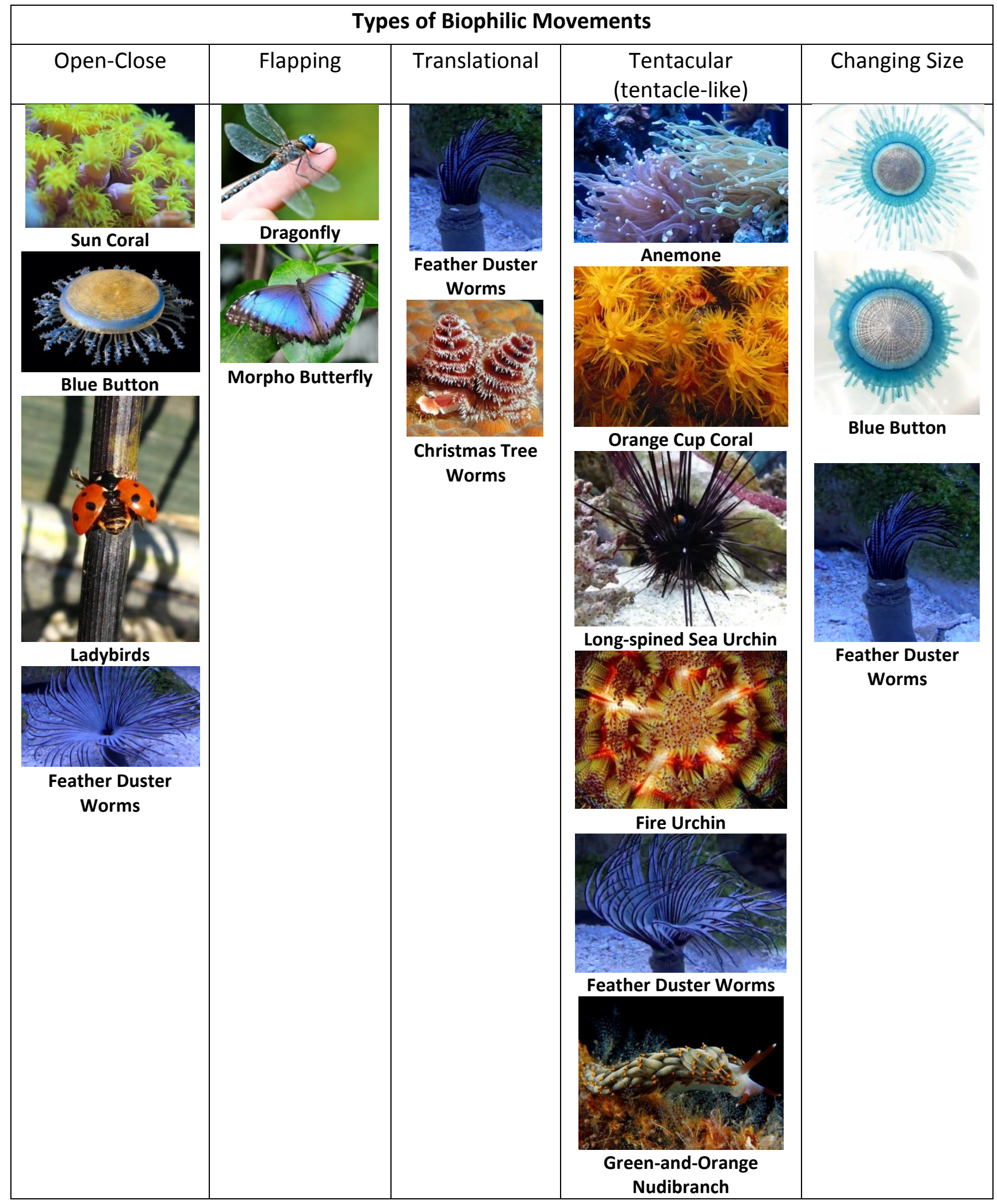

Movements were classified into five different types: open-close, flapping, translational, tentacle-like, and changing size. This classification categorized movements based on the 
direction and shape they form in space. This research considers only the quality of direction. Other qualities were not taken into account. The open-close movement occurs when an object moves outwards from a center and goes back to the center again. The opening and closing movement of a blue button is a simple example of this type of movement. Flapping movement refers to symmetrical wing shapes that come together and apart in unison. This movement can be seen in a butterfly's wings when flying. Translational movement refers to the movement of the object from one point to the other point in a direct path like the direct movement of the feather duster worm from one point inside the tube to the other point in the same path outside the tube. Tentacle-like movement is the wavy movement of an object, which does not have the same continuity or rhythm such as the movement of an anemone in the water. Translational and open-close movements result in a change of size, while flapping and tentacle-like movements do not.

\subsubsection{Result of Brainstorming Workshop}

The workshop helped the researcher gain insight into how to translate and design moving physical forms for making the phase two biophilic prototypes.

Even though participants were sitting close to each other, they did not copy each other's ideas at all. Each participant explored different forms and three-dimensional kinetic models. However it was interesting that some workshop participants made the same type of movements through various forms. Figure 23 (A) shows two different models from the workshop. Both have translational movement, but the movement is represented through different forms. The final forms showed that, based on the models' direction of movement, some participants represented the movement through a circular or a direct path while others showed movement through a change in shape. (Figure 23, Panel A, B, C) 


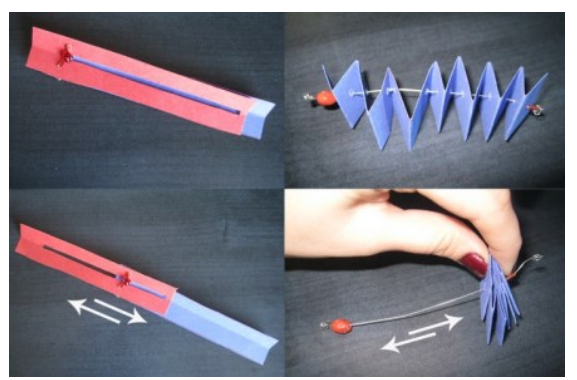

A. Translational Movement- Same direction of Movement, Different Forms
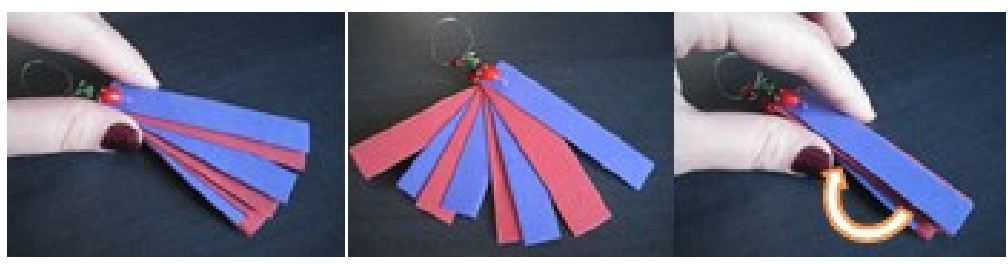

B. Circular Direction

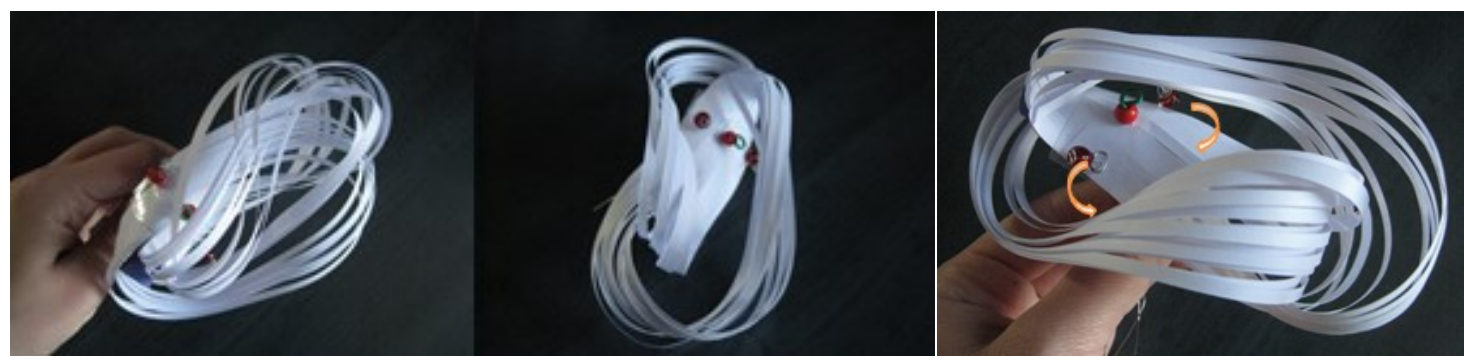

C. Different Directions

Figure 23. Different Directions of Movement Presented through Various Forms

Some of the forms presented in the workshop such as model C (Figure 23) provided ideas for the researcher about how to create organic forms (in particular the kind of curvilinear lines that are found in nature) for presenting the biophilic movements of Table 3. Even though participants were asked to create any type of forms to present movement in the models, one can see that some of the movements and forms presented in the workshop resembled movements in nature . For example, the movement of Model B, Figure 23 resembles that of a male peacock when it opens its feathers.

\subsection{DESIGN PROCESS}

After gathering information about 'movement' and 'biophilic movement', the investigation in this study turned to brainstorming, sketching, and prototyping. Prototyping is a 
useful tool for testing to understand users' perceptions regarding the concept of 'biophilic movement'.

\subsubsection{Idea Generation: Generating Form to Represent Movements}

Data collected from the previous methods revealed the importance of form while designing movement for an object. In the process of creating physical prototypes with biophilic movement, organic forms were designed and combined with an appropriate type of biophilic movement taken from Table 3. Different forms and movements were designed and generated through 2-dimensional and 3-dimensional sketches (Figure 24).
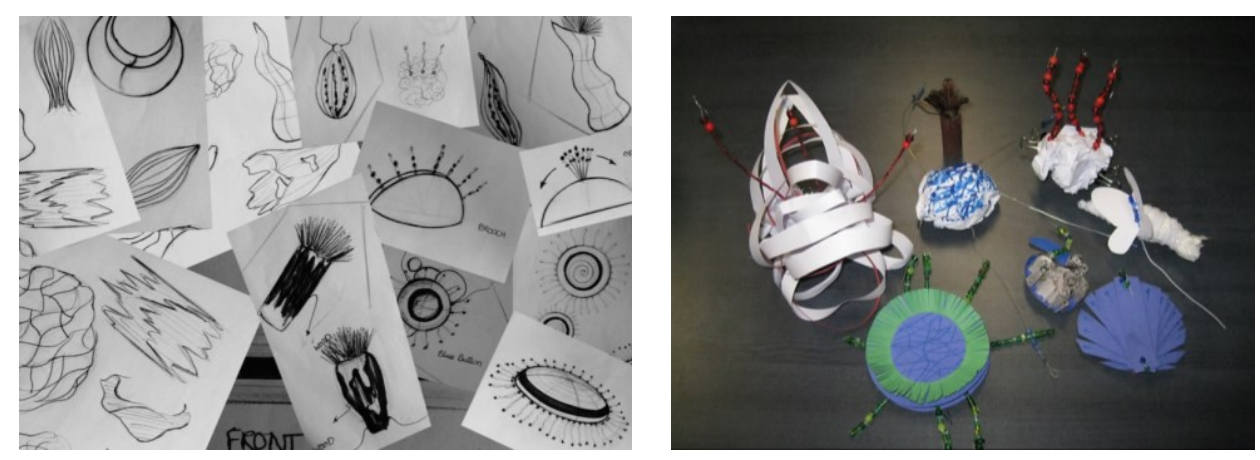

Figure 24. 2-Dimensional \& 3-Dimensional Sketches

\subsubsection{Prototype Making}

Physical prototypes were developed to explore people's emotional responses toward wearable objects with biophilic movements. Four different types of wearable objects with various movements were built; the objects were inspired by butterfly, feather duster worm, anemone, and blue button movements. As shown in Table 3, each of these creatures exhibit specific types of movements. Furthermore, the movements of marine animals and butterflies seem to have a positive impact on human psychological states. As previously mentioned, these four objects were chosen because of their specific movement type: flapping movement for the butterfly, translational movement for the feather duster worm, tentacle-like movement for the anemone, and open-close movement for the blue button. 
Mechanisms were designed and added to the objects to make each one move in a certain direction, mimicking its inspirational biological animal. For these prototypes, movement was activated by a hand-controlled mechanism. This is often the case in early prototypes to minimize the cost, effort, and time involved in creating working models before finalizing the design concept. It is easy to foresee future studies using electronics and sensors to easily accomplish more sophisticated prototypes. Mechanisms were designed and built in the biology lab, at Carleton University with the assistance of Professor J. Dawson.

\subsubsection{Prototype $A$}

This interactive wearable object, which is worn as a brooch, uses the element of light as well as movement as the interactive object's output. The element of light was added to the design of this brooch to make the movement more visible from a distance. To make the object light up, optical fiber was used in the prototype. Optical fiber is a flexible, transparent fiber that can transmit light between the two ends of the fiber (Figure 25, Panel 1).

The movement and form of this object was inspired by a marine animal, the feather duster worm (Figure 25, Panel 2). Its movements are translational, open-close, and tentacle-like (see Table 3). The movement is also accompanied by a change in size. Feathers come out of the tube, open and close, and undergo a dancing movement in water. Similarly, in this brooch, the fibers come out of the tube (translational movement), open and then close (open-close movement), and go back inside the tube again (translational movement). Moreover, this brooch includes a 'changing size' type of movement (Figure 25, Panel 3).

Two wires come out of the tube which would not be part of the final design concept; they are part of the manual mechanism for responding with light and movement. The black wire takes the power charge and sends electricity from the battery to the LED inside the tube. The other wire is attached to help activate the movement of the object manually (Figure 24, Panel 4). 


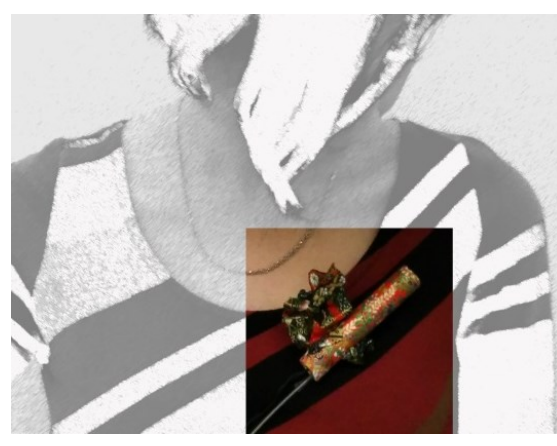

Panel 1. Prototype A

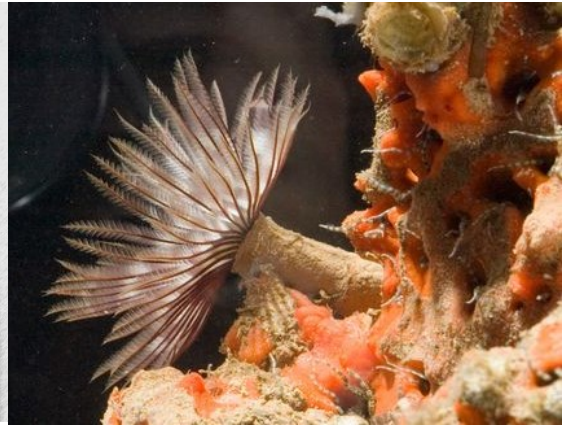

Panel 2. Feather Duster Worm

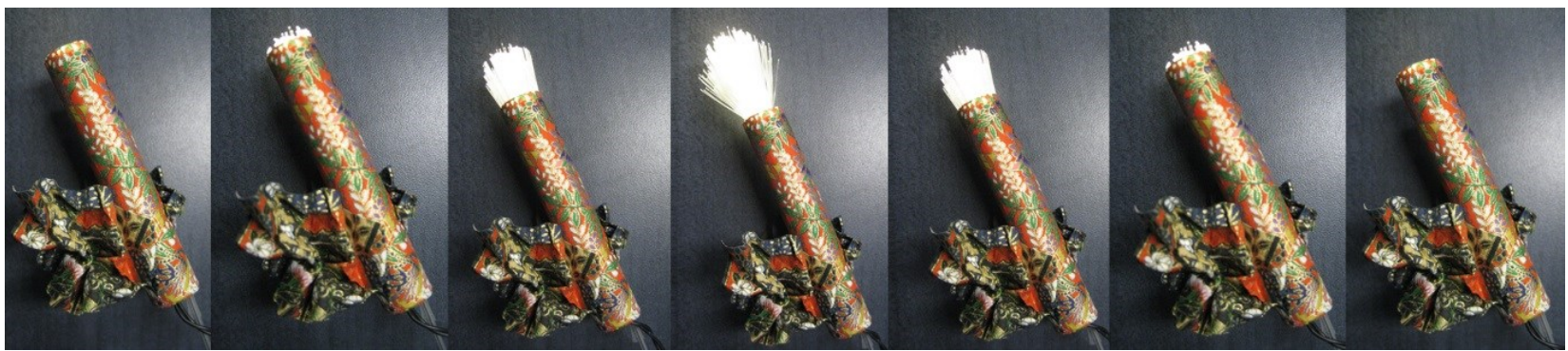

Panel 3. Movement \& Light

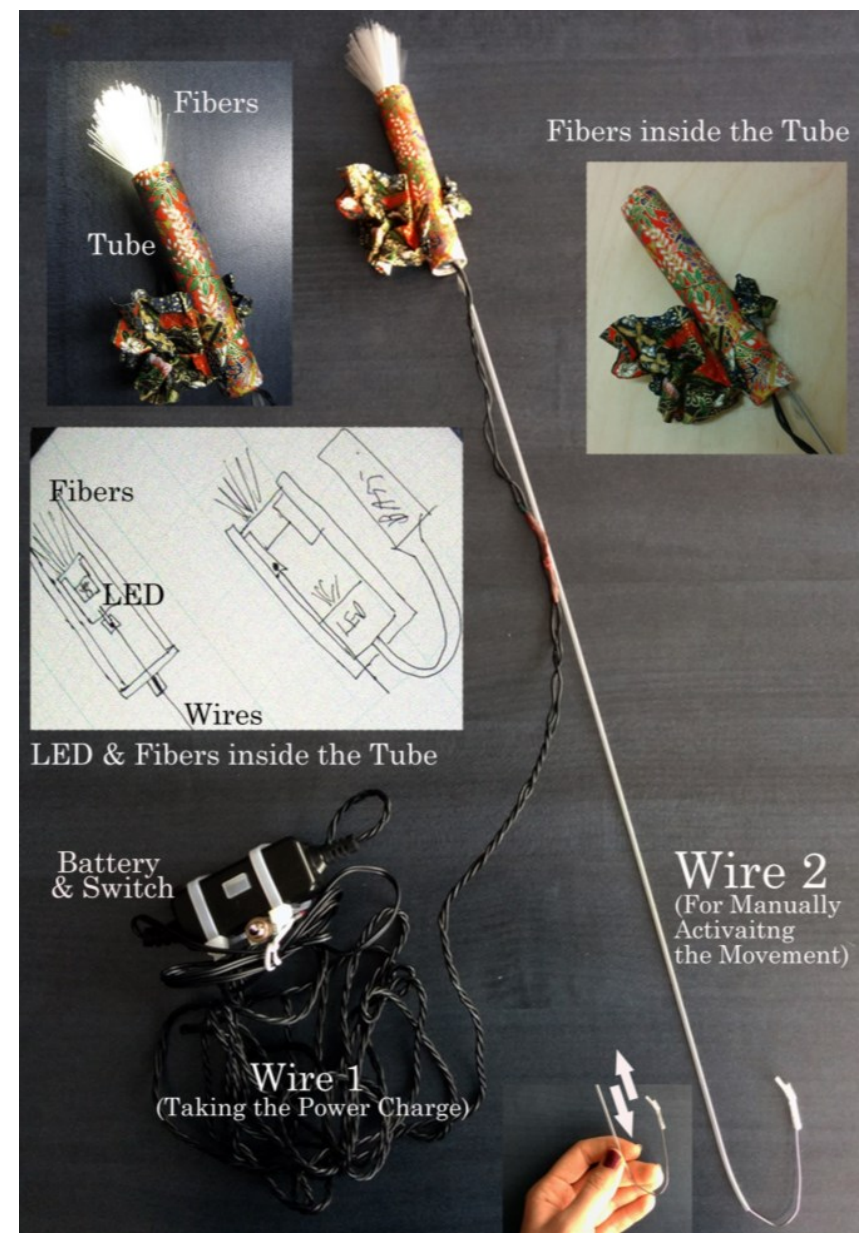

Panel 4. Mechanism

Figure 25. Prototype A 


\subsubsection{Prototype B}

Prototype B is an interactive wearable object that can also be worn as a brooch. It has the element of movement as an output of the interactive object (Figure 26, Panel 1). The movement and form of this object is inspired by the movement and the form of a butterfly (Figure 26, Panel 2). The butterfly's movement is a flapping motion (refer back to table 3) with a symmetrical up and down movement of the wings. Similarly, in this brooch, the wings have a symmetrical up and down movement (Figure 26, Panel 3) that is activated manually through the threads attached to the wings (Figure 26, Panel 4).

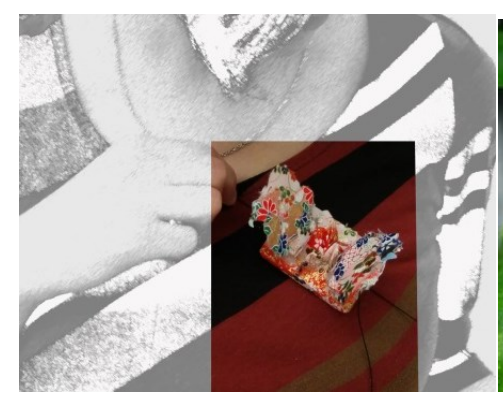

Panel 1. Prototype B

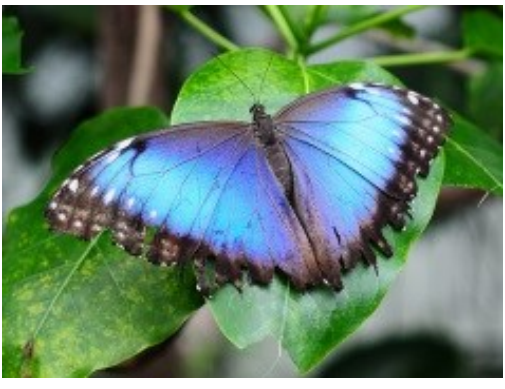

Panel 2. Butterfly

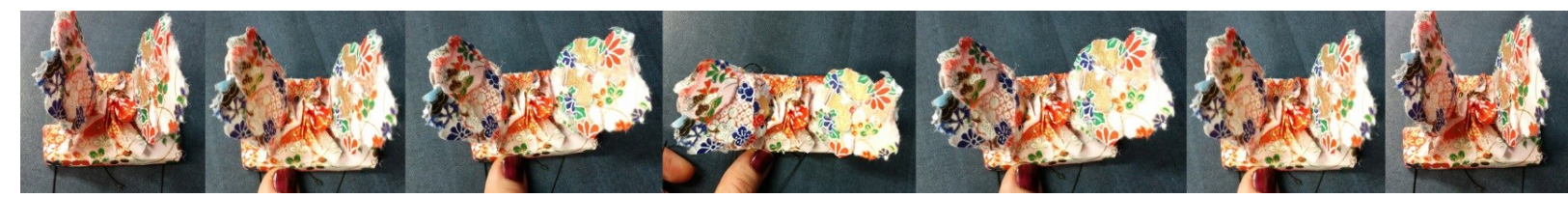

Panel 3. Movement
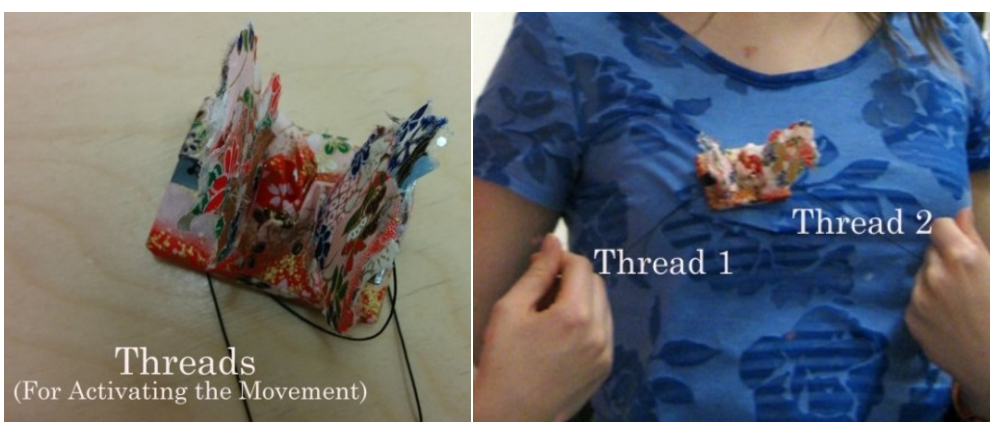

Panel 4. Mechanism

Figure 26. Prototype B 


\subsubsection{Prototype $C$}

This interactive wearable object is also worn as a brooch and has the element of movement as the interactive object's output (Figure 27, Panel 1). The movement and form is inspired by the a blue button (Figure 27, Panel 2). The movements of this animal, mentioned in Table 3, are open-close and changing size. This marine animal has many strands, each having multiple branchlets. The strands come outward and go back inward to their previous position. In this brooch, the five attachments come out of the blue dome shape, move outward (which enlarges the overall size) and return inward again. Therefore, this brooch includes an 'openclose', and a 'changing size' movement (Figure 27, Panel 3). The movement is activated manually through the threads attached to the strands (Figure 27, Panel 4).

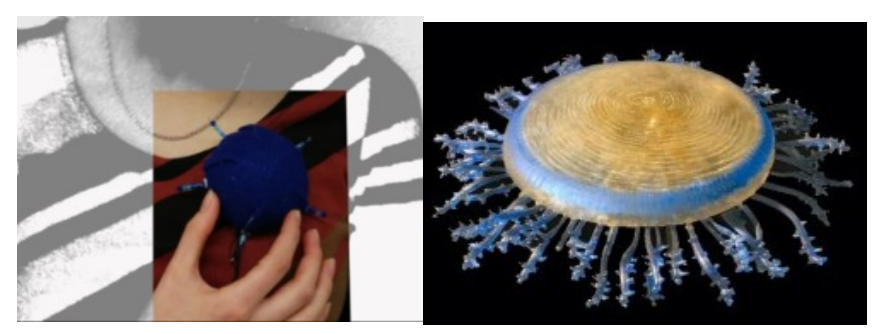

Panel 1. Prototype C

Panel 2. Blue Button

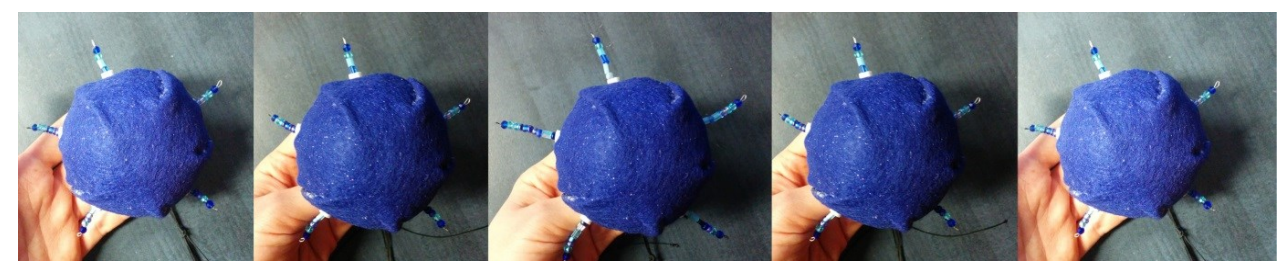

Panel 3. Movement

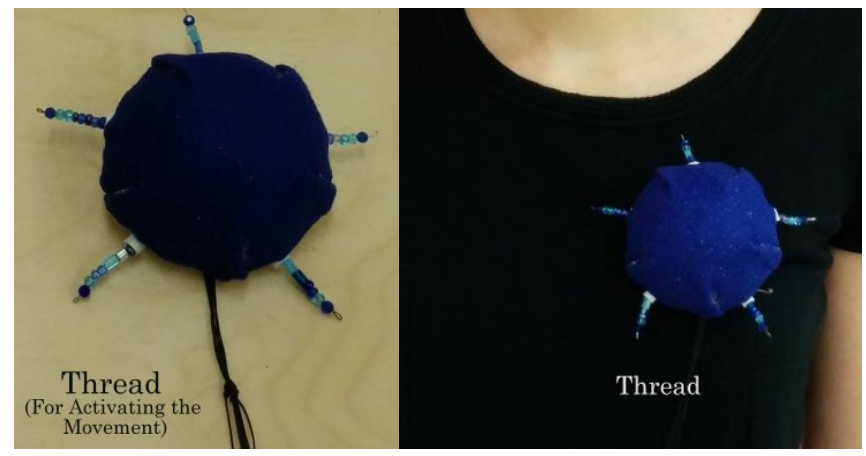

Panel 4. Mechanism

Figure 27. Prototype C 


\subsubsection{Prototype D}

Another interactive wearable object worn as a brooch, with the element of movement as an output of the interactive object (Figure 28, Panel 1). The form and tentacle-like movement of this object is inspired by an anemone (Figure 28, Panel 2) and is also accompanied by change in size. The organic form of the brooch consists of curvilinear strips that curl to make its shape. The prototype includes three strands filled with red beads that can be seen from inside the shape. These strands come out of the whole shape and go inside again (open-close movement). When these strands move outward, they also vibrate in a tentacle-like movement form. This prototype includes an 'open-close' and a 'tentacle-like' movement. Moreover, this brooch has a 'changing size' type of movement (Figure 28, Panel 3). The movement is activated manually through the tube and syringe attached to the brooch (Figure 28, Panel 4).

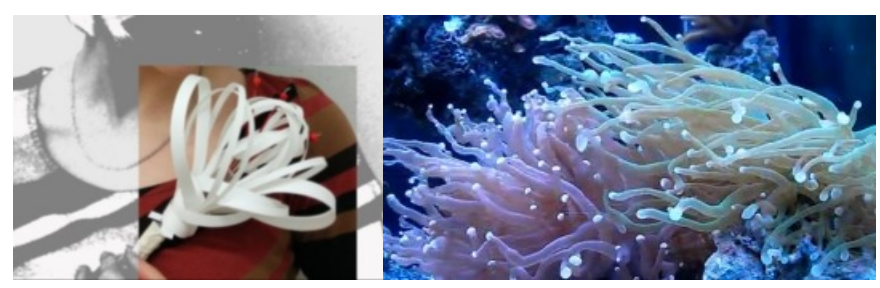

Panel 1. Prototype D

Panel 2. Anemone

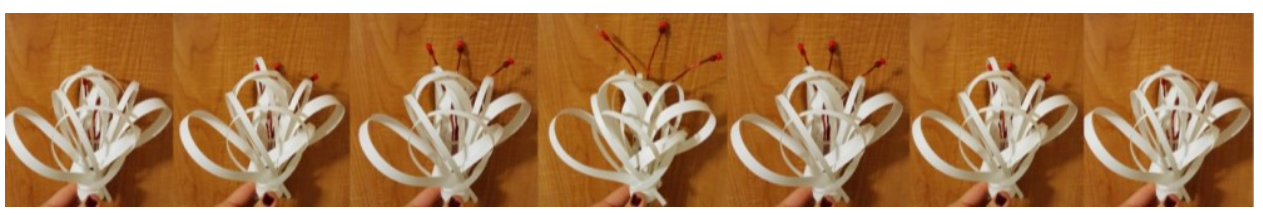

Panel 3. Movement- Prototype

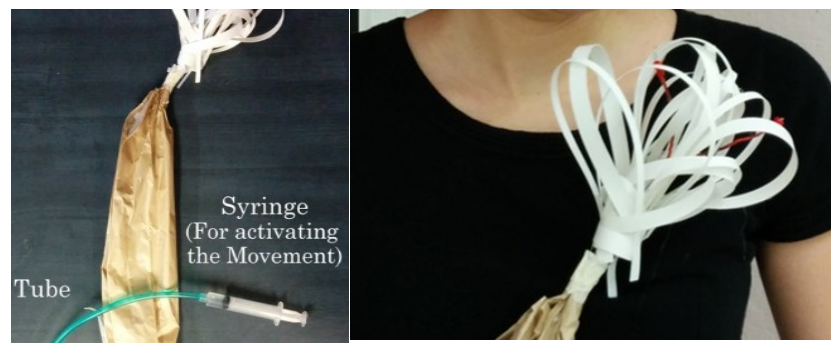

Panel 4. Mechanism

Figure 28. Prototype D 
SUMMARY-PHASE ONE

Phase one explored the tangible expression of movement and biophilic movement in the design discipline. Here are the main results achieved from this Investigative Field Research.

Internet Survey of videos, museum visits, and exhibition visits:

- Classifications: By observing natural settings, as well as plants and animals, and consulting with a biology expert, several types of movements were identified and classified into groups (Table 3). These groups of biophilic movements are open-close, flapping, translational, tentacle-like, and changing size.

\section{Brainstorming Workshop:}

- The workshop helped the researcher gain insight into how to generate ideas and create tangible forms for designing the phase two prototypes.

- Different movements through different or similar forms: Through the workshop, the researcher observed how different forms can incorporate similar or different movements. The same type of movement, such as translational movement, can be combined with different forms, which may communicate different information and elicit different emotions.

Considering the importance of form while designing movement for an object, in the Design Process, biology-inspired-forms were designed and combined with an appropriate type of biophilic movement taken from Table 3. Four different types of wearable objects with various movements were built. In the next chapter (phase two), these prototypes are tested in order to understand people's emotional response to wearable objects with biophilic movements. 


\section{CHAPTER FOUR: PHASE TWO}

EXERCISES: Emotional Responses to Wearable Objects with Incorporated Biophilic Movement

\subsection{INTRODUCTION}

This phase of the study includes two exercises. For conducting these exercises, data was gathered through observation, verbal, and non-verbal reports such as 'Emocards' and 'Semantic Differential Scales' to explore people's emotional responses. The main objective of this phase was to explore the emotional response of people to wearable objects with 'biophilic movement'.

\subsection{METHODS}

The following section discusses the methods used to address exercises one and two.

\subsubsection{Exercise One}

The aim of exercise one was to explore the emotional responses of people who meet someone wearing a wearable object with moving parts.

Setting and Materials: This exercise was conducted in one of the final sessions of the ‘Sensory Aspects of Design' class taught by Professor Lois Frankel. The class exercises throughout the semester involved explorations of the sensory experiences people have with common products. This course was offered to industrial design undergraduate students in the autumn 2013. Fifty-two industrial design students registered in this class; fifty undergraduate students and two graduate students.

In this first exercise, Professor Lois Frankel participated in the study and wore the interactive brooch. Students, at first unknowingly, albeit with ethics clearance, took part as viewers of the wearable object. Prototype A was the first prepared prototype; therefore, it was tested in this exercise. 
Twenty minutes before the start of the class, Professor Frankel and the researcher organized the exercise settings. The brooch was worn on the left side (Figure 29). The colour of the cloth was intentionally black to create a contrast with the colour of the brooch and to help the students view the object.

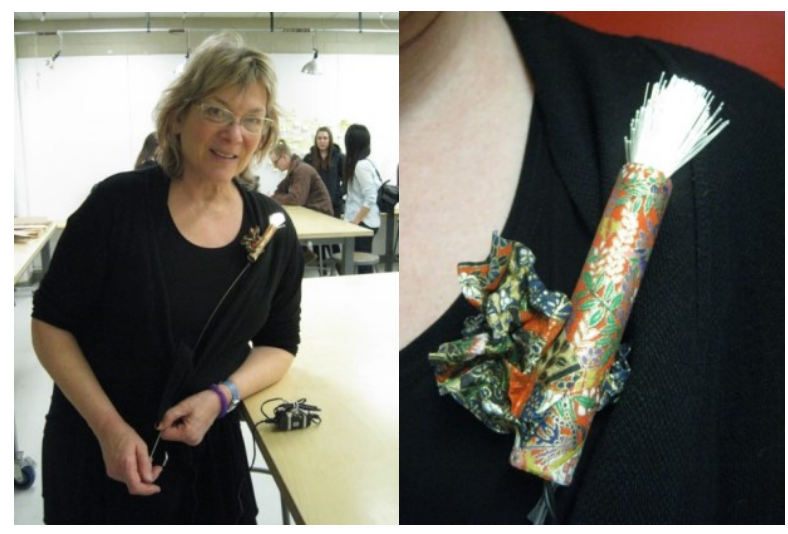

Figure 29. Exercise One: Brooch A (Worn)

Since the output of this interactive device — the movement and light — were activated manually through different wires, the researcher stood next to the professor during the exercise to assist in activating the light through the switch. As noted earlier, the element of light was added to the design of this brooch to make the movement more visible from a distance. The wearer activated the movement through the wire attached to the piece. In order to hide the mechanisms of the brooch, the professor and researcher had to stand behind the podium. Figure 30 shows the plan of the classroom where this exploration took place.

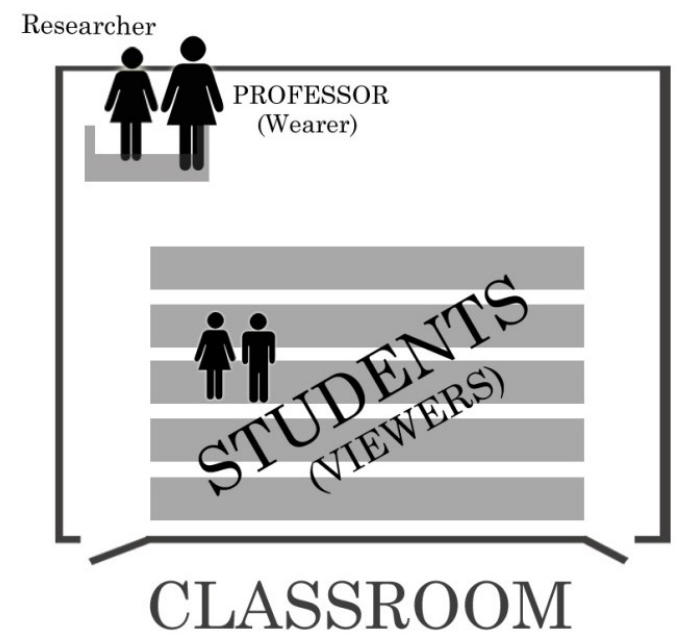

Figure 30. Location-Exercise One 
Procedure and Participants: Students arrived at class one by one and the class began at 8:30 on a Monday morning as usual. Only the twenty-five students there for the first 10 minutes of the session participated in this exercise. The video recorder was set up within the podium in order to record the exercise. Since the students were not aware of this exercise, this study did not have permission to video record the expression of the viewers. In the first minute after starting the class, the professor mentioned that the researcher was standing next to her to set up her slides for the PowerPoint presentation she was about to give; the researcher, a student of the class, was supposed to give her presentation right after running this exercise. Therefore, the unusual situation of the researcher standing next to the professor was clarified.

While the professor was reviewing the previous class, she was also activating the movement of the object through the wire with her right hand that was hidden behind the podium. After the professor activated the mechanism to push the fibres up and down from the tube several times, the researcher started turning on the light switch that enabled the light that accompanied the movement. The researcher noticed that some of the students' facial expressions became unusual as the exercise began. Seeing the unusual expressions on the students' faces made Professor Frankel laugh. However, she ignored this aspect and continued with her lecture. Some students started giggling and talking to other students sitting next to them. Still, no one said anything or provided any verbal expression to the class. The professor continued her talk and the wave of laughter attacked everybody in the class again; this led to a student finally asking a question about the brooch. The question was: "I know you are involved in interactive wearable technology; I am just wondering if you might just happen to be wearing something along those lines this morning?"

After the brooch was acknowledged, the professor and researcher confessed to the class that the viewers' feelings or reactions to interactive wearable objects was part of this research exercise. 
Based on the ethics permission form received for this part of the study, students were asked to participate in the study through the methods described below. Participants were asked to express the feelings they had when they viewed the interactive kinetic wearable object.

\subsubsection{Emocards, Multiple-Choice \& Open-ended Questionnaires}

In this exercise, the emotional response of participants is determined through a nonverbal tool named 'Emocards', developed by Desmet and Overbeeke in 2001 (Figure 31). The 16 'Emocards' show cartoon faces (eight male faces and eight female faces) with eight different emotional expressions. The expressions differ on the basis of the factors of 'pleasantness' and 'arousal' (physical state of activation). Each emotion can be explained based on the level of pleasantness and arousal; the excited emotions are located on the upper side of the circle and the calm ones on the bottom. The left side of the circle locates the unpleasant emotions and the right side locates the pleasant (Desmet \& Overbeeke, 2001). Participants were asked to indicate the feelings they had when they first viewed the movement of the interactive kinetic wearable object by choosing the cartoon face that best fit their feeling.

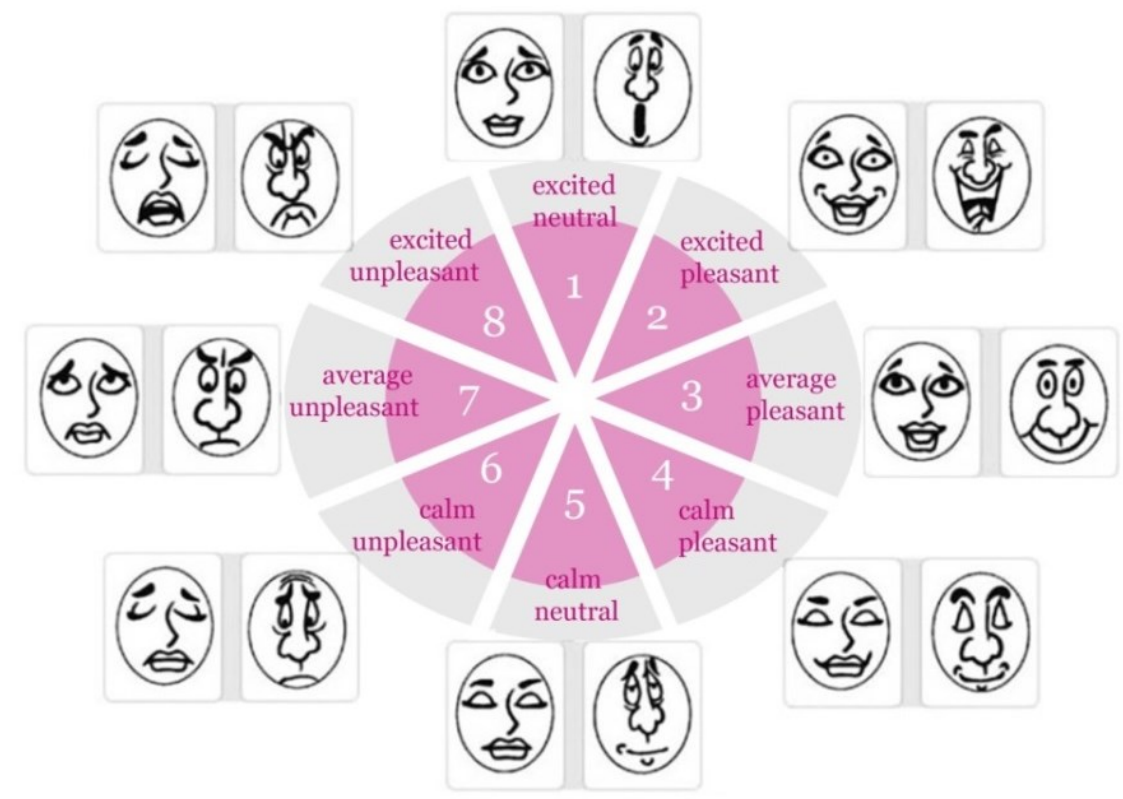

Figure 31. Eight Emotional Categories and Emocards (Desmet \& Overbeeke, 2001) 
After choosing the Emocards, a multiple-choice and open-ended questionnaire was handed out to participants, giving them an opportunity to verbally explain their emotional response to the movement. Participants also expressed comments and gave ethics consent in specific spaces provided on the sheet.

\subsubsection{Exercise Two}

This exercise explored participants' emotional response to four different kinetic wearable objects with different biophilic movements. The exercise aimed to explore:

- Wearer's reactions to interactive wearable objects with different biophilic movements

- Characteristics people assigned to each of the prototypes

The methods include card sorting, Semantic Differential Scale, observation and a multiple-choice questionnaire.

\subsubsection{Polar Adjectives, Card Sorting \& Semantic Differential Scale}

The Semantic Differential Scale (SDS) is a tool that helps measure emotion by asking participants to report their emotional response using a set of rating scales. There are many existing semantic scales such as Patrick Jordan's Product Personality Assessment (PPA) tool that can be used. Jordan's PPA is a method that includes polar adjectives to find out people's emotional responses to products (Jordan, 2002). The researcher, however, wanted to use a unique set of polar adjectives that were relevant to nature for the semantic differential scale.

In order to find the best polar adjectives for this study, and using the rating scale in SDS, a session was conducted with ten participants to explore suitable adjectives for the scale. Seven biology students and three industrial design students participated in the study. Participants were recruited from the Biology and Industrial Design departments at Carleton University. Since the academic background of the participants was not a control factor in this study, the participants 
were chosen as a convenience sample. The researcher had no connection to the biology students; they received an email request to participate in the study. The industrial design students were requested orally to participate in the study on the same day. The participants watched four short videos that revealed the movements of a butterfly, a blue button, a feather duster worm, and a coral reef. After watching each video, all participants chose the adjectives that were best suited to each creature. This study was conducted to determine terms for articulating peoples' emotional response to natural scenes and specifically to the movements of four types of creatures. This process helped define the adjectives that best describe the characteristics of the nature scenes on the videos. Participants chose the adjectives from a pool of positive and negative adjectives. Afterwards, the researcher chose the opposites of the adjectives through card sorting.

The Setting \& Materials: The study was conducted in an industrial design studio in the School of Industrial Design, Mackenzie building at Carleton University. Materials used for this exercise were the four prototypes, a mirror, a chair, a video recorder, consent forms, and questionnaires. Since light had added an unexpected complication to the previous exploration it was not included in the next three prototypes. Figure 32 shows the setting for this study.

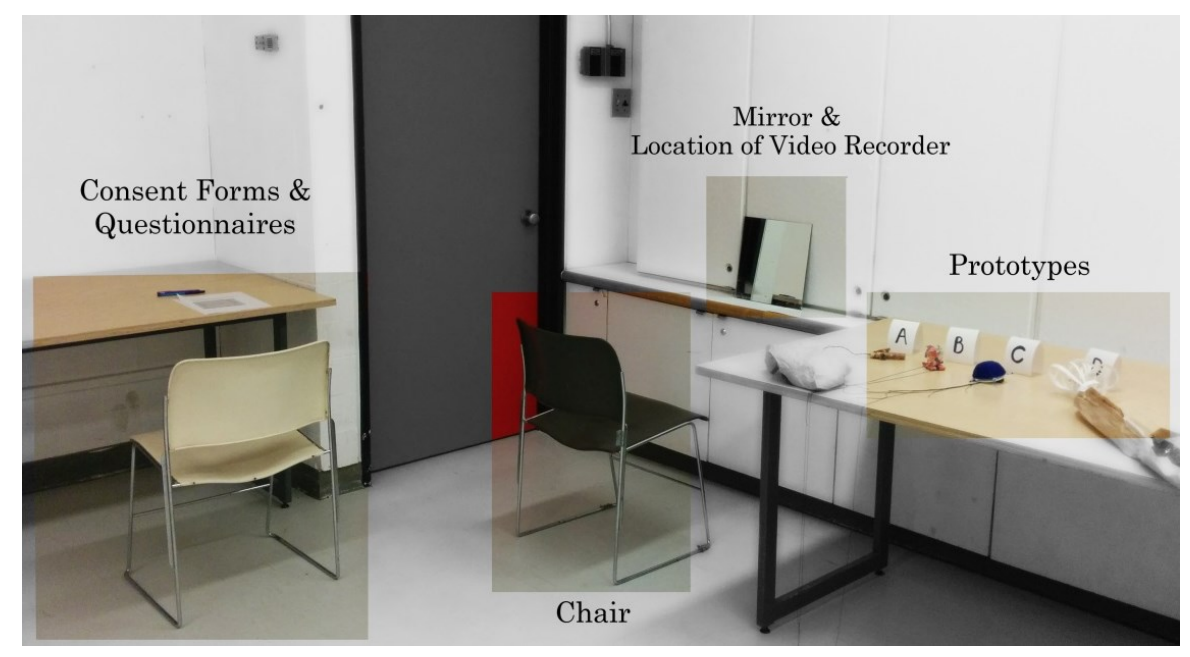

Figure 32. Location \& Materials-Exercise Two 
Participants: Ten individuals, male and female, participated in the research. $90 \%$ of the participants were between $20-30$ years old, $10 \%$ were middle-aged, and $80 \%$ of the participants were industrial design students. Since modern fashion books show a lot of men wearing "brooch-type" objects, the focus of this study is not to make comparison between males and females in how they respond emotionally to 'biophilic movement' in designed objects. Therefore gender is not a concern.

Procedure: The exercise took about 20 minutes for each individual. Each participant experienced the prototypes individually, and each was recruited on the same day as the exercise through personal request and an announcement in the School of Industrial Design. Each participant was asked to choose the prototypes to wear and interact with. Participants were given the choice of picking any one of the prototypes. The researcher did not suggest which prototype to choose. They each chose the prototypes on their own, in different order. The participants, one by one, one after another, put on each prototype, sat on the chair, and looked at themselves in the mirror. At the same time the researcher, who was located behind the participant's chair, activated the mechanism. After interacting with each prototype, the Semantic Differential Scale for that prototype was answered by each participant (see Appendix K). In this scale, to minimize pattern answering and increase accuracy, dimensions of similar meaning are presented with reversed polarity. After experiencing all the prototypes, a comparative multiple-choice questionnaire was answered by individuals (see Appendix L). During the exercise observations were made and most of the interactions were video recorded. The recorder was set up next to the mirror, so it could frame the participant's face and record facial and verbal expressions during the interaction.

\subsubsection{Observation, Verbal Comments}

The participants' facial and verbal expressions during their interaction with the prototypes, and their reactions and behaviours, provide informative data about people's 
emotional response to products. The participants were asked to think out loud and express their feelings during the interaction. Some individuals freely communicated their feelings by facial and verbal expressions. Since identifying the real emotions toward an object is not an easy task, the verbal comments accompanying the facial expressions assisted the researcher greatly.

\subsubsection{Comparative Questionnaire}

Right after interacting with each prototype, the Semantic Differential Scale for that prototype was answered by each participant. At the end, after interacting with all four prototypes and answering the Semantic Differential Scales, participants answered the comparative questionnaire. The questionnaire contained both multiple choice and open-ended questions. The goal of applying this questionnaire was to assign certain kind of characteristics to the prototypes. Moreover, it explored whether or not the movement was appealing in at least one of the brooches.

\subsection{RESULTS}

The following section explains the results achieved from exercise one and exercise two.

\subsubsection{Results of Exercise One: Classroom viewing of Prototype A on Professor Frankel}

The results of Emocards, multiple-choice and open-ended questions are analysed below.

\subsubsection{Results of Emocards}

Data analysis from Emocards reveals that $\mathrm{t} 72 \%$ of the viewers of prototype A found the movement pleasant. Moreover $36 \%$ of the participants were excited when viewing the kinetic object (20\% found the kinetic object excited pleasant and 16\% excited neutral). $20 \%$ of the participants found the kinetic object calming (12\% found it calming pleasant and $8 \%$ calming neutral). The emotional response of $\mathbf{2 4 \%}$ of the participants was neutral to the kinetic object. 4\% did not answer the Emocards. No one found this experience unpleasant (Figure $33 \&$ Table 4). 
Table 4. Results of Emocards

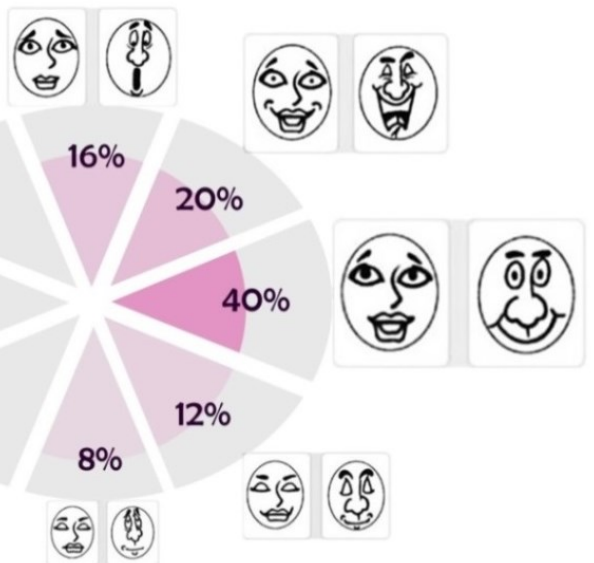

\begin{tabular}{ll}
\hline Emotional Response & Percentage \\
\hline Excited neutral & 16 \\
Excited pleasant & 20 \\
\hline Average pleasant & 40 \\
Calm pleasant & 12 \\
Calm neutral & 8 \\
Calm unpleasant & 0 \\
\hline Average unpleasant & 0 \\
Excited unpleasant & 0 \\
No answer & 4 \\
\hline
\end{tabular}

Figure 33. Emocard Analysis

\subsubsection{Results of Multiple-choice Questionnaire}

Eight participants mentioned that they first noticed the object and its movement after noticing the wearer's reaction. Seven participants noticed the movement after seeing other students' reactions. Five participants recognized the movement by themselves. Three students perceived it from both the wearer's and other student's behaviours. One student mentioned that he understood the movement by himself and through the element of light as a factor that grabbed his attention to the movement. Another student also pointed to the light as a factor that helped identify the movement (Figure 34).

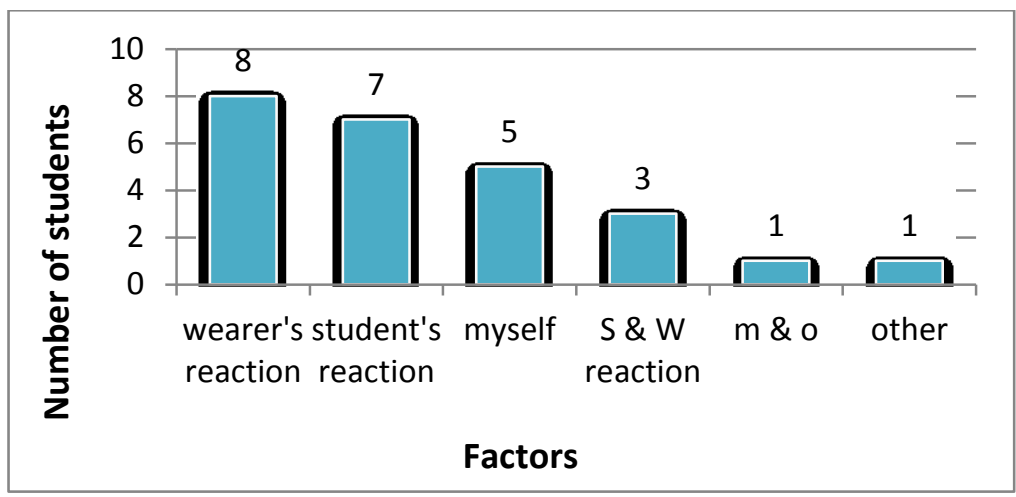

Figure 34. Factors Involved in Perceiving the Movement of the Brooch by the Participants

Based on the results shown in figure 35 , a considerable number of students (sixteen participants) found their experience of viewing this wearable object moderate, not that much, or 
a little enjoyable. For nine students, it was quite a bit enjoyable and no students found it extremely enjoyable.

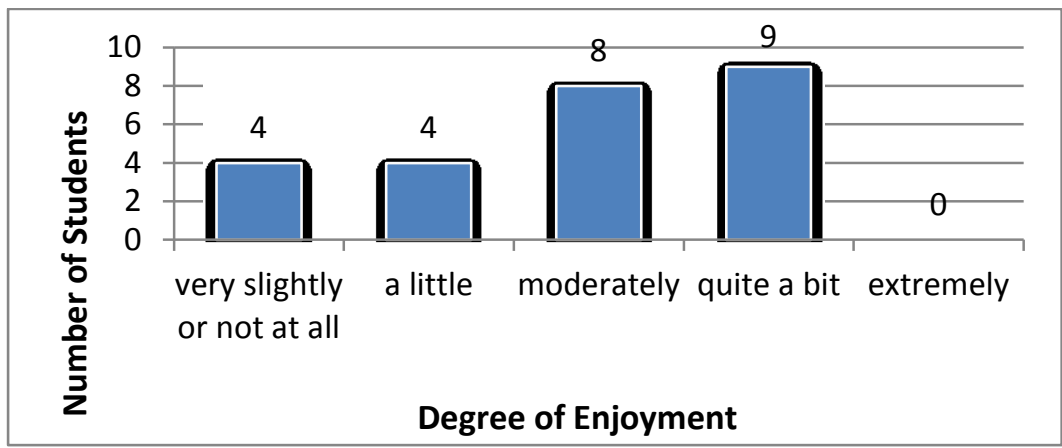

Figure 35. Degree of Enjoyment from Viewing Kinetic Wearable Object

Although the result of Emocards shows a considerable number of students ( $72 \%$ ) found this experience pleasurable for the first viewing, the result of the multiple choice question revealed that only nine students (36\% of the participants) found the kinetic object quite a bit enjoyable for viewing.

\subsubsection{Results of Open-ended Questionnaire}

Participants in this research made various comments regarding their experience. Table 5 (below) shows participants' descriptions of the object itself and their interaction with the product.

Table 5. Participants' Comments-Exercise One

\begin{tabular}{|l|}
\hline \multicolumn{1}{|c|}{ Participant's Comment Regarding the Experience } \\
\hline Cool idea/ Distracting/ Confusion \\
\hline larger size of the object draw my attention \\
\hline I did not realize it was glowing from far, I thought the fibers were a full piece of metal \\
\hline movement of the object came as a little surprise \\
\hline reminds things I have seen in futuristic movies but in real like, this might be funny \\
\hline very interesting \\
\hline pleasant surprise \\
\hline strange-mildly distracting \\
\hline I did not really notice until you told us about it \\
\hline $\begin{array}{l}\text { I did not pay attention to it and I thought it was a piece of Lois's jewellery and was more } \\
\text { interested in her laughing. }\end{array}$ \\
\hline I found it funny that it was a little brooch that was moving and lighting up and acting silly. \\
\hline
\end{tabular}


Results of open-ended questionnaire show:

- Qualities of Interactive Wearable Object: Participants assigned different qualities to the interactive wearable object. They considered this object as interesting, cool, funny, strange, and distracting.

- Emotions Elicited: People also experienced different emotions such as confusion, surprise, and pleasantness during this interaction.

- Movement Recognition: At first, not all the participants recognized the movement of the object,, however everyone who filled out a form saw the moving piece after something or someone brought their attention to it. One student pointed out that he did not realize the piece was glowing from far, and he thought the fibres were a full piece of metal. Since, not all participants recognized the movement at first, it was assumed that proximity was an issue in whether the movement was perceived in the first place.

To sum up, exercise one reveals that $\mathbf{7 2 \%}$ of the viewers said their emotional response to the kinetic wearable object was pleasant. The emotional response of the rest of the participants was neutral $(24 \%)$ and $4 \%$ of the participants did not answer the question. Therefore, it can be concluded that this experience was pleasant for most participants. Although according to the results of the multiple-choice questionnaire it was not extremely enjoyable for them.

\subsubsection{Results of Exercise Two}

The following section explains the results of the methods applied in exercise two.

\subsubsection{Result of Polar Adjectives, Card Sorting \& Semantic Differential Scale}

Upon analysis of the results, eleven adjectives best matched responses to the videos. Some of the top adjectives had similar meanings so these words were highlighted with the same colour and one of them was chosen as the final adjective. Some adjectives were meaningless and not applicable for the questionnaire and were deleted (Table 6. Top Adjectives). For example, 
'tropical' was an adjective that was common to a wide range of natural movements, and therefore could not be used as a distinguishing adjective. Moreover, one adjective, 'familiar', was added to the list in order to have a comparison between emotions elicited from familiar and unfamiliar objects (see Table 7. Chosen Adjectives).

Table 6. Top Adjectives

\begin{tabular}{|l|l|}
\hline Frequency & Top Adjectives \\
\hline 22 natural \\
18 calm \\
14 beautiful \\
14 interesting \\
13 peaceful \\
12 alive \\
\hline 12 colourful \\
\hline 12 tranquil \\
\hline 12 open (frienldy) \\
\hline 12 dynamic \\
\hline 12 serene \\
11 gentle \\
11 positive \\
10 bright \\
10 pleasant \\
10 harmonious \\
\hline 10 scenic \\
10 beauty \\
10 flexible \\
9 tropical \\
9 impressive \\
9 adaptive \\
9 real \\
8 unique \\
\hline
\end{tabular}

Table 7. Chosen Adjectives

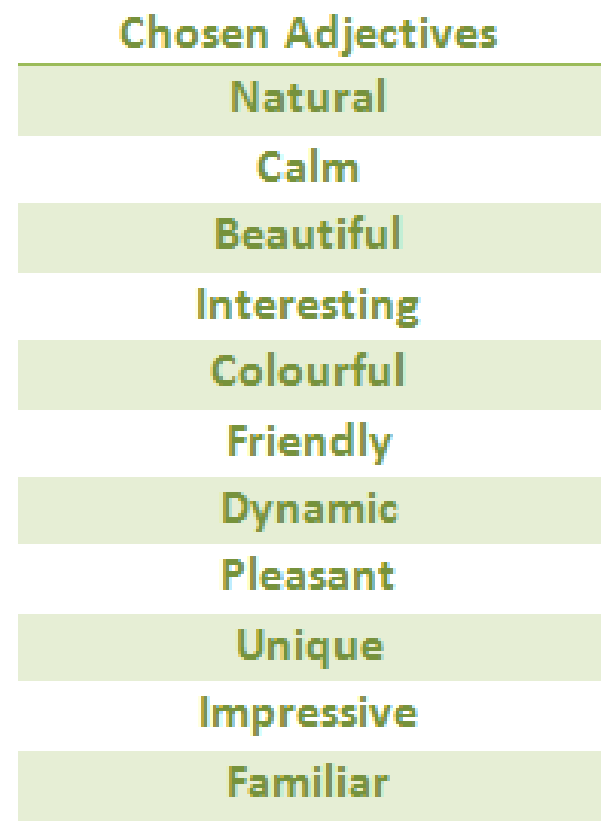

Table 8 shows the polar adjectives selected for the semantic differential rating scale. This preliminary biophilic semantic differential scale was used to understand how people interpret biophilic movements in the four prototypes. 
Table 8. Polar Adjectives

\begin{tabular}{cc}
\hline \multicolumn{2}{c}{ Polar Adjectives } \\
\hline Positive Adjectives & Negative Adjectives \\
\hline Natural & Artificial \\
Calm & Tense \\
\hline Beautiful & Ugly \\
Interesting & Boring \\
\hline Colourful & Plain \\
\hline Friendly & Unfriendly \\
\hline Dynamic & Static \\
\hline Pleasant & Unpleasant \\
\hline Unique & Ordinary \\
\hline Impressive & Unimpressive \\
\hline Familiar & Unfamiliar \\
\hline
\end{tabular}

The final pair of polar adjectives were added to the Semantic Differential Scale to investigate the familiarity or unfamiliarity of the emotions elicited by products. The result of Semantic Differential Scale is shown in a diagram for each of the four prototypes. The results are interpreted based on the mode, average, and STDEV for each polar adjective.

The characteristics for each of the prototypes are described based on the result achieved from Semantic Differential Scale. The description and related diagram for each brooch is explained below. 
Prototype A:

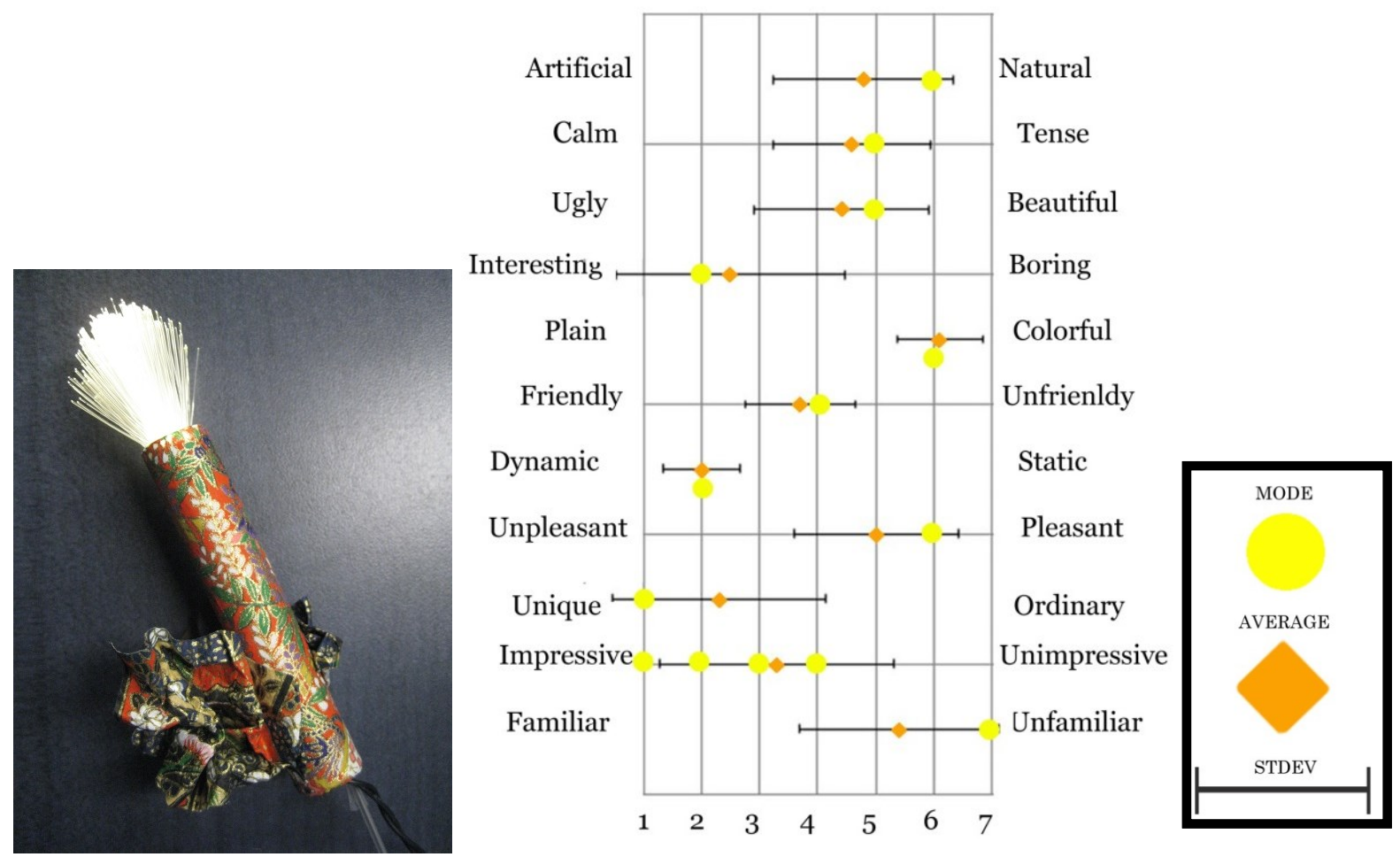

Figure 36. Prototype A Characteristics

Most participants found this kinetic brooch natural, tense, beautiful, interesting, colourful, dynamic, pleasant, unique, impressive, and unfamiliar (Figure 36).

For the friendly-unfriendly category, the mode is exactly in the middle which shows most of the participants were neutral in response to this question; however, it still shows there is a tendency toward the friendly side rather than unfriendly. 
Prototype B:
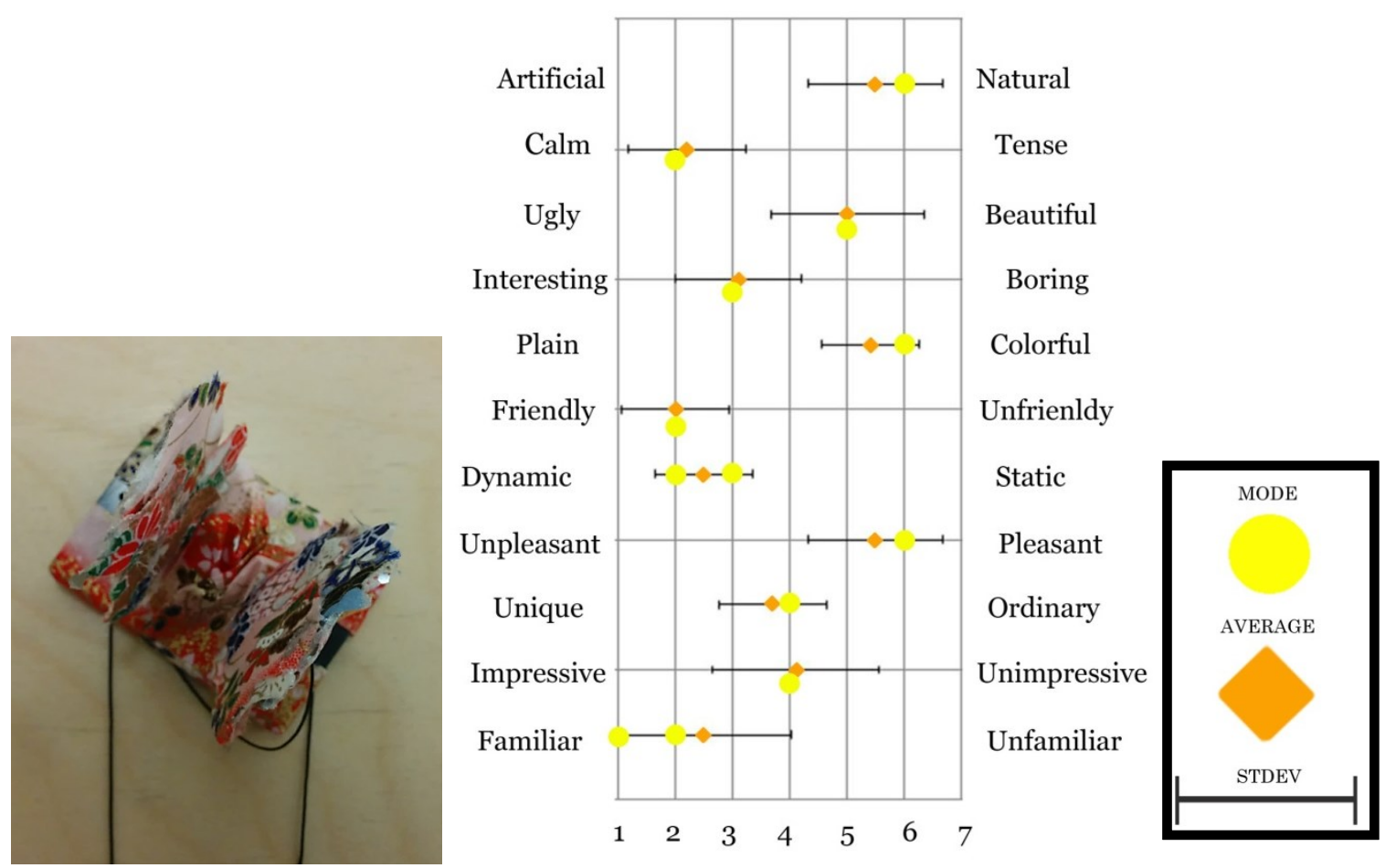

Figure 37. Prototype B Characteristics

Most participants found this kinetic brooch natural, calm, beautiful, interesting, colourful, friendly, dynamic, pleasant, and familiar (Figure 37).

For the impressive-unimpressive category, the mode is exactly in the middle which indicates most of the participants were neutral in response to this question. 
Prototype C:
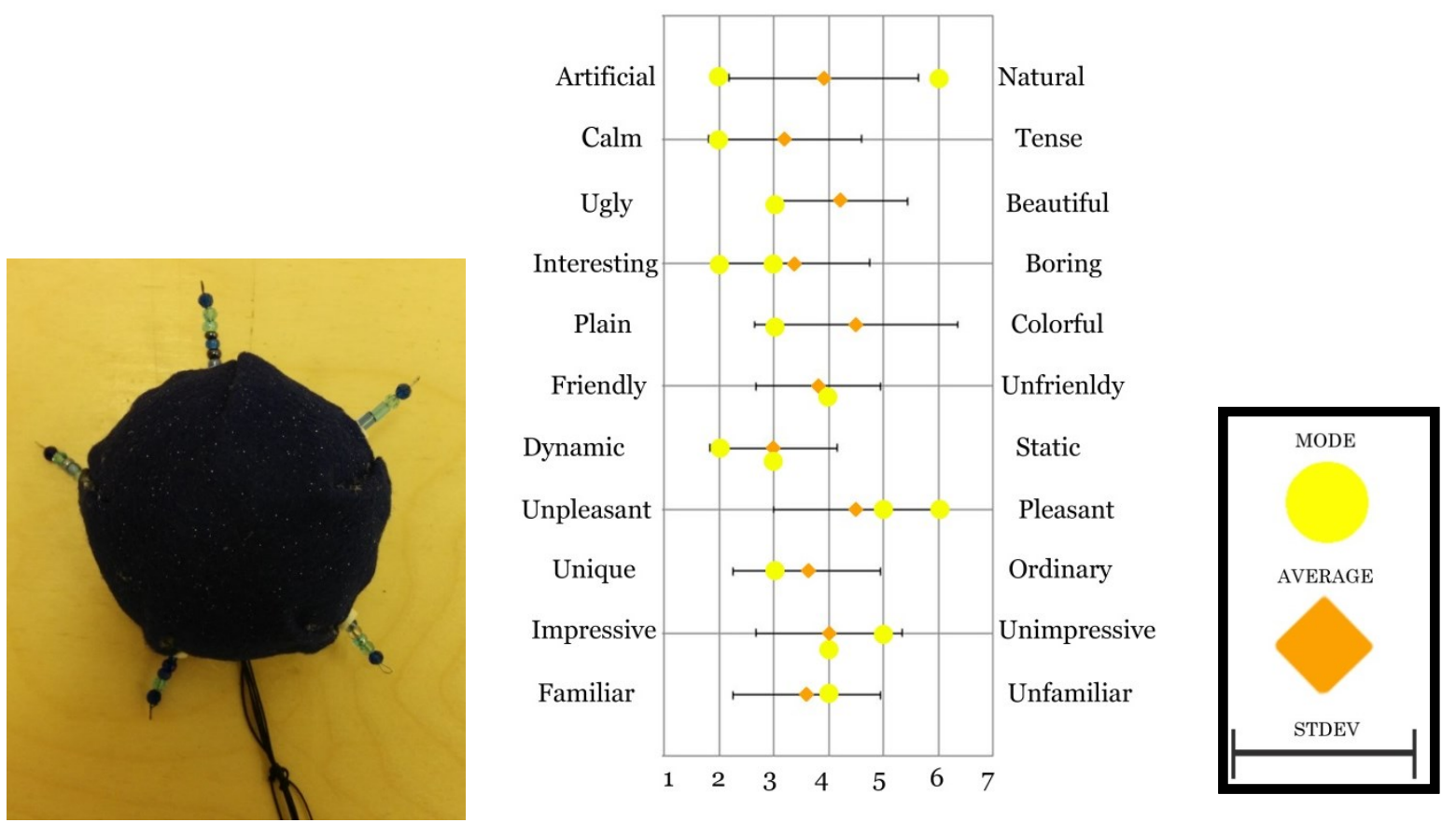

Figure 38. Prototype C Characteristics

Most participants found this kinetic brooch calm, interesting, plain, dynamic, and pleasant (Figure 38). For this brooch, most of the results are close to the middle indicating that the participants' emotions were neutral toward the object. The result of the Semantic Differential Scale can be linked with the results of other methods regarding this brooch. The observation and multiple-choice questions also showed that people did not have a very good interaction with this brooch.

For the natural-artificial category, the mode is both on the side of natural and artificial showing the same number of participants found this object to be natural as those who found it artificial. As mentioned before, the mechanism in this prototype did not work as well as other prototypes. This is a factor that intensely affected participants' responses. 
Prototype D:
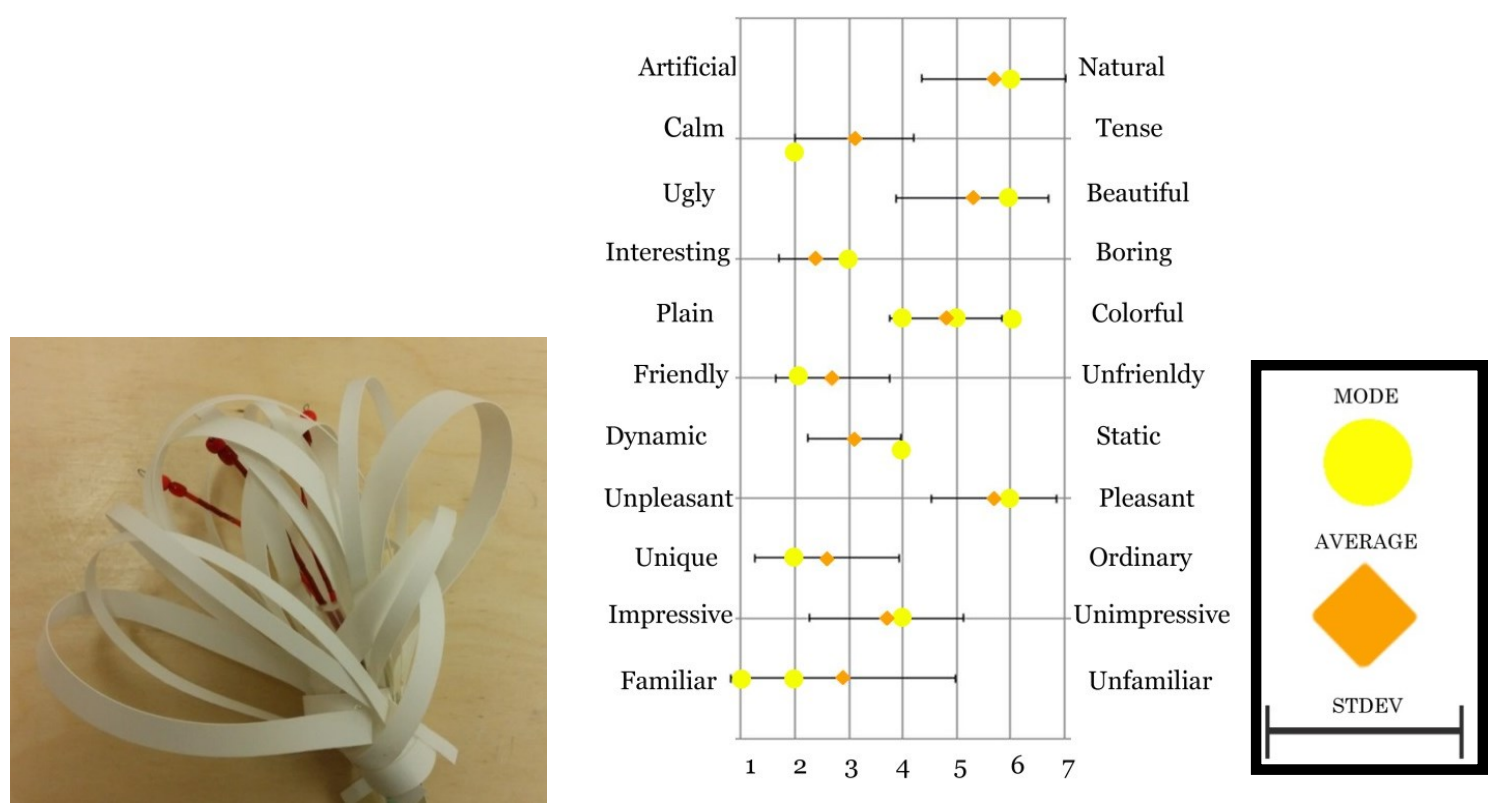

Figure 39. Prototype D characteristics

Most participants found this kinetic brooch natural, calm, beautiful, interesting, colourful, friendly, pleasant, unique, and familiar (Figure 39).

Familiar objects can create a calm experience for users and bring about pleasure. Similar to brooch B, this brooch is also familiar for most wearers; therefore it is friendly and calm. This brooch was quite unique for the participants in contrast to prototype B.

\subsubsection{Results of Observation \& Verbal Comments}

Each participant's detail of the interaction was observed and all the comments and behaviours were transcribed (see Appendix M). Highlights of the facial and verbal expressions of participants during the interaction with prototypes are mentioned in Table 9. 
Table 9. Facial and Verbal Expressions - Exercise Two

\begin{tabular}{|c|c|c|}
\hline Prototype & $\begin{array}{l}\text { User's Facial Expressions \& } \\
\text { Body Gestures }\end{array}$ & User's Verbal Expressions \& Comments \\
\hline \multirow{6}{*}{$\mathrm{A}$} & \multirow{2}{*}{$\begin{array}{l}\text { Smiling } \\
\text { Laughing }\end{array}$} & Participant A-1: "I like the light" \\
\hline & & $\begin{array}{l}\text { Participant A-2: "Oh, I like it most. Because of the } \\
\text { light" "If you add the light to D, that would be nice" }\end{array}$ \\
\hline & \multirow{4}{*}{$\begin{array}{l}\text { No facial Expression } \\
\text { Focusing on the object's } \\
\text { behaviour } \\
\text { Touching the wearable object } \\
\text { Bending head and looking at the } \\
\text { object worn on the body }\end{array}$} & $\begin{array}{l}\text { Participant A-3: "I am afraid!!!!!" "Wow! That is } \\
\text { cool!!!!" }\end{array}$ \\
\hline & & $\begin{array}{l}\text { Participant A-4: "Maybe the flashing light is a bit } \\
\text { distracting, unless it has a safety reason. I prefer it to } \\
\text { be off and interact with it" }\end{array}$ \\
\hline & & $\begin{array}{l}\text { Participant A-5: "Wow!! that is very very distracting, } \\
\text { the form and the light and the movement"/ "I think } \\
\text { light is more distracting than the movement" }\end{array}$ \\
\hline & & $\begin{array}{l}\text { Participant A-6: "How beautiful?" "I was afraid when } \\
\text { it first came out! but I liked it..." }\end{array}$ \\
\hline \multirow{5}{*}{ B } & \multirow{5}{*}{$\begin{array}{l}\text { Smiling } \\
\text { Laughing } \\
\text { More focusing and relaxed mood } \\
\text { Smiling } \\
\text { No facial expression }\end{array}$} & Participant B-1: "B \& D looks more natural." \\
\hline & & $\begin{array}{l}\text { Participant B-2: "It is so cool!!" "Is it a butterfly?" "I } \\
\text { think it is a butterfly, because it is just a butterfly that } \\
\text { sit somewhere" "It was interesting" }\end{array}$ \\
\hline & & $\begin{array}{l}\text { Participant B-3: "I like this one better than A" "It is a } \\
\text { lot more.....It is less aggressive. It is more calming" } \\
\text { "I like it better when I activate it myself" "All the } \\
\text { prototypes except B are like coming at you, like } \\
\text { being attacked with what I am wearing...... } \\
\text { prototype B is more calming and natural" }\end{array}$ \\
\hline & & $\begin{array}{l}\text { Participant B-4: "It is kind of a butterfly" "what is } \\
\text { weird with this one is that compare with the other } \\
\text { ones. I did not like the appearance of it, because it is } \\
\text { actually like a cactus. But regarding the movement } \\
\text { when I saw the movement, I prefer this simple } \\
\text { movement of opening and closing compare with } \\
\text { other movements. It is never got bigger. Those three } \\
\text { they get bigger but this one simply moves. this is } \\
\text { pretty natural that nothing is growing out of it" }\end{array}$ \\
\hline & & $\begin{array}{l}\text { Participant B-5: "Is it butterfly? It looks like a } \\
\text { butterfly" }\end{array}$ \\
\hline \multirow{3}{*}{$\mathrm{C}$} & \multirow{3}{*}{$\begin{array}{l}\text { Laughing } \\
\text { No facial expression }\end{array}$} & Participant C-1: "This is funny" \\
\hline & & $\begin{array}{l}\text { Participant C-2: "Wow!" "I like to see the } \\
\text { mechanism" }\end{array}$ \\
\hline & & Participant C-3: "This is so colourful" \\
\hline \multirow{5}{*}{$\mathrm{D}$} & \multirow{5}{*}{$\begin{array}{l}\text { Smiling } \\
\text { Laughing } \\
\text { Bending head and looking at the } \\
\text { object worn on the body }\end{array}$} & Participant D-1: "I like it better than C \& B" \\
\hline & & $\begin{array}{l}\text { Participant D-2: "Wow!! That is so big!!" "Oh my } \\
\text { God! I think it is going to open now" "I like this... } \\
\text { first I like A and then D. It is just over-sized" }\end{array}$ \\
\hline & & $\begin{array}{l}\text { Participant D-3: "Oh, that is fantastic!!" "I found it } \\
\text { uneasy. It is actually like a hand reaching out at you, } \\
\text { I found it kind of creepy" "I like the idea that it is like } \\
\text { a flower and it is more interesting" }\end{array}$ \\
\hline & & Participant D-4: "For me, it is like a flower" \\
\hline & & $\begin{array}{l}\text { Participant D-5: "Is it a flower?" "I am afraid" "that } \\
\text { is cool!!!"It is a flower" }\end{array}$ \\
\hline
\end{tabular}


Table 9 shows the participants experienced a range of different emotions during the interaction with the objects. According to the comments and expressions in Table 9:

\section{Element of Light:}

- While some people found the element of light in prototype A very interesting, some found it distracting.

\section{Emotional Responses- 'Fear, Surprise, Laugh':}

- Two participants mentioned that they were afraid during the interaction with prototype A, since they did not see the fibres first, and suddenly they emerged from the tube. But after knowing the product's behaviour, they laughed and found the interaction with the object really fascinating. It seems the element of surprise plays a significant role in creating this experience for participants. One participant mentioned that she was afraid before experiencing prototype $\mathrm{D}$.

\section{Sensory Experience:}

- During the interaction with prototype A, some participants touched the fibres while coming out of the tube.

\section{Biophilic Wearable Object-Representation of Nature:}

- As soon as people viewed the movement of prototype B, they understood it was inspired by a butterfly's movement. People found this experience calming.

- Some participants said that prototype D reminds them of a flower blooming.

\section{Changing Size \& Emotion:}

- Two participants mentioned that prototype B has a simple flapping movement without changing size. The other prototypes get bigger and create a sense of being attacked by the wearer's own jewellery piece.

\section{Limitation; Mechanism \& Interaction:}

- Although prototype $\mathrm{C}$ was found aesthetically appealing for the participants, not that much interaction took place between the prototype and wearers. The mechanism in this 
prototype did not work as well as other prototypes. This is a factor that affected userproduct interaction.

\subsubsection{Results of Comparative Questionnaire}

The results of the comparative questionnaire between the prototypes reveals that out of ten individuals who participated in the study, five participants found brooch A more engaging during the exercise, three individuals mentioned $\mathrm{D}$, and two participants found $\mathrm{B}$ more engaging (Figure 40).

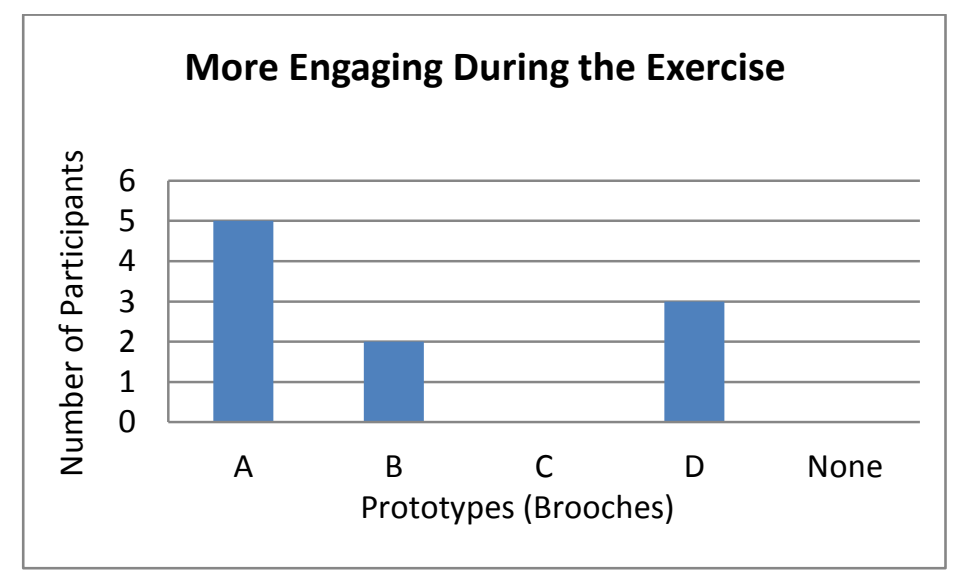

Figure 40. The Most Engaging Prototype during the Interaction

According to participants' comments, they found brooch A more engaging because of the element of light and movement incorporated in the object design. Other prototypes were one dimensional (movement). Adding light to the design of this object affects people's interaction with the object. People were engaged with brooch B since it reminded them of a butterfly and gave them the sense of calm and beauty. Brooch D engaged some participants because it reminded them of a flower, calming motion, and had a fancy organic shape.

Five participants selected brooch A as more enjoyable, three participants selected brooch B, and two selected brooch C (Figure 41). 


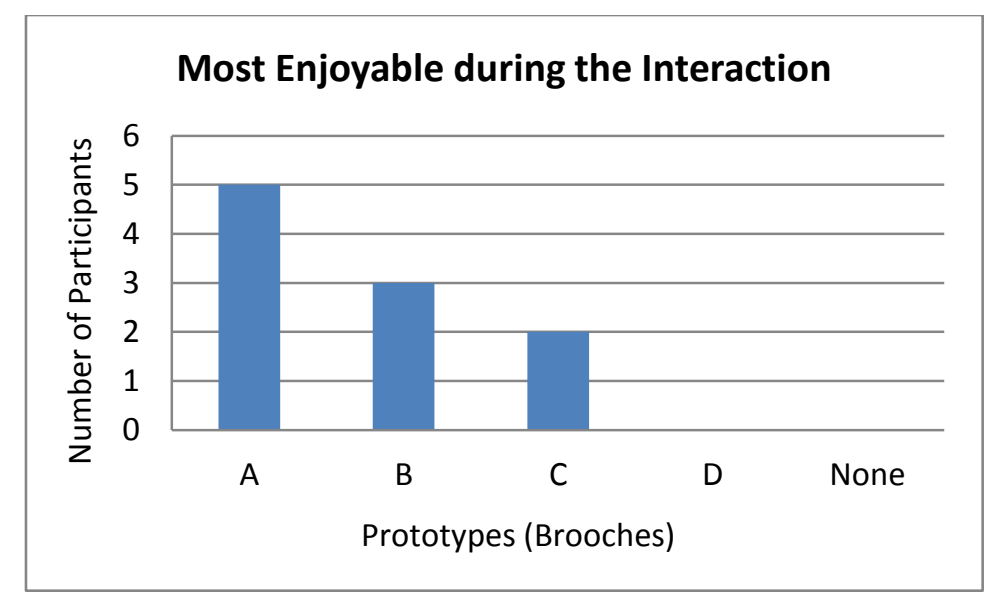

Figure 41. The Most Enjoyable Prototype during the Interaction

Participants found brooch A enjoyable because the movement and light made it visually interesting. Interacting with brooch B was enjoyable due to its simple movement and shape its calming and natural feeling. The appearance of prototype $\mathrm{C}$ without movement is visually appealing which makes this interaction enjoyable for some participants.

Four participants found the movement of brooch B was the most appealing while three individuals found the movement of $\mathrm{D}$, two individuals found $\mathrm{A}$, and one individual found $\mathrm{C}$ (Figure 42).

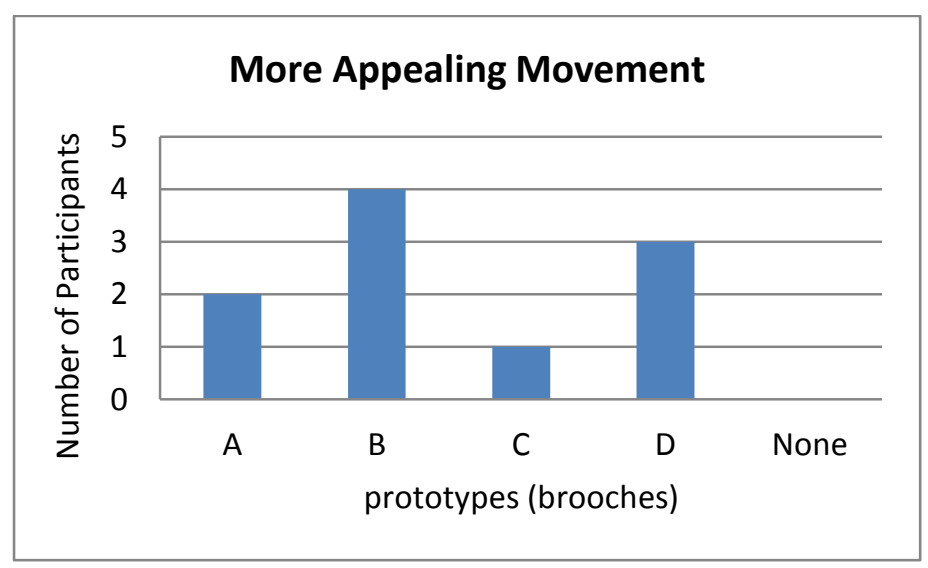

Figure 42. The Most Appealing Movement during the Interaction 
People found the movement of brooch B appealing since it has a calming and less aggressive motion. It reminded them of a butterfly and nature which adds to the aesthetic value of the object. Some participants also considered the movement of prototype D to be calming and one participant felt the movement of brooch D was similar to that of a jellyfish.

At the end, participants were asked what they would pick if they had a chance to wear one of the prototypes. Four participants chose A, and mentioned the element of light, aesthetic form, and uniqueness as their main reasons. Three participants chose brooch B because of the simple calming movement, which reminded them of nature. The static visual appearance of brooch C and the movement of prototype D attracted few participants (Figure 43).

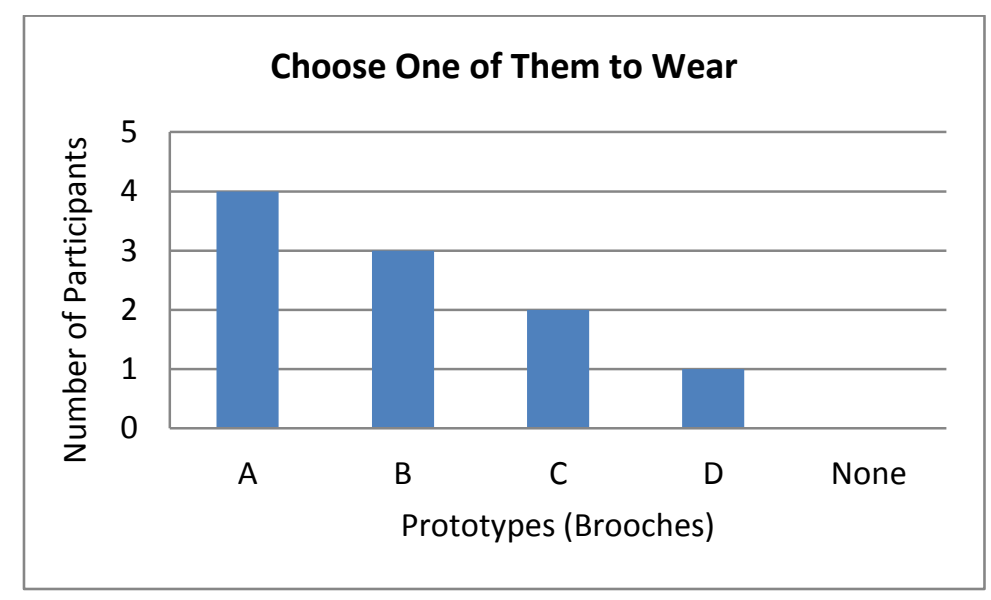

Figure 43. The Prototype You Choose to Wear

The table below summarizes the reasons why participants chose each specific prototype $(\mathrm{A}, \mathrm{B}, \mathrm{C}$, or D) as appealing or perceived them as engaging (Table 10). 
Table 10. Reasons for Choosing Each Prototype

\begin{tabular}{|c|c|c|c|c|}
\hline Prototypes & Engaging & Enjoyable & $\begin{array}{l}\text { Appealing } \\
\text { movement }\end{array}$ & Choose this to wear \\
\hline $\mathbf{A}$ & $\begin{array}{l}\text { Element of light } \\
\text { and movement }\end{array}$ & $\begin{array}{l}\text {-Visually interesting } \\
\text {-Elements of } \\
\text { movement and light }\end{array}$ & No reason & $\begin{array}{l}\text {-Light } \\
\text {-Aesthetic form } \\
\text { Uniqueness }\end{array}$ \\
\hline $\mathbf{B}$ & $\begin{array}{l}\text {-Reminded them } \\
\text { of a butterfly } \\
\text {-Gave them the } \\
\text { sense of calming } \\
\text { and beauty }\end{array}$ & $\begin{array}{l}\text {-Simple movement } \\
\text { and shape } \\
\text {-Calming and } \\
\text { Natural feeling }\end{array}$ & $\begin{array}{l}\text {-Calming and } \\
\text { less aggressive } \\
\text { motion } \\
\text {-Reminded } \\
\text { them of a } \\
\text { butterfly and } \\
\text { nature }\end{array}$ & $\begin{array}{l}\text {-Simple calming } \\
\text { movement } \\
\text {-Reminded them of } \\
\text { nature }\end{array}$ \\
\hline $\mathbf{C}$ & - & $\begin{array}{l}\text {-Visually appealing } \\
\text { (without movement) }\end{array}$ & No reason & -Visual appearance \\
\hline D & $\begin{array}{l}\text {-Reminded them } \\
\text { of a flower } \\
\text {-Calming motion } \\
\text {-Fancy organic } \\
\text { shape }\end{array}$ & - & $\begin{array}{l}\text {-Calming } \\
\text {-Similar to a } \\
\text { jellyfish } \\
\text { movement. }\end{array}$ & -Movement \\
\hline
\end{tabular}

Interestingly, no one picked the last choice, which is none of the prototypes. Therefore, every participant found the movements in at least one of the brooches appealing.

\section{SUMMARY - PHASE TWO}

Phase two involved two exercises that explored the participants' emotional responses to the element of biophilic movement incorporated into the design of interactive wearable objects.

The exercises conducted in this study revealed that there is potential for adding the element of biophilic movement in the design of wearable objects to elicit pleasant emotional responses from people. 


\section{CHAPTER 5}

\section{DISCUSSION}

The results of this research support the literature regarding the beneficial application of 'movement' and 'nature' in designed objects. Moreover, this preliminary study provides new information and insight about designing 'biophilic movement' for interactive wearable objects. This chapter relates the main findings of this research to the research questions. It explains the main implications of the findings, points out the importance of this research, and identifies the limitations of the study.

5.1 Creating the potential for Pleasure through Interactive Biophilic Wearable Objects This section addresses the following question:

- How is it possible to elicit people's emotional responses through the incorporation of biophilic movement in wearable objects?

The literature noted that incorporating the physical element of movement and biologically inspired design could evoke a customer's pleasure and enhance the emotional value of the objects (Chang and Wu 2007; Nam et al. 2007). The findings from exercises one and two of this research revealed that adding biophilic movement can add interest to biophilic forms in jewellery by engaging the people who interact with it.

The result of the Emocards study showed that a considerable number (72\%) of students found this experience pleasurable upon first viewing. The result of the multiple-choice questionnaire also revealed that this experience was moderate and 'quite a bit enjoyable' for sixty-eight per cent of the participants.

In exercise two, the degree of participants' enjoyment tended to be closer to pleasant than unpleasant for all the brooches. Despite wearers having slightly different tastes when answering the questions and choosing different preferred prototypes, overall, every participant 
found one brooch engaging and enjoyable. This was further reinforced by participants' complete lack of response to questions about brooches or movements they did not like.

Based on the literature review, a product can be a medium for facilitating social interaction. Jordan (2002) defined the pleasure and enjoyment that is derived from relationships with other people, and society as Socio-Pleasure. As the results of exercise one in this study show, interactive wearable objects can be a vehicle for facilitating social interaction and relationships between the wearer and the people who meet the wearer. The behaviours facilitate social interaction by attracting people's comments. Therefore, the element of 'biophilic movement' in the design of wearable objects can create socio-pleasure.

Based on the literature, symbolic interactions with nature in the form of representations and reminders of nature such as images, videos, statues, and jewellery have significant impact on human psychological states and satisfy people's biophilic desire for nature (Flannery 2005; Shepard 1996; Ulrich 1984; Kellert 2005). The findings achieved from exercise two indicate that jewellery with biophilic movements can be a reminder of nature. This jewellery can be a medium for reconnecting the emotional bond between humans and nature, and for providing positive experience for people while satisfying their biophilic desire.

Results of the SDS revealed that the wearers of these interactive objects considered all four prototypes to be inspired by the natural world. Based on the participants' verbal comments, they even assigned specific characteristics to prototype B and D. Participants found prototype B's flapping movement similar to that of a butterfly. They also found prototype D's movement similar to a flower booming. Both of these had a positive impact on the wearers' emotional states.

People could not feel the movement of the wearable object directly on their skin because the types of movements chosen for this study were not in close relationship to the human skin. The movement of the object was only perceived through vision along with a small tactile experience perceived through faint vibrations on the body. Tactual experiences with a wearable object can take place in different ways; for example by carrying the wearable objects. During 
exercise two, some wearers touched the object in order to explore it. This type of interaction took place in order to explore the behaviour of the object. The literature shows when something is new and unknown, people want to explore how it feels. Even familiar objects are touched just to have contact with them (Sonneveld and Schifferstein 2008). Auditory experiences with the object can also be achieved through the little sounds produced by the prototype when it moves. Therefore, by incorporating movement into a biophilic object, one can engage people through sensory experiences.

\subsection{Design Guidelines}

This section discusses the answer to the following sub-questions:

- How is it possible to develop design suggestions for incorporating biophilic movement in wearable objects?

This study identified and categorized biologically-inspired movements that can help designers in the area of biology-to-design. In phase one of the study, different types of biophilic movements in nature were identified, classified, and provided in a table. These classifications were based on observations of nature and conducted in consulation with a biologist. The table shows different directions of biologically inspired movements. The movements were classified as open-close, tentacle-like, flapping, translational, and changing size.

Findings from the interview with Ben Hopson and exercise two of this study reveal that since this type of object (jewellery) has a constant relationship with the body, the issue of usability arises when it comes to designing movement for the object. Qualities of movements that lead to a change in the size of the object might have negative effects on humans. Changing the size of the object during movement should be applied with caution when incorporated into wearable objects. As the results of the exercise reveal, some participants felt that as it was growing bigger they were being attacked by their piece of jewellery. To evoke positive emotions it is much safer to apply the quality of movement that does not enlarge, but that might not bring 
the surprise and wow experience similar to those that change shape. The results of SDS also reveal that both types of objects create pleasant experience for the users (Table 12).

Table 11. Kinetic Wearable Object and Usability-Design Considerations

\begin{tabular}{|l|l|l|l|l|}
\hline $\begin{array}{l}\text { Type of } \\
\text { Biophilic } \\
\text { Movement }\end{array}$ & Prototype & $\begin{array}{l}\text { Emotional } \\
\text { Responses }\end{array}$ & $\begin{array}{l}\text { Type of } \\
\text { Experience }\end{array}$ & $\begin{array}{l}\text { Design } \\
\text { Considerations }\end{array}$ \\
\hline change in Size & $\begin{array}{l}\text { brooch A, } \\
\text { C, D }\end{array}$ & $\begin{array}{l}\text { being attacked } \\
\text { by their own } \\
\text { piece of jewellery } \\
\text { surprise/ tense and } \\
\text { calm/ friendly and } \\
\text { unfriendly/ } \\
\text { dynamic/ familiar } \\
\text { and unfamiliar/ } \\
\text { unique/ interesting/ } \\
\text { beautiful/ } \\
\text { impressive/ } \\
\text { pleasant }\end{array}$ & $\begin{array}{l}\text { pleasant- } \\
\text { unpleasant, }\end{array}$ & $\begin{array}{l}\text { usability issues: } \\
\text { should be designed } \\
\text { with caution }\end{array}$ \\
& brooch B & $\begin{array}{l}\text { the most calming } \\
\text { type of movement } \\
\text { Calm, beautiful, } \\
\text { interesting, friendly, } \\
\text { dynamic, pleasant, } \\
\text { familiar. }\end{array}$ & Pleasant & $\begin{array}{l}\text { safe way of } \\
\text { incorporating } \\
\text { movement to } \\
\text { achieve positive } \\
\text { response without } \\
\text { having usability } \\
\text { issues }\end{array}$ \\
\hline $\begin{array}{l}\text { without } \\
\text { change in size }\end{array}$ & & & \\
\hline
\end{tabular}

The results of the SDS and verbal comments indicate that although the experience of brooch A brought a little fear, it was more unique and impressive, and provided the experience of surprise.

While interacting with brooch A (exercises one and two), some of the participants mentioned that they were afraid, excited, and surprised when the fibre came out of the tube for the first time; they may have had this reaction because the behaviour of the brooch was unfamiliar. The literature also explains that novel and unfamiliar objects can evoke a sense of pleasure and excitement, even though they might not be exciting in the long term (Biederman and Vessel 2006 in Hekkert and Leder 2008; Veryser and Hutchinson 1998 in Hekkert and Leder 2008; Desmet, Porcelijn, and Van Dijk 2007). In this study, people found brooch A tense 
because, based on the observation and the researcher's notes, the movement and the way the object changes its form is unexpected, which can lead to a variety of emotions at the same time (fear, surprise, laugh, joy). Nonetheless, all of them can lead to a pleasant experience for the user. According to Desmet (2005), there is no isolated emotion that leads to the experience of fun; several emotions can be combined to bring about that experience.

In contrast to brooch A, SDS results indicate that wearers found brooch B calming and friendly. The fact that this brooch was familiar to them might be a reason that they responded to this prototype with a friendlier and calming emotion. But, this brooch was familiar to participants, not unique, which may have decreased the degree of surprise. Similar to brooch B, brooch D was also familiar to most wearers, which may be why participants assigned it values of friendly and calm.

The study also provided a preliminary biophilic semantic differential scale that may be used to understand how people interpret biophilic movements in biophilic artifacts. This scale was applied in exercise two of this study to explore people's emotional responses to four wearable objects with different biophilic movements.

\subsection{Implications and Contribution of the Study}

The study contributed the term "biophilic movement" to the area of biophilic design. The results of the explorations undertaken in this study suggest that biophilic movement adds interest to biophilic forms in interactive jewellery by engaging the people who interact with it. This study provides the following recommendations for designers:

- Study biological movements for a biology-to-design approach by consulting with a biologist to determine suitable sources of inspiration. Confirm categories of biophilic movements with a biologist. Therefore, biologists may be able to provide designers with examples of organisms that may be of interest in designing. Biologists that study 
mechanisms of movement may have insights of value to designers in the context of which types of movement may be possible to implement in a wearable object.

- Consider usability when designing movement for wearable objects since the objects have a constant relationship with the body. Movements with changes in size seem to elicit emotions, either negative or positive (surprise and wow experience).

- Incorporating familiar biophilic movement in a designed object may result in positive responses of calmness and friendliness, leading to a pleasurable experience.

- Incorporating unfamiliar biophilic movements in a designed object may also engage users (wearers and observers) through emotional responses of fear, laughter, excitement, and surprise, leading to a pleasurable experience.

- Users' responses to biophilic jewellery with biophilic movement may be understood by using the biophilic semantic differential scale developed in this study.

\subsection{Limitations of the Study}

This study provides preliminary research about incorporating biophilic movement in designed artifacts. Therefore, all the outcomes of this research require further investigation.

The research focused specifically on incorporating four types of biophilic movements in wearable objects and people's emotional responses to the prototypes with different movements. Testing different prototypes with other biophilic movements would provide more complete knowledge about this topic.

In this study, in order to explore the emotional responses of people to wearable objects with moving parts, biophilic movements were designed for "looks-like" and "works-like" prototypes of jewellery pieces and activated by the researcher manually. If the prototypes had been more interactive using Arduino and sensor technologies, the result would be different. As a result, this study should be considered a preliminary investigation for interactive biophilic moving wearable jewellery. 
Proximity is also an issue, which affected exercise one's participants' ability to perceive the movement in the first place. Although the 'when' and 'how' viewers perceived the movement it is not important for this study, it was understood that intimacy is important while testing wearable objects. Therefore, it is important for the viewers (people who meet the wearer) to be located close to the object and the wearer.

In brooch $\mathrm{A}$, adding the element of light made movement more visible. However, it became apparent that it added complexity to the exercises. 
CHAPTER 6

\section{CONCLUSION \& SUGGESTIONS}

\subsection{CONCLUSION}

This thesis studied the role of the design element of biophilic movement as an output in interactive wearable objects in a biology-to-design approach. It explored the application of 'biophilic movement' in the design of interactive wearable objects by incorporating both natural inspiration (discipline of biology) and physical movement in the design of products, to create the potential for a pleasurable user experience.

This study took a user-centred approach that explored the users' emotional responses to the integration of biophilic movements into the design of interactive wearable objects. The results achieved from this interdisciplinary study provide considerable knowledge regarding the disciplines of design and biology. This knowledge can offer guidelines for jewellers, fashion designers, and industrial designers when they are designing movement for interactive biophilic wearable objects. The main findings of this research into biophilic movement are:

1. Incorporating biophilic movement can add interest to interactive biophilic wearable objects by engaging the people who interact with it in a variety of ways. For example familiar and unfamiliar movements as well as changing sizes elicit different emotional responses.

2. A design method for identifying and categorizing biologically-inspired movements can help designers in the area of biology-to-design.

3. A biophilic semantic differential scale can be used to understand how people interpret biophilic movements in biophilic artifacts. 


\subsection{SUGGESTIONS FOR FUTURE RESEARCH}

Movement has different qualities such as speed, time or beat, continuity, direction, volume, and rhythm. A change in any of these qualities can affect the way people perceive the movement of objects, elicit different emotional responses, and provide different experiences, whether positive or negative. Using sensor technology could provide a better opportunity to control the speed of the objects and attain different results. Further research could examine the effect of biophilic movements while incorporating different speeds, rhythm, or continuity. Future research could also investigate more biologically inspired movements and expand the table (Table 3).

Future research could also explore the viewer's emotional responses while a wearer activates the interactive object consciously or without wearer's knowledge. In this case, it may be interesting to have a comparison between the two situations. The results could provide useful information in designing outputs for interactive objects. 


\section{References}

Astfalck, J., Broadhead, C., \& Derrez, P. (2005). New Directions in Jewellery. London: Black Dog Publishing.

Agarwal, A., \& Meyer, A. (2009, April). Beyond usability: Evaluating emotional response as an integral part of the user experience. In CHI'09 Extended Abstracts on Human Factors in Computing Systems (pp. 2919-2930). ACM.

Bacigalupi, M. (1998, May). The craft of movement in interaction design. In Proceedings of the working conference on Advanced visual interfaces (pp. 174-184). ACM.

Broadhead, C. (2005). A Part/ Apart. In J. Astfalck, C. Broadhead, \& P. Derrez (Eds.), New Direction in Jewellery (pp. 25-35). London: Black Dog Publishing.

Benyus, J. M. (2008). A good place to settle: Biomimicry, biophila, and the return to nature's inspiration to architecture. In S. Kellert, J. H. Heerwagen, \& M. L. Mador (Eds.), Biophilic design: The theory, science, and practice of bringing buildings to life (pp. 27-42). New Jersey, NJ: John Wiley \& Sons.

Chao, P. Y., Cimen, I., Lancee, W., Offermans, S. A. M., \& Veenstra, R. (2004, June). Exploring semantics of movement in context. In Dutch HCI'04 Proceedings of the conference on Dutch directions in HCI (pp. 5). ACM.

Carpi, F., \& De Rossi, D. (2005). Electroactive polymer-based devices for e-textiles in biomedicine. Information Technology in Biomedicine, IEEE Transactions on, 9(3), 295-318.

Cheung, L. (2006). Wear, wearing, worn: The translations of jewels to jewellery. In L. Cheung, B. Clarke, I. Clarke, \& A. Sackville (Eds.), New Direction in Jewellery 2 (pp.12-23). London: Black Dog Publishing.

Derrez, P. (2005). Jewellery? What kind of jewellery are we actually talking about? In J. Astfalck, C. Broadhead, \& P. Derrez (Eds.), New Direction in Jewellery (pp.11-17). 
London: Black Dog Publishing.

Desmet, P. M. A., Overbeeke, K., \& Tax, S. (2001). Designing products with added emotional value: development and Application of an approach for research through design. The design journal 4(1), 32-47.

Desmet, P. M.A., \& Hekkert, P.P.M. (2002). The basis of product emotions. In W. S. Green \& P. W. Jordan (Eds.), Pleasure with products: beyond usability (pp. 61-68). London: Taylor \& Francis.

Desmet, P. M. A. (2005). Measuring emotion: Development and application of an instrument to measure emotional responses to products. In M. A. Blythe, K. Overbeeke, A. F. Monk, \& P. C. Wright (Eds.), Funology: From Usability to enjoyment (pp.111123). Netherlands: Springer.

Desmet, P. M. A., \& Hekkert, P. P. M. (2007). Framework of product experience. International Journal of Design, 1(1), 57-66.

Desmet, P. M. A., Porcelijn R., \& Van Dijk, M. B. (2007). Emotional design: Application of a research-based design approach. Knowledge, Technology \& Policy, 20(3), 141-155.

Dormer, P., \& Turner, R. (1986). The new jewellery: trends and traditions. New York, NY: Thames and Hudson.

Fayazi, N., \& Frankel, L. (2014). Creating meaningful movement in the design of products. Forthcoming Paper, Presented at the Eight International Conference on Design Principles \& Practices, Vancouver, British Columbia, (January 2014).

Flannery, M. C. (2001). Living with organisms. The American Biology Teacher, 63(1), 67-70.

Flannery, M. C. (2005). Jellyfish on the ceiling and deer in the den: The biology of interior decoration. Leonardo, 38(3), 239-244.

Flannery, M. C. (2007). Weeds on the lapel: Biology and jewellery. The American Biology Teacher, 69(1), 44-47. 
Flannery, M. C. (2008). For the love of nature: Biopholia \& contemporary jewellery. Metalsmith, 28(3), 34-41.

Friesen, C. (2011). Collaborating with the past. Ornament, 35(2), 64-65.

Frankel, L. (2007). Connecting virtual and visceral: An introduction to the evolution of wearable computers for industrial designers. Presented and in Proceedings 2007 CONNECTIONS 07, National Conference, Congress and Education Symposium, Industrial Designers Society of America and the International Council of Societies of Industrial Design. San Francisco, October 17-20,75-81.

Fusakul Sompit, M. (2002). Interactive Ornaments: Emotions in Motions (Doctoral dissertation). Retrieved from Ethos Electronic Thesis Online Services.

Galton, E. (2012). Basics fashion design 10: Jewellery design: From fashion to fine jewellery 10. Switzerland: AVA Publishing.

Heerwagen, J. H., and Orians, G. H. (1986). Adaptations to windowlessness: A study of the use of visual decor in windowed and windowless offices. Environment and Behavior, $18(5), 623-639$.

Heerwagen, J. H., and Hase, B. (2001). Building biophilia: Connecting people to nature in building design. Environmental Design and Construction, 3, 30-36.

Heerwagen, J. H. (2003). Bio-inspired design: What can we learn from nature. Unpublished manuscript. Retrieved from http://www.usgbc.org/Docs/Archive/External/Docs8542.pdf

Heerwagen, J. H. (2009). Biophilia, health and well-being. Restorative Commons: Creating Health and Well-being through Urban Landscapes, USDA Forest Service, Pennsylvania, 39-57.

Hekkert, P. (2006). Design aesthetics: Principles of pleasure in design. Psychology Science, 
$48(2), 157$.

Hekkert, P., and Leder, H. (2008). Product aesthetics. In H. N. J. Schifferstein, \& P. Hekkert (Eds.), Product experience (pp. 259-285). Amsterdam: Elsevier.

Hekkert, P., Van Dijk, M. (2011). Vision in design: A guidebook for innovators. Amsterdam: BIS.

Helmer, R. J. N., Mestrovic, M. A., Farrow, D., Lucas, S., \& Spratford, W. (2009). Smart textiles: Position and motion sensing for sport, entertainment and rehabilitation. Advances in Science and Technology, 60, 144-153.

Hopson, B. (2009, March 1). Kinetic Design and the Animation of Products.

Retrieved from http://www.core77.com/blog/featured_items/kinetic_design_and_the_animation_of_prod ucts_by_ben_hopson_12642.asp

Jordan, P. W. (2000). Designing pleasurable products: An introduction to the new human factors. London: Taylor \& Francis.

Jordan, P. W. (2002). Designing pleasurable products: An introduction to the new human factors. US: CRC Press.

Jordan, P. W. (2002). The personalities of products. In W. S. Green and P W. Jordan (Eds.), Pleasure with products: Beyond usability (pp.109-119). London: Taylor \& Francis.

Joye, Y. (2011). Biophilic design aesthetics in art and design education. The Journal of Aesthetic Education, 45(2), 17-35.

Kaplan, R., and Kaplan, S. (1989). The experience of nature: A psychological perspective. New York, NY: Cambridge University Press.

Karana, E. (2010). How do materials obtain their meanings? METU Journal of the Faculty of Architecture, 27(2), 271-285.

Katcher, A., Segal, H., and Beck, A. (1984). Comparison of contemplation and hypnosis for the reduction of anxiety and discomfort during dental surgery. American Journal of 
Clinical Hypnosis, 27(1), 14-21.

Kellert, S. R., and Wilson, E.O. (1993). The biophilia hypothesis. US: Island Press.

Kellert, S. R. (2005). Building for life: Designing and understanding the human-nature connection. US: Island press.

Kellert, S. R. (2008). Dimensions, elements, and attributes of biophilic design. In S. R. Kellert, J. Heerwagen, and M. L. Mador (Eds.). Biophilic design: The theory, science, and practice of bringing buildings to life (pp. 3-19). New Jersey, NJ: John Wiley \& Sons.

Kluszczynski, R. W. (2010). Strategies of interactive art. Journal of Aesthetics \& Culture, 2. Retrieved from http://web.b.ebscohost.com/ehost/pdfviewer/pdfviewer?sid=c580bf6b-3d62-4aff-a3695 f8ace4de01c\%40sessionmgr $114 \&$ vid $=2 \&$ hid $=123$

Kuhn, S. L., and Stiner, M. C. (2007). Paleolithic ornaments: Implications for cognition, demography and identity. Diogenes, 54(2), 40-48.

Özcan, E., Vanegmond, R. (2009). Product sound design: an inter-disciplinary approach? In: Undisciplined! Design Research Society Conference 2008, Sheffield Hallam University, Sheffield, UK, 16-19 July 2008.

Owens, Cody. (n.d.). Wearable technology: Fashion meets applied science. Retrieved from http://student.uscupstate.edu/owensch/FinalPaper.pdf

Macdonald, A. S. (2002). The scenario of sensory encounter: Cultural factors in sensoryaesthetic experience. In W. S. Green and P W. Jordan (Eds.), Pleasure with products: Beyond usability (pp.109-119). London: Taylor \& Francis.

Meilach, D. Z. (2003). Art jewelry today.: Schiffer Publishing.

Nam, T. J., Lee, J. H., \& Park, S. Y. (2007). Physical Movement as Design Element to Enhance Emotional Value of a Product. International Association of Societies of 
Design Research. The Hong Kong Polytechnich University $\left(12^{\text {th }}\right.$ to $15^{\text {th }}$ November 2007).

Norman, D. A. (2004). Emotional design. New York, NY: Basic Books.

Norman, D. A. (1988). The psychology of everyday things. New York, NY: Basic books.

Philips, C. (1996). Jewellery: From antiquity to present. London: Thames \& Hudson Ltd.

Parkes, A., Poupyrev, I., \& Ishii, H. (2008). Designing kinetic interactions for organic user interfaces. Communications of the ACM, 51(6), 58-65.

Russell, J. A. (2003). Core affect and the psychological construction of emotion. Psychological review, 110(1), 145.

Schifferstein, H. N. J., \& Spence, C. (2011). Multisensory product experience. In H. N. J. Schifferstein, \& Hekkert, P. (Eds.), Product experience (pp.133-163). Amsterdam: Elsevier.

Sonneveld, M. H., \& Schifferstein, H. N. (2008). The tactual experience of objects. In Schifferstein, H. N., and Hekkert, P. (Eds.), Product experience (pp. 41-67). Amsterdam: Elsevier.

Shepard, P. (1996). Traces of an Omnivore. Washington, DC: Island Press.

Seymour, S. (2009). Fashionable Technology The intersection of design, fashion, science and technology. Austria: Springer.

Seymour, S., and Beloff, L. (2008). Fashionable Technology-The Next Generation of Wearables. In C. Sommerer, L. C. Jain, and L. Mignonneau (Eds.). The Art and Science of Interface and Interaction Design, (pp. 131-140). Berlin Heidelberg: Springer.

Snyder, J. B. (2008). Art Jewelry Today 2. Pennsylvania, PA: Schiffer Pub.

Suri, J. F. (2002). Designing experience: Whether to measure pleasure or just tune in. In Green W. S. and Jordan, P. W. (Eds.), Pleasure with products: Beyond usability 
(pp.161-174). London: Taylor \& Francis.

Riddick, C. C. (1985). Health, aquariums, and the non-institutionalized elderly. Marriage \& Family Review, 8(3-4), 163-173.

Tang, S. L. P. (2007). Recent developments in flexible wearable electronics for monitoring applications. Transactions of the Institute of Measurement and Control, 29(3-4), 283300.

Trait, H. (2008). 7000 years of jewellery. New York, NY: Firefly Books.

Ulrich, R. S. (1979). Visual landscapes and psychological well-being. Landscape Research, $4(1), 17-23$.

Ulrich, R. S. (1984). View through a window may influence recovery. Science 224(4647), 224-225.

Ulrich, R. S., Simons, R. F., Losito, B. D., Fiorito, E., Miles, M. A., and Zelson, M. (1991). Stress recovery during exposure to natural and urban environments. Journal of Environmental Psychology 11(3), 201-230.

Uğur, S. (2013). Wearing Embodied Emotions: A Practice Based Design Research on Wearable Technology. New York, NY: Springer.

Vaughan, L. C. (1997, March). Understanding movement. In Proceedings of the ACM SIGCHI Conference on Human factors in computing systems, 548-549.

Van Gorp, T., \& Adams, E. (2012). Design for emotion. Massachusetts, MA: Elsevier.

Vincent, J. (2007). Background to Biomimetics. In Report of a DTI Global Watch Mission, Biomimetics: Strategies for Product Design Inspired by Nature, 8-11.

Volstad, N. L., \& Boks, C. (2012). On the use of Biomimicry as a useful tool for the industrial designer. Sustainable Development, 20(3), 189-199.

Wallace, J., Jackson, D., Ladha, C., Olivier, P., Monk, A., Blythe, M., \& Wright, P. (2007). Digital jewellery and family relationships. In Workshop on the family and communication technologies, Northumbria University. 
Wallace, J. (2007). Emotionally charged: A practice-centred enquiry of digital jewellery and personal emotional significance (Doctoral dissertation, Sheffield Hallam University). Retrieved from ProQuest Dissertations \& Theses: UK \& Ireland.

Wu, T. Y., \& Chang, W. (2007). The study of products with bios forms in conveying pleasure. International Association of Societies of Design Research. The Hong Kong Polytechnich University (12 th $15^{\text {th }}$ November 2007).

Young, R., Pezzutti, D., Pill, S., \& Sharp, R. (2005). The development of tools to assist the design of motion in system operated products. Proceedings of Design and Semantics of Form and Movement-DesForM, (pp.13-22).

Young, R., Pezzutti, D., Pill, S., \& Sharp, R. (2005). The language of motion in industrial design. Proceedings of Design and Semantics of Form and Movement-DesForM, (pp.6-12).

Professor Friedrich Becker eV. The Artistic Work [Web log comment]. Retrieved November 3, 2013 from http: //www.prof-friedrich becker.com/artist_artwork.html

Professor Friedrich Becker [Video file]. Retrieved from http://www.youtube.com/watch? $\mathrm{v}=\mathrm{xV}$ PIhRim XSE 
APPENDIX A

Consent Form-Participating in Interview

\section{CONSENT TO PARTICIPATE IN INTERVIEW}

\section{Carleton \\ U N I V E R S I T Y}

Title of the research project: Investigating Interactive Biophilic Wearable Objects

This interview is about the role of "Movement" in the design of interactive products.

Date of ethics clearance: November 21, 2013

Ethics Clearance for the Collection of Data Expires: May 31, 2014

This is to state that I, , agree to participate in a program of research being conducted by Neda Fayazi of the School of Industrial Design at Carleton University, under the supervision of Prof. Lois Frankel.

I understand that I am free to withdraw from the study at any time, up until December 30, 2013. I may also decline from answering any question. If I elect to withdraw during or after participation, my data will not be used in further research and will be erased (destroyed).

Once collected, my data will be kept confidential and stored on a personal computer and flash memory cards. It will only be accessible to the researcher and supervisor and will be destroyed after the research is complete. My data may be presented as research findings only in an aggregate form from which I am not personally identifiable. Pictures and videos will be recorded and no personal information will be collected. Any other information will be discarded after finishing the project.

The overall time of the interview is approximately 20 minutes, and no special assistance is needed to conduct the research.

\section{$\underline{\text { RISKS AND BENEFITS }}$}

There are no physical risks.

\section{CONDITIONS OF PARTICIPATION}

- I understand that I am free to withdraw my consent and discontinue my participation at any time until December 30, 2013 without negative consequences.

- I understand that I may choose to participate without being photographed, or audio- and video-recorded

- I understand that my participation in this study is CONFIDENTIAL (i.e., the researcher will know, but will not disclose my identity) 
Questions about the study can be directed to:

Neda Fayazi, MDES Student

School of Industrial Design

Carleton University

neda.fayazi@,carleton.ca
Lois Frankel, Associate Professor

School of Industrial Design

Carleton University

lois_frankel@.carleton.ca

The project was reviewed and received ethics review and clearance by the Carleton University Research Ethics Board.

\section{REB contact information:}

Professor Andy Adler, Chair

Professor Louise Heslop, Vice-Chair

Research Ethics Board

Carleton University

1325 Dunton Tower

1125 Colonel By Drive

Ottawa, ON K1S 5B6

Tel: 613-520-2517 / ethics@carleton.ca

I AGREE TO PARTICIPATE IN THE STUDY: __ Yes _ _ No

I AGREE TO BE PHOTOGRAPHED, AUDIO-RECORDED AND/OR VIDEO-RECORDED:

Yes No

NAME (please print):

SIGNATURE: 


\title{
APPENDIX B
}

\author{
Expert Interview Questions
}

\section{Interview with Ben Hopson}

Owner at Hopson Kinetic, Assistant Professor of Industrial Design at Pratt Institute

1- Why do you think the aesthetic value of movement in products is ignored by industrial designers? What are the benefits of adding movement to the design of products? What are the benefits of the awareness of designers about this value in the design discipline?

2- In choosing colours for the products, we have certain kinds of considerations (using cold colours or warm colours) and the emotional feeling that each of them elicit for the user. However, colours chosen for a design can be meaningful, purposeful, and even functional. Regarding to the movement of the object, what are the considerations or principles that designers should have while designing movement for the objects? What should designers pay attention to when they want to design movement for an object? (What are the principles?)

3-What aspects of movement do you consider important for someone who is designing movement for small pieces?

4-What is your opinion about different types of movement such as organic movements or non-organic movement? Do you think there should be any preference for users interacting with objects with organic movement or non-organic movement?

5-In which stage of the design process is the aspect of movement considered? Meaning, does the form of a product precede the movement, or does the movement of a product precede form in the design process. Or, are they both considered simultaneously? Can designing movement be placed in each stage of the design process?

6-Are the viewers of kinetic objects more influenced by the form of the object or the movement of the object? How about other design elements such as colour, texture, light? Do you think the viewers are more influenced by the colour, form, texture, or the movement of the object?

7-You have some works in kinetic jewellery; the scissors collection and the jewellery pieces which can move and change shape by the wearer. So, the movement can actually be activated by the user. In designing the movement for an object, what should designers pay attention to regarding the way the object is going to be activated? Should movement be activated by the user, randomly, or by responsive objects (response to certain kind of conditions)? 


\section{APPENDIX C}

Internet Survey of Videos \& Exhibition

\section{Exhibitions:}

-Carleton University's 'Annual Butterfly Show', Ottawa, Canada

Museums:

-Canadian Museum of Nature, Ottawa, Canada

-American Museum of Natural History, New York, US

-Insectarium, Botanical Garden, Montreal, Canada

$\underline{\text { Web Sources: }}$

-www.nationalgeographic.com

-www.bbc.co.uk/nature/wildlife

- http://www.amnh.org/

- http://nature.cal

- http://www.youtube.com/watch? $v=k I o N 2 P C v L 4 o$

- http://www.youtube.com/watch? $v=H G s Z f d m z g O U$

- http://www.youtube.com/watch? $v=K e C_{-} F W S Q Y R U$

- http://www.youtube.com/watch?v=RFxrF_hbQRU

- http://www.youtube.com/watch? $v=y$ alRGgrm3ac

- http://www.youtube.com/watch?v=J1ik_SeNrmU

- http://www.youtube.com/watch? $v=K 2 q O \operatorname{Imlg} Y 4 Y$

- http://www.youtube.com/watch?v=_vinCblLjrw

- http://www.youtube.com/watch?v=A7nMWjnrelQ 


\section{APPENDIX D}

Consent Form-Participating in Workshop

\section{CONSENT TO PARTICIPATE IN STUDY}

\section{Carleton

Title of the research project: Investigating Interactive Biophilic Wearable Objects

This study was to explore the role of "Movement" in the design of wearable objects and the emotional response of people to products with moving parts.

Date of ethics clearance: November 21, 2013

Ethics Clearance for the Collection of Data Expires: May 31, 2014

$\mathrm{I}$, (please print your name), volunteered to participate in a study on Investigating Interactive Biophilic Wearable Objects. This study was being conducted by Neda Fayazi of the School of Industrial Design at Carleton University, under the supervision of Prof. Lois Frankel.

I understand that this was a brainstorming workshop and I worked with simple materials such as paper, cardboard, etc. making $3 \mathrm{~d}$ models. I understand that my participation in the study was voluntary and I am free to withdraw from the study up to March 15, 2014.

Once collected, my data will be kept confidential and stored on a personal computer and flash memory cards. It will only be accessible to the researcher and supervisors and will be destroyed after the research is complete. My data may be presented as research findings only in an aggregate form from which I am not personally identifiable. Pictures and videos will be recorded and no personal information will be collected. Any other information will be discarded after finishing the project.

\section{PROCEDURES:}

The activity was as follows:

1) Brainstorming

2) Making Three Dimensional Models

The overall time of the workshop was 2 hours, and no special assistance was needed to conduct the research.

\section{RISKS AND BENEFITS}

There were no risks and will be no risks by using this information in the research project..

\section{CONDITIONS OF PARTICIPATION}

- I understand that I am free to withdraw my consent and discontinue my participation at any time until March 15, 2014.

- I understand that my participation in this study is CONFIDENTIAL (i.e., the researcher will know, but will not disclose my identity) 
Questions about the study can be directed to:

Neda Fayazi, MDES Student

School of Industrial Design

Carleton University

neda.fayazi@,carleton.ca
Lois Frankel, Associate Professor

School of Industrial Design

Carleton University

lois_frankel@.carleton.ca

The project was reviewed and received ethics review and clearance by the Carleton University Research Ethics Board.

REB contact information:

Professor Andy Adler, Chair

Professor Louise Heslop, Vice-Chair

Research Ethics Board

Carleton University

1325 Dunton Tower

1125 Colonel By Drive

Ottawa, ON K1S 5B6

Tel: 613-520-2517 / ethics@carleton.ca

I AGREE TO PARTICIPATE IN THE STUDY: Yes _ No

NAME (please print):

SIGNATURE: 
APPENDIX E

Workshop Hand out

Hello \& welcome to the workshop!!!!!

First of all, thank you for coming! I really appreciate your presence today.

The topic of this workshop is 'Creating Movement'.

"If you want to show 'movement', how would you show it with the materials provided?"

By making simple models, show your idea of 'movement'. Try and built something with the materials provided which has any kind of movement. If you do not have anything in your mind, start making whatever you want out of paper and wait until the moment comes.

Thank you

Neda 


\section{CONSENT TO PARTICIPATE IN STUDY}

Title of the research project: Investigating Interactive Biophilic Wearable Objects

This study is to explore the role of "Movement" in the design of wearable objects and the emotional response of people to products with moving parts.

Date of ethics clearance: November 21, 2013

Ethics Clearance for the Collection of Data Expires: May 31, 2014

$\mathrm{I}$, (please print your name), volunteer to participate in a study on Investigating Interactive Biophilic Wearable Objects. This study is being conducted by Neda Fayazi of the School of Industrial Design at Carleton University, under the supervision of Prof. Lois Frankel.

I understand that I will interact with the movable wearable objects. I will also be asked to complete a questionnaire about my experience. I understand that my participation in the study is voluntary and I am free to withdraw from the study at any time, up until December 9, 2013. I may also decline from answering any question. If I elect to withdraw during or after participation, my data will not be used in further research and will be erased (destroyed).

Once collected, my data will be kept confidential and stored on a personal computer and flash memory cards. It will only be accessible to the researcher and supervisors and will be destroyed after the research is complete. My data may be presented as research findings only in an aggregate form from which I am not personally identifiable. Pictures and videos will be recorded and no personal information will be collected. Any other information will be discarded after finishing the project.

\section{PROCEDURES:}

The activity will be as follow:

Exercise 1:

1) Viewing the object

2) Answering the questionnaire

The overall time of the test is approximately 20 minutes, and no special assistance is needed to conduct the research. 


\section{RISKS AND BENEFITS}

There are no physical risks.

\section{CONDITIONS OF PARTICIPATION}

- I understand that I am free to withdraw my consent and discontinue my participation at any time until December 9, 2013 without negative consequences.

- I understand that I may choose to participate without being photographed, or audio- and videorecorded

- I understand that my participation in this study is CONFIDENTIAL (i.e., the researcher will know, but will not disclose my identity)

Questions about the study can be directed to:

Neda Fayazi, MDES Student

School of Industrial Design

Carleton University

neda.fayazi@, carleton.ca
Lois Frankel, Associate Professor

School of Industrial Design

Carleton University

lois_frankel@carleton.ca

The project was reviewed and received ethics review and clearance by the Carleton University Research Ethics Board.

\section{REB contact information:}

Professor Andy Adler, Chair

Professor Louise Heslop, Vice-Chair

Research Ethics Board

Carleton University

1325 Dunton Tower

1125 Colonel By Drive

Ottawa, ON K1S 5B6

Tel: 613-520-2517 / ethics@carleton.ca

I AGREE TO PARTICIPATE IN THE STUDY: Yes _ No

NAME (please print):

SIGNATURE: 


\section{APPENDIX G}

Exercise One: Emocards \& Multiple-choice Questionnaire

1) As a viewer of this object, what was your emotional feeling when you first saw this wearable object with the moving parts?

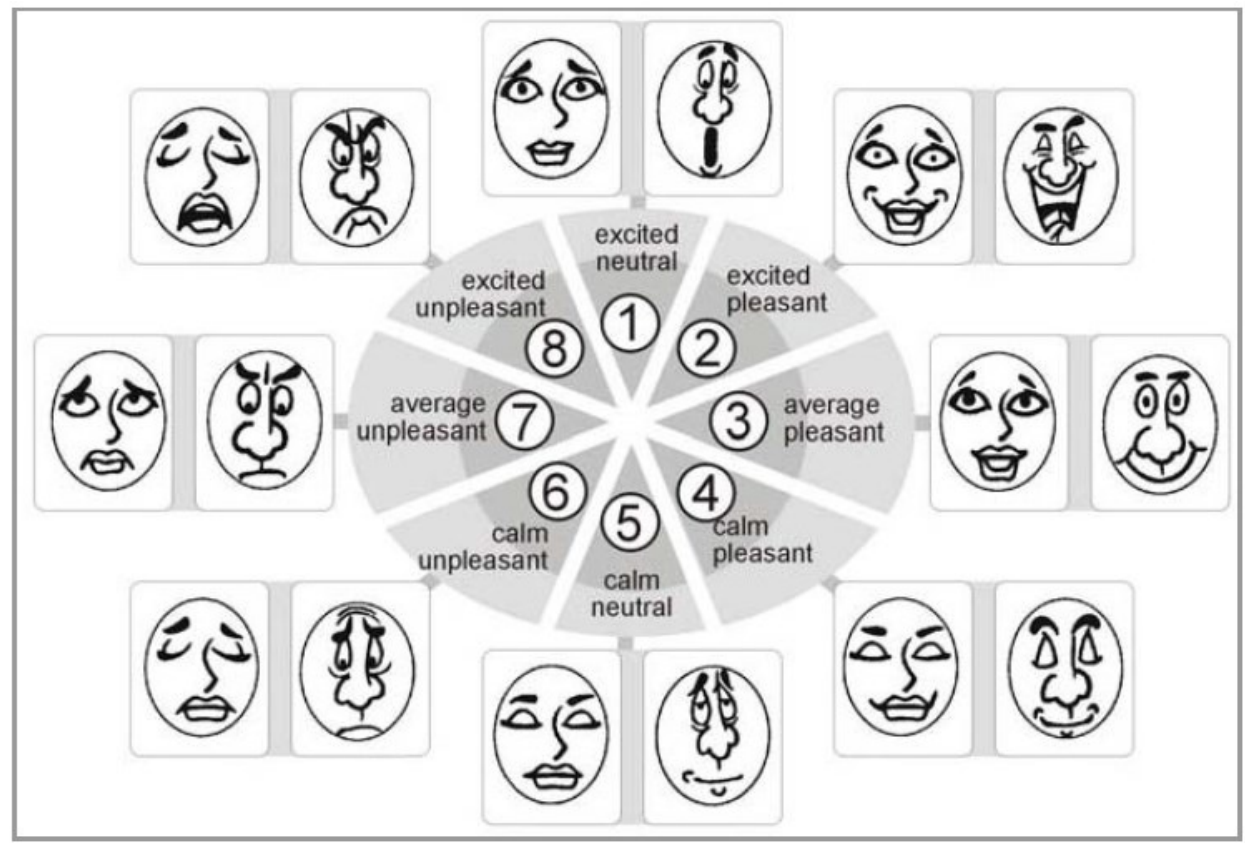

2) What draw your attention to the movement of the object?

From other student's reactions....

From the wearer's reaction

I considered it myself.

Other (please indicate if you choose this choice)

3) As a viewer of this wearable object, to what extent did you enjoy viewing the wearable object with the moving part?

very slightly or not at all...... a little ..... $\quad$ moderately..... quite a bit .... extremely....

4) If you have any comments, please share them here.

"Thank you for your participation"

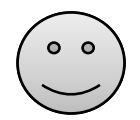




\section{APPENDIX H}

Consent Form-Choosing the Adjectives for SDS

\section{CONSENT TO PARTICIPATE IN STUDY}

Title of the research project: Investigating Interactive Biophilic Wearable Objects

This study is to explore the role of "Movement" in the design of wearable objects and the emotional response of people to products with moving parts.

Date of ethics clearance: November 21, 2013

Ethics Clearance for the Collection of Data Expires: May 31, 2014

I, __ (please print your name), volunteer to participate in a study on

Investigating Interactive Biophilic Wearable Objects. This study is being conducted by Neda Fayazi of the School of Industrial Design at Carleton University, under the supervision of Prof. Lois Frankel.

I understand that my participation in the study is voluntary and I am free to withdraw from the study at any time, up until November 30, 2013. I may also decline from answering any question. If I elect to withdraw during or after participation, my data will not be used in further research and will be erased (destroyed).

Once collected, my data will be kept confidential and stored on a personal computer and flash memory cards. It will only be accessible to the researcher and supervisors and will be destroyed after the research is complete. My data may be presented as research findings only in an aggregate form from which I am not personally identifiable. Pictures and videos will be recorded and no personal information will be collected. Any other information will be discarded after finishing the project.

\section{PROCEDURES:}

The activity will be as follow:

1) Watching the videos

2) Choosing the suitable cards according to the video

The overall time of the test is approximately 20 minutes, and no special assistance is needed to conduct the research.

\section{RISKS AND BENEFITS}

There are no physical risks.

\section{CONDITIONS OF PARTICIPATION}

- I understand that I am free to withdraw my consent and discontinue my participation at any time until November 30, 2013 without negative consequences.

- I understand that I may choose to participate without being photographed, or audio- and videorecorded

- I understand that my participation in this study is CONFIDENTIAL (i.e., the researcher will know, but will not disclose my identity) 
Questions about the study can be directed to:

Neda Fayazi, MDES Student

School of Industrial Design

Carleton University

neda.fayazi@,carleton.ca
Lois Frankel, Associate Professor

School of Industrial Design

Carleton University

lois_frankel@.carleton.ca

The project was reviewed and received ethics review and clearance by the Carleton University Research Ethics Board.

REB contact information:

Professor Andy Adler, Chair

Professor Louise Heslop, Vice-Chair

Research Ethics Board

Carleton University

1325 Dunton Tower

1125 Colonel By Drive

Ottawa, ON K1S 5B6

Tel: 613-520-2517 / ethics@carleton.ca

I AGREE TO PARTICIPATE IN THE STUDY: Yes _ No

NAME (please print):

SIGNATURE: 


\section{APPENDIX I}

\section{Form-Choosing Adjectives}

Please complete this form for each of the four videos $(A, B, C, \& D)$ :

After watching each video, please write the positive or negative adjectives that best describe your feelings toward each video (You can also use the pool of adjectives in order to choose the adjectives best suited with each video).

Video

peaceful/ calm/ open/ pure/ serene/ original/unique/ genuine/ real/ beautiful/verdant/ alive/ relax/ invigorating/ refreshing/ cooling/ pristine/ preserved/ delightful/ natural/ beauty/ flawless/ clean/ happy/ scenic/ intelligence/ grace/ humour/ goodwill/ positive/ inspiring/ absolute/ great/ successful/ creative/ empowered/Capable/ Understanding/ Flexible/ compromising/ Humanist/ Supportive/ Encouraging/ Respectful/ Diligent/ Attentive/ Adaptive/ caring/ modest/ active listener/ tolerant/ agreeable/ brave/ faithful/ gentle/ jolly/ lively/ nice/ obedient/ proud/ relieved/ silly/ thankful/ victorious/ witty/ zealous/ honest/ assertive/ direct/ broad-minded/ committed/ conscientious/ dynamic/ hard-worker/ persistent/ mature/ methodical/ motivated/ objective/ tenacious/ sociable/ friendly/ realistic/ reliable/ resourceful/ responsible/ confident/ traditional/ trustworthy/ unconventional / eclectic/ naive/ green/ stable/ strong/ articulate/ artistic/ adept/ amazing/ bright/ colourful/ creepy/ crowded/ deserted/ different/ dry/ enchanted/ hot/ incredible/ interesting/ magnificent/ modern/ mysterious/noisy/ perfect/ pleasant/ quit/ remarkable/ shiny/ silent/ stormy/ strange/ terrific/ ugly/ unusual/ warm/ wild/ windy/ tranquil/ tropical/ harmonious/ sensational/ romantic/ magical/ fairytale-Like/ mystical/ charming/ comfortable/ cooperative/ courageous/ eager/ elated/ enchanting/ energetic/ enthusiastic/ exuberant/ fine/ funny/ healthy/ joyous/fantastic/ glorious/ hilarious/ kind/ lucky/ Abashed/ abhorrent/ angry/ annoyed/ anxious/ arrogant/ ashamed/ awful/ bored/ condemned/ confused/ defeated/ defiant/ depressed/ disgusted/ dizzy/ envious/ foolish/ frightened/ grumpy/ homeless/ ill/ jittery/lonely/ obnoxious/ panicky/ scary/ terrible/ thoughtless/ troubled/ weary/ worried/ disturbed/ embarrassed/ fierce/ frantic/ grieving/ helpless/ hungry/ itchy/ lazy/ nutty/ outrageous/ repulsive/ sore/ testy/ tired/ uptight/ wicked/Aberrant/ aberrational/ abeyant/ abiding/ ablated/ abnormal/ absent/ annoying/ bad/ better/ brainy/ breakable/ busy/ careful/ clever/ crazy/ dead/ difficult/ easy/ frail/ important/ inexpensive/ inquisitive/ odd/ outstanding/ powerful/ shy/ stupid/ tame/ cautious/ concerned/ curious/ doubtful/ expensive/ fragile/ horrible/ impossible/ innocent/ mushy/ poor/ puzzled/ rich/ sleepy/ super/ tough/ uninterested/ vast/ wandering/ wrong/ gorgeous /Pretty/ Wonderful/ Spectacular/ Attractive/ Fair/ Handsome/ Stunning/ ravishing/ Good-Looking/ Beauteous/ Lovely/ Grand/ Breath-taking/ Impressive/ Awe/ inspiring/Elegant/ Dazzling/ Brilliant/ Alluring/ Prepossessing/ Appealing/ Engaging/ glamorous/ Bewitching/ Exquisite/ Divine/ Drop/ on the eye/ Cute/ Foxy /Comely /nice-looking/ Fetching/ 


\section{APPENDIX J}

Consent Form-Participating in Exercise Two

\section{Carleton U N I VER S I T Y}

\section{CONSENT TO PARTICIPATE IN STUDY}

Title of the research project: Investigating Interactive Biophilic Wearable Objects This study is to explore the role of "Movement" in the design of wearable objects and the emotional response of people to products with moving parts.

Date of ethics clearance: November 21, 2013

Ethics Clearance for the Collection of Data Expires: May 31, 2014

I,

Investigating Interactive Biophilic Wearable Objects. This study is being conducted by Neda Fayazi of the School of Industrial Design at Carleton University, under the supervision of Prof. Lois Frankel.

I understand that I will interact with the movable wearable objects. I will also be asked to complete a questionnaire about my experience. I understand that my participation in the study is voluntary and I am free to withdraw from the study at any time, up until February 15, 2013. I may also decline from answering any question. If I elect to withdraw during or after participation, my data will not be used in further research and will be erased (destroyed).

Once collected, my data will be kept confidential and stored on a personal computer and flash memory cards. It will only be accessible to the researcher and supervisors and will be destroyed after the research is complete. My data may be presented as research findings only in an aggregate form from which I am not personally identifiable. Pictures and videos will be recorded and no personal information will be collected. Any other information will be discarded after finishing the project.

\section{PROCEDURES:}

The activity will be as follow:

Phase 2:

1) Touching and wearing the objects

2) Answering the questionnaires

The overall time of the test is approximately 20 minutes, and no special assistance is needed to conduct the research.

\section{RISKS AND BENEFITS}

There are no physical risks.

\section{CONDITIONS OF PARTICIPATION}

- I understand that I am free to withdraw my consent and discontinue my participation at any time until December 20, 2013 without negative consequences.

- I understand that I may choose to participate without being photographed, or audio- and video- 
recorded

- I understand that my participation in this study is CONFIDENTIAL (i.e., the researcher will know, but will not disclose my identity)

Questions about the study can be directed to:

Neda Fayazi, MDES Student

Lois Frankel, Associate Professor

School of Industrial Design

School of Industrial Design

Carleton University

Carleton University

neda.fayazi@,carleton.ca

lois frankel@carleton.ca

The project was reviewed and received ethics review and clearance by the Carleton University Research Ethics Board.

REB contact information:

Professor Andy Adler, Chair

Professor Louise Heslop, Vice-Chair

Research Ethics Board

Carleton University

1325 Dunton Tower

1125 Colonel By Drive

Ottawa, ON K1S 5B6

Tel: 613-520-2517 / ethics@carleton.ca

I AGREE TO PARTICIPATE IN THE STUDY: __ Yes _ _ No

I AGREE TO BE PHOTOGRAPHED, AUDIO-RECORDED AND/OR VIDEO-RECORDED:

Yes _ـ No

NAME (please print):

SIGNATURE: 


\section{APPENDIX K}

Exercise Two: Semantic Differential Scale

The scale consists of a number of affective terms (biopolar adjectives) that describe different feelings and emotions. Please indicate to what extent you have felt the product elicited this emotion during the interction with the prototype.

\begin{tabular}{|c|c|c|c|c|c|c|c|c|}
\cline { 2 - 8 } \multicolumn{1}{c|}{} & $\mathbf{1}$ & $\mathbf{2}$ & $\mathbf{3}$ & $\mathbf{4}$ & $\mathbf{5}$ & $\mathbf{6}$ & $\mathbf{7}$ & \multicolumn{1}{|c|}{} \\
\hline Artificial & & & & & & & & Natural \\
\hline Calm & & & & & & & & Tense \\
\hline Ugly & & & & & & & & Beautiful \\
\hline Interesting & & & & & & & & Boring \\
\hline Plain & & & & & & & & Colorful \\
\hline Friendly & & & & & & & & Unfriendly \\
\hline Dynamic & & & & & & & & Static \\
\hline Unpleasant & & & & & & & & Pleasant \\
\hline Unique & & & & & & & & Ordinary \\
\hline Impressive & & & & & & & & Unimpressive \\
\hline Familiar & & & & & & & & Unfamiliar \\
\hline
\end{tabular}




\section{APPENDIX L}

Exercise Two: Comparative Questionnaire

\section{Comparative Questionnaire}

Please answer the questions below.

1) With which prototype were you more engaged during the exercise?

prototype A prototype B prototype C prototype D none of them

Please indicate your reason.

2) Which prototype did you enjoy interacting most?

prototype A prototype $\mathrm{B}$ prototype $\mathrm{C}$ prototype $\mathrm{D}$ none of them

Please indicate your reason.

3) In which prototype did you find the movement more appealing? prototype A prototype $\mathrm{B}$ prototype $\mathrm{C}$ prototype $\mathrm{D}$ none of them Please indicate your reason.

4) If you want to choose one of them to wear, which one would you choose? prototype A prototype $\mathrm{B}$ prototype $\mathrm{C}$ prototype $\mathrm{D}$ none of them Please indicate your reason.

"Thank you for your participation" 


\section{APPENDIX M}

Exercise Two- Observation Chart

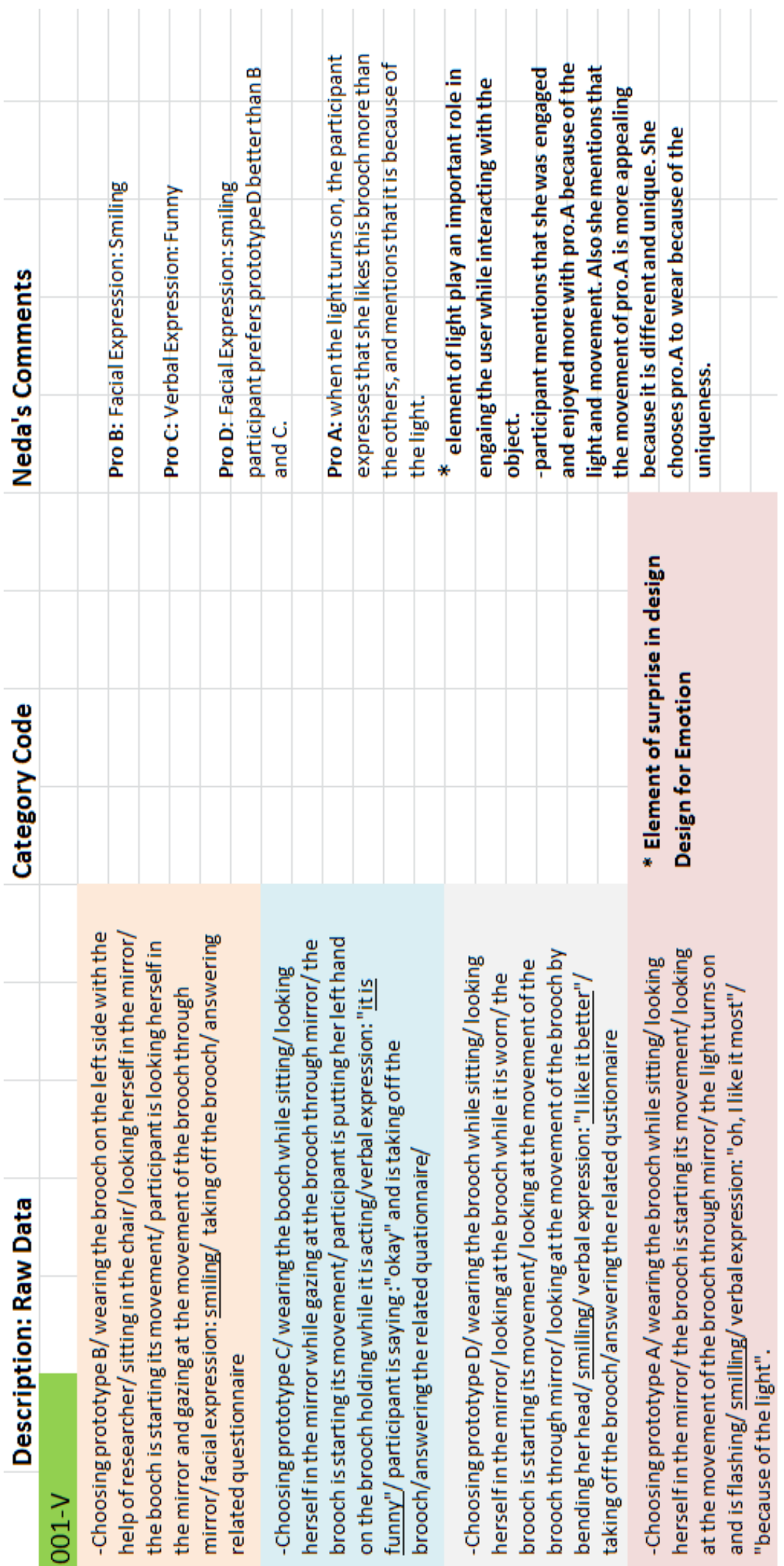



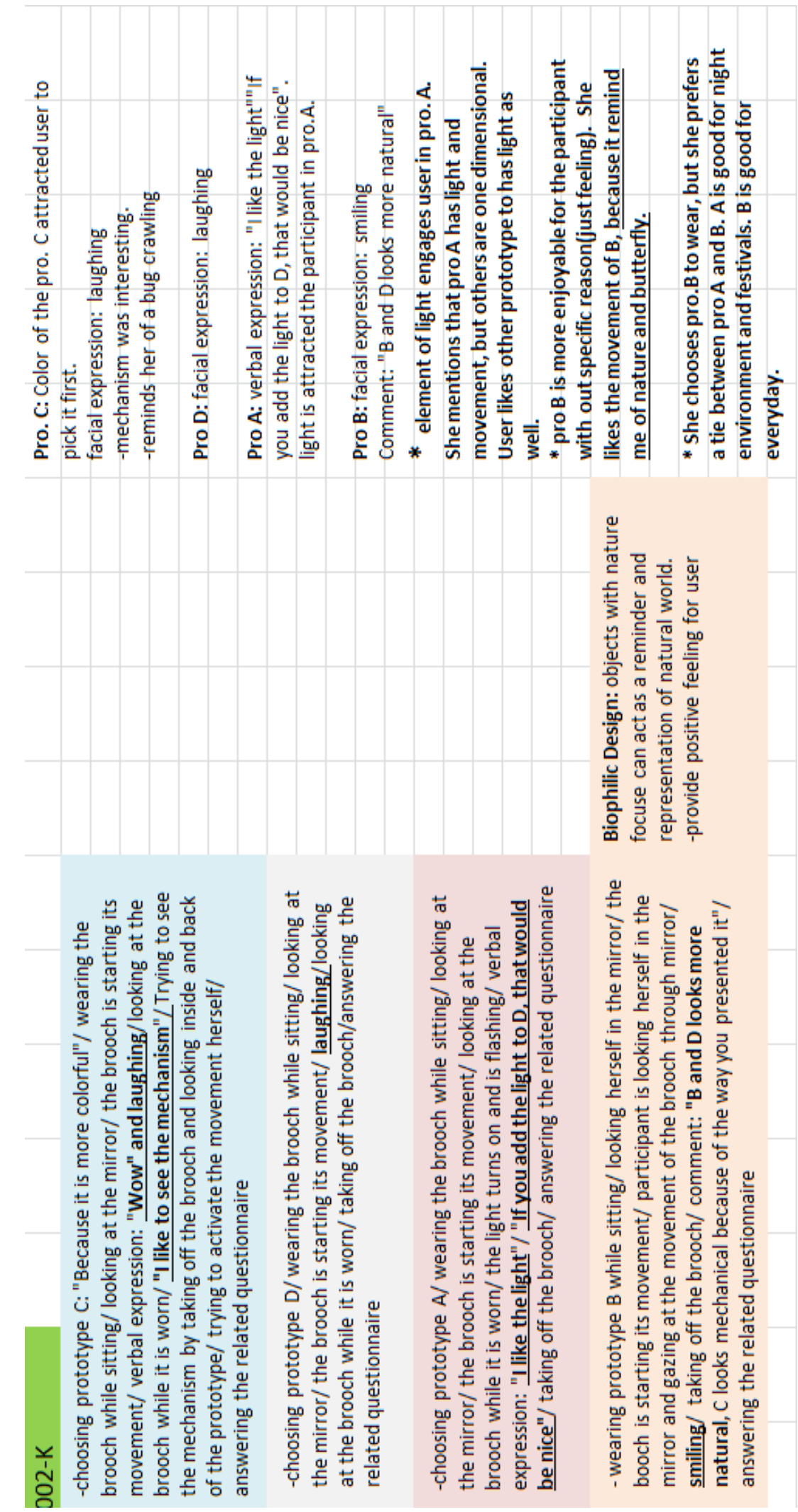


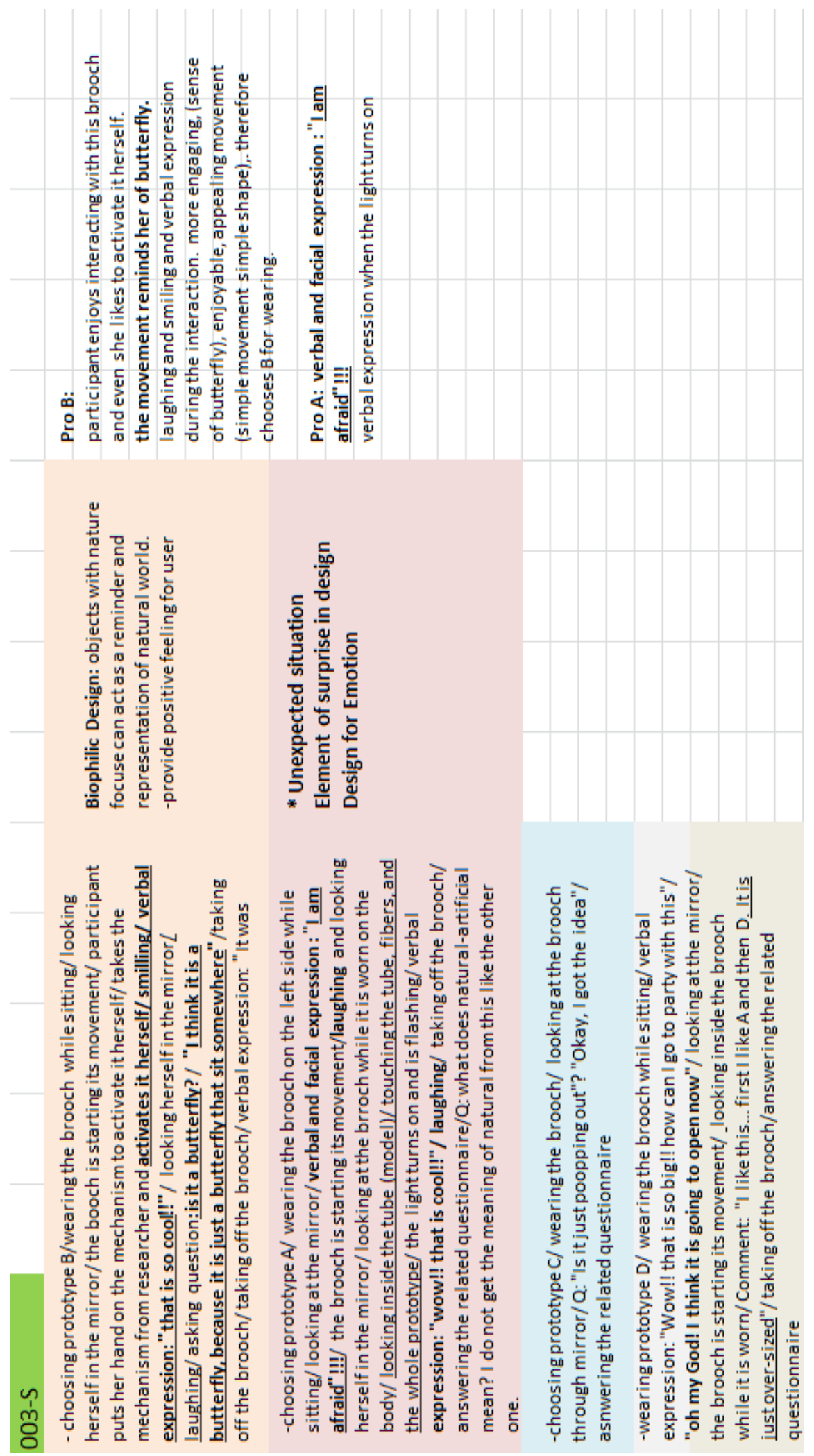




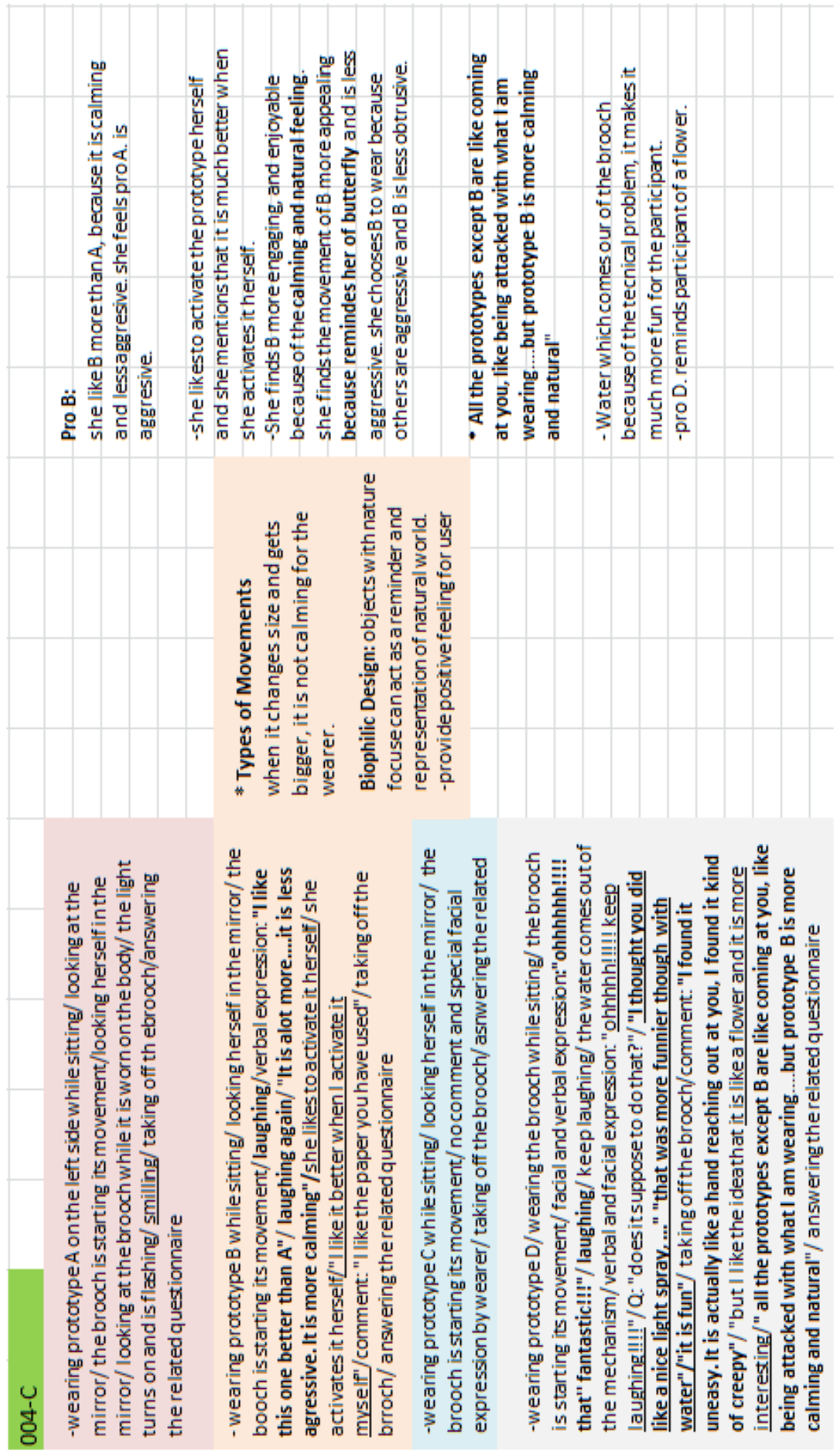




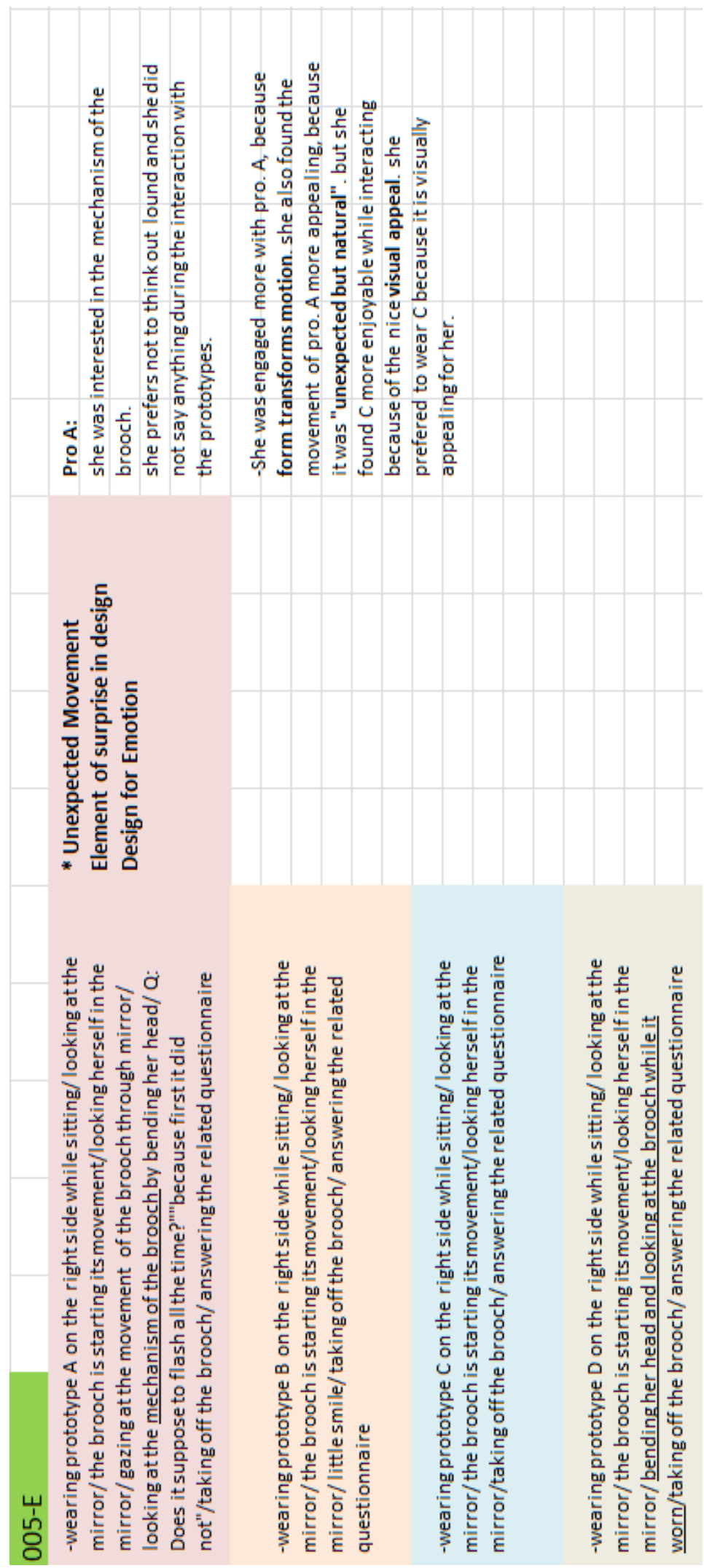



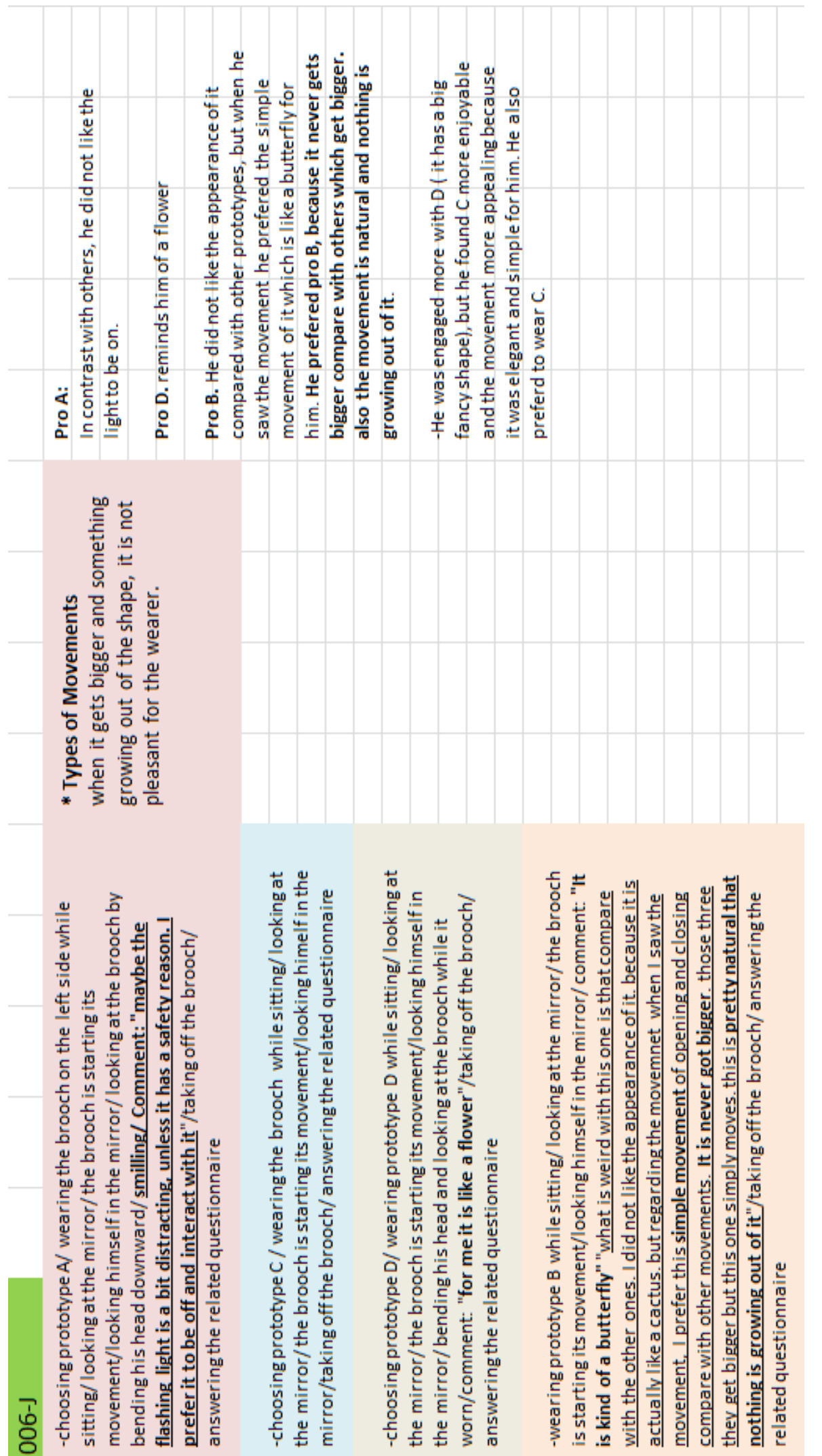


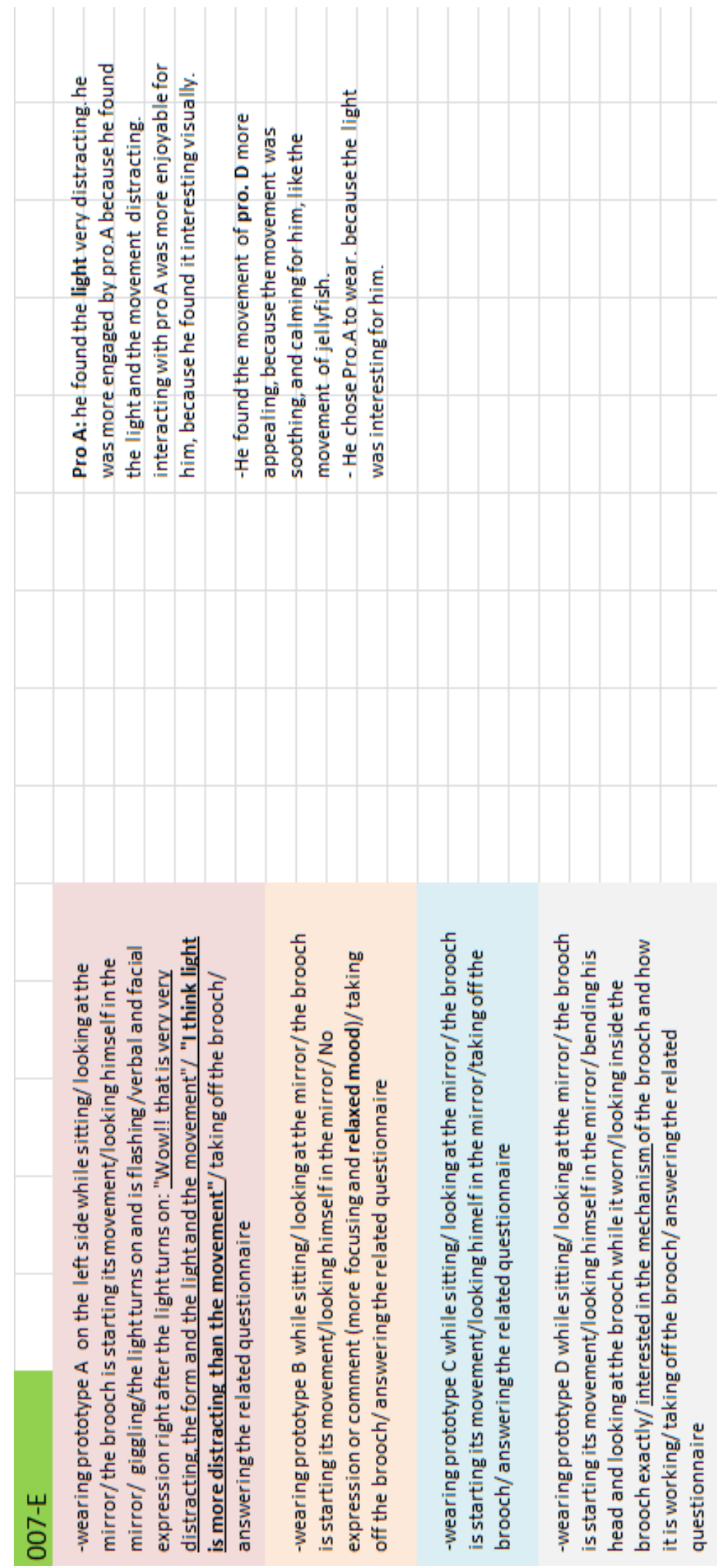




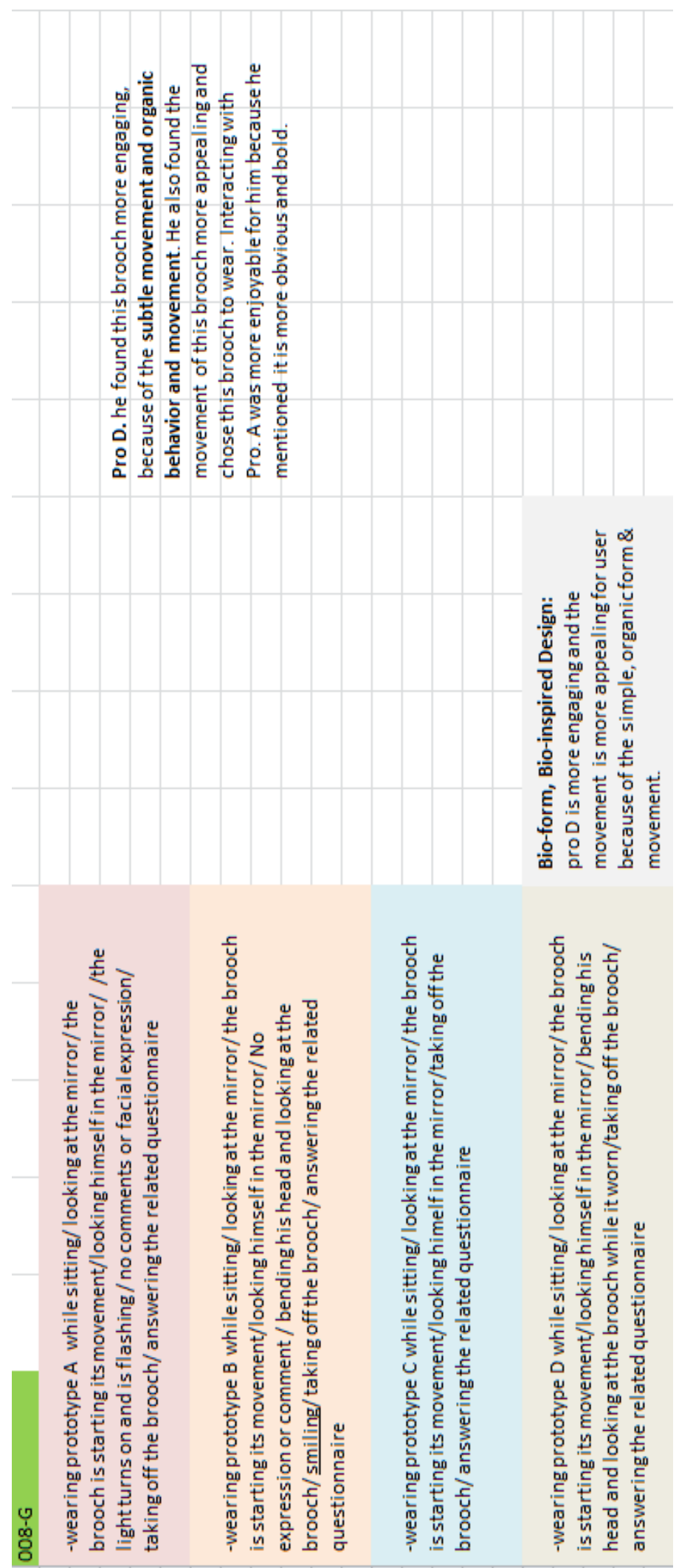




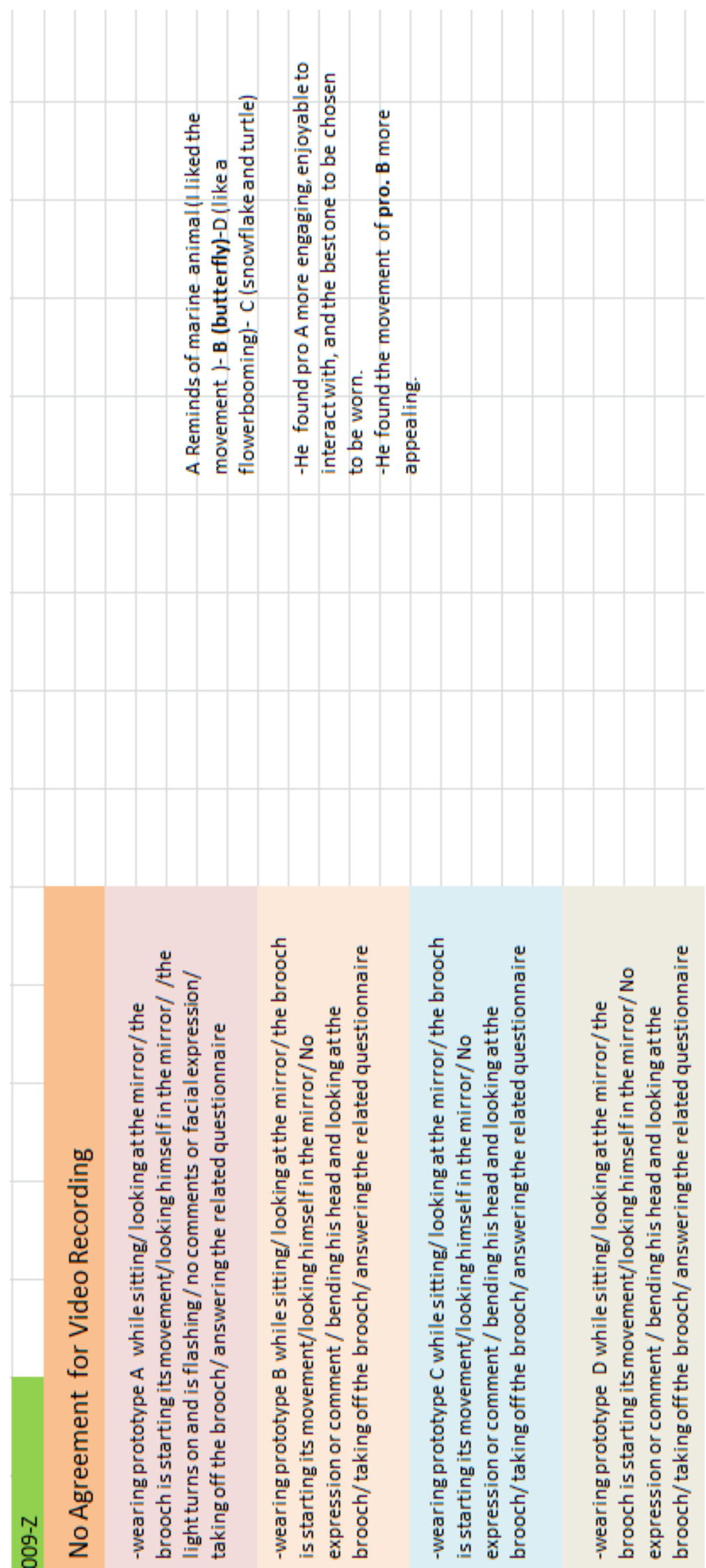




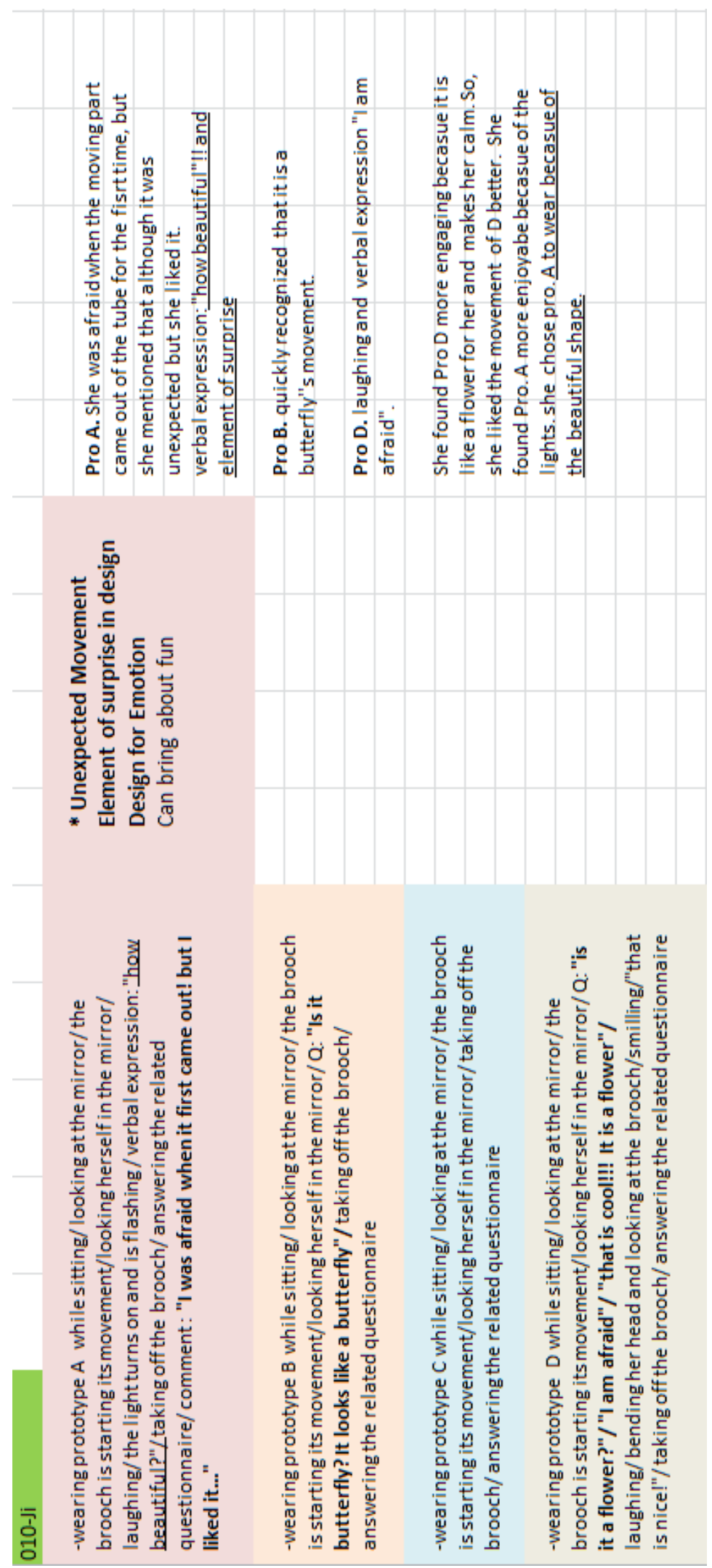




\section{APPENDIX N}

Exercise Two- Semantic Differential Scale Analysis

A

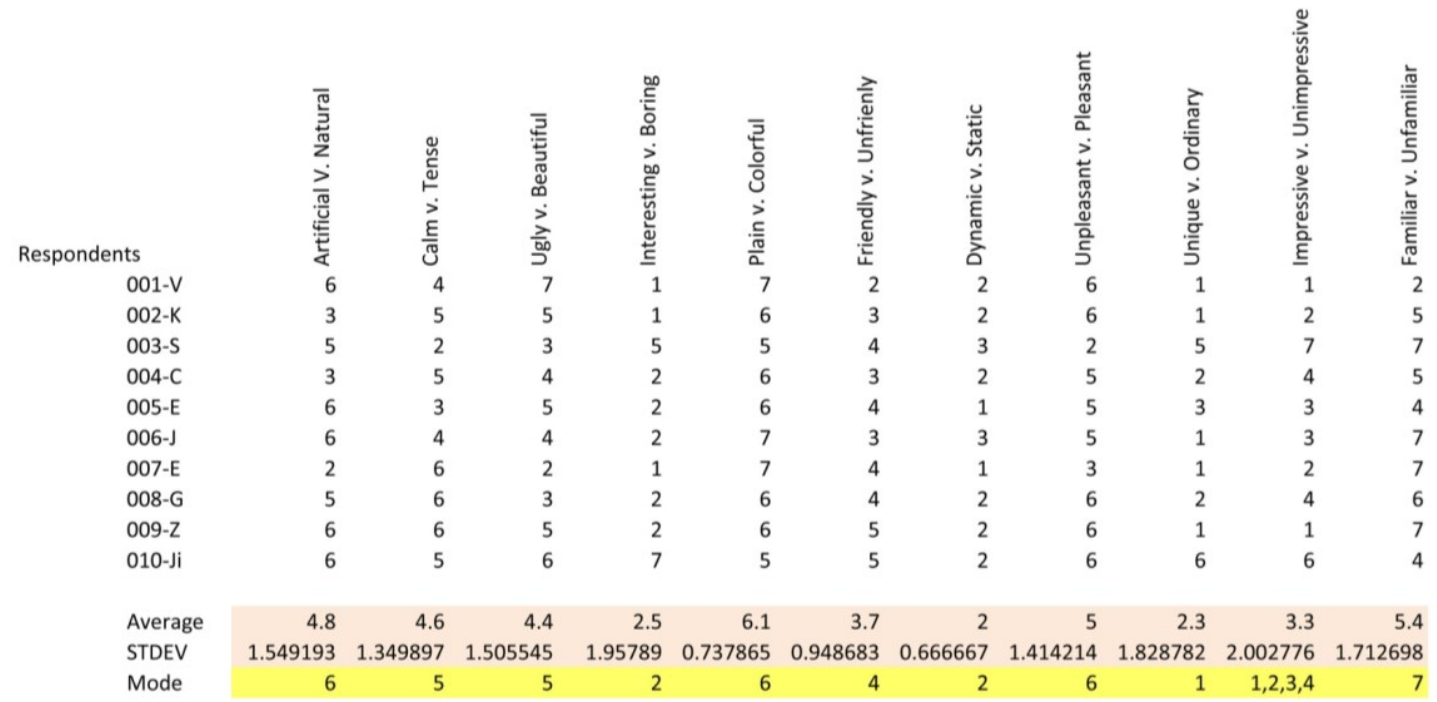

B

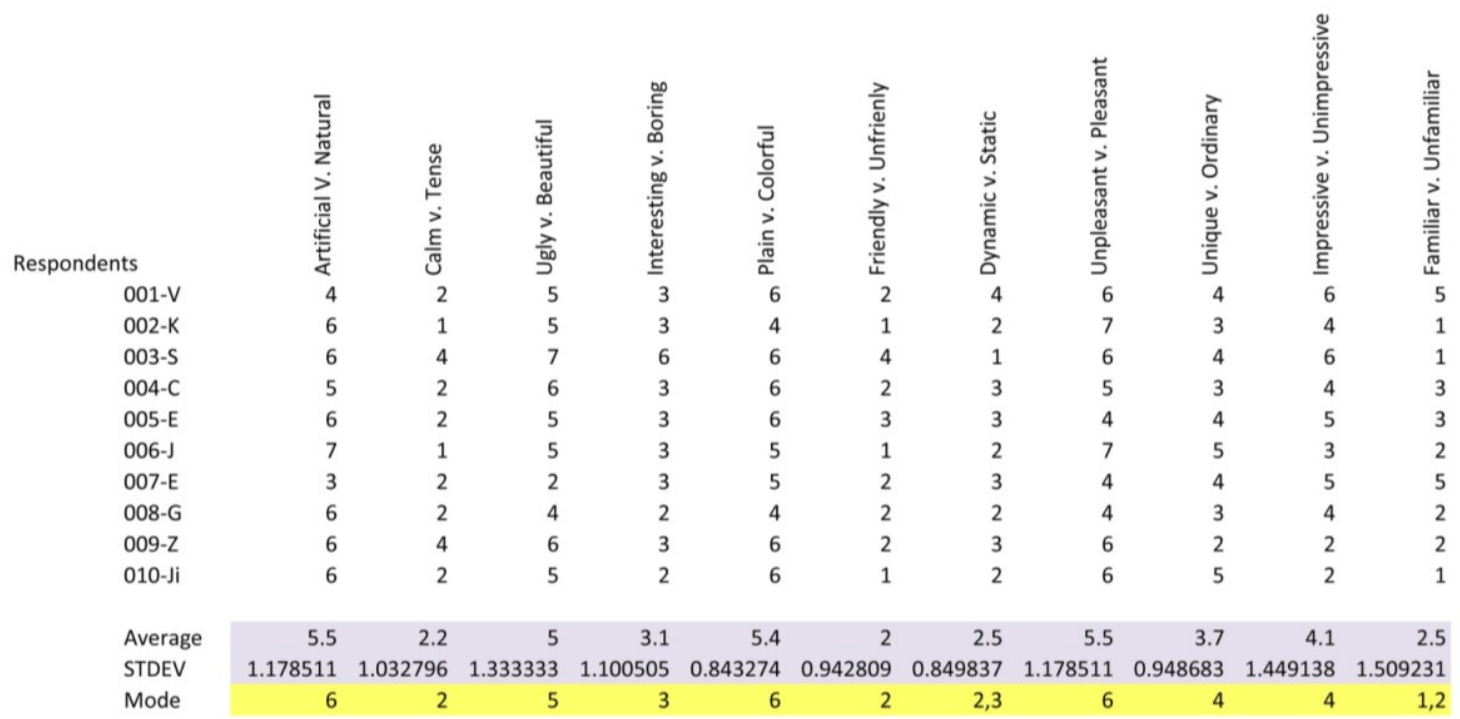




\section{C}

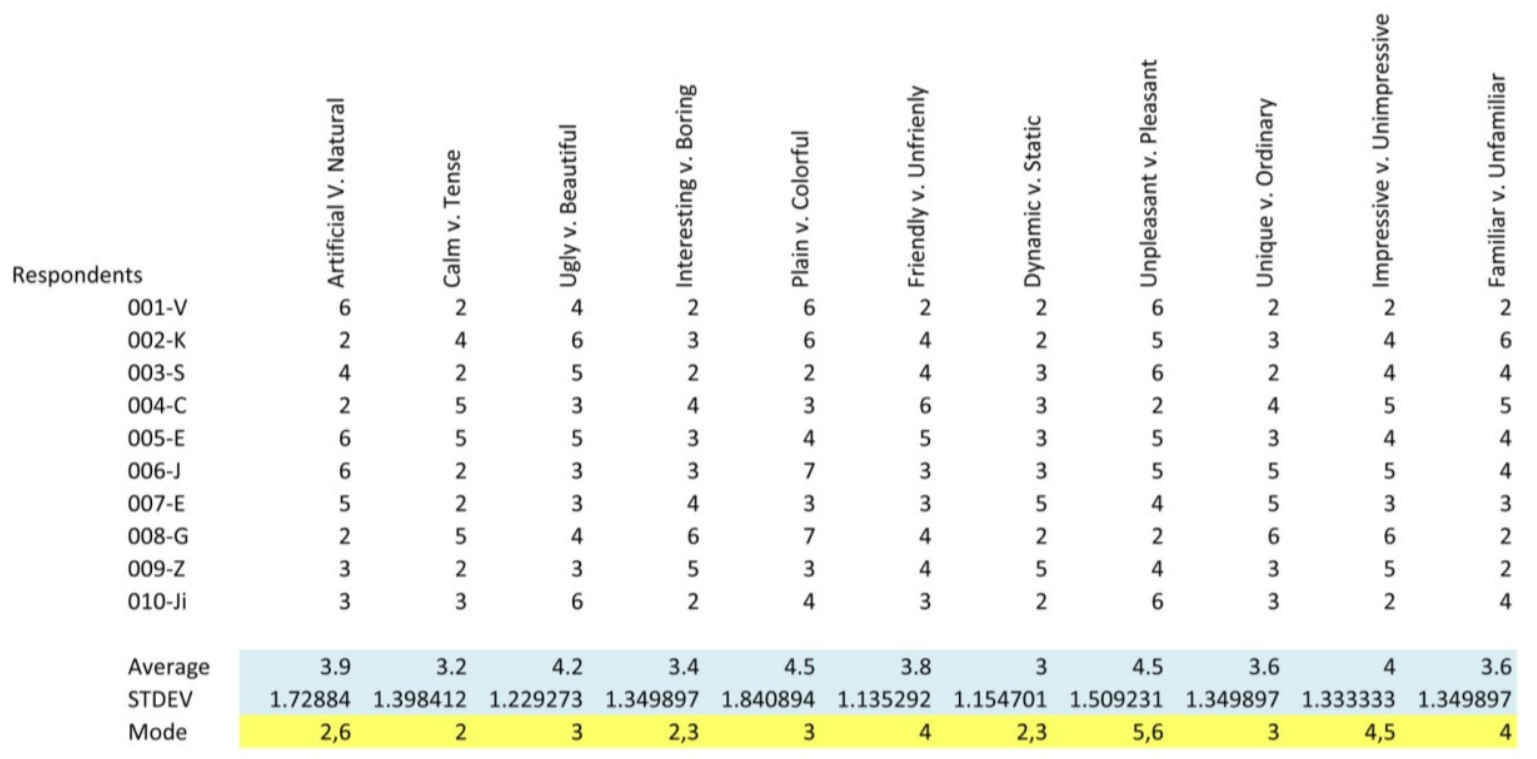

D

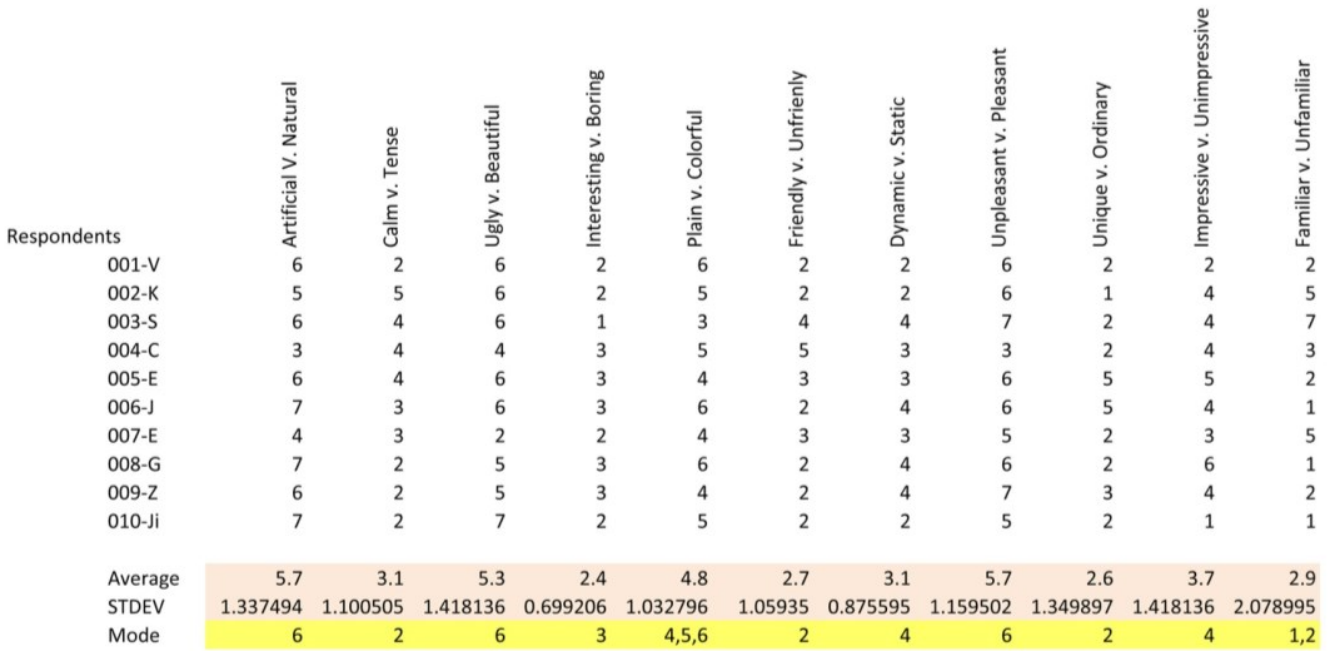


APPENDIX O

Exercise Two- Comparative Questionnaire Analysis
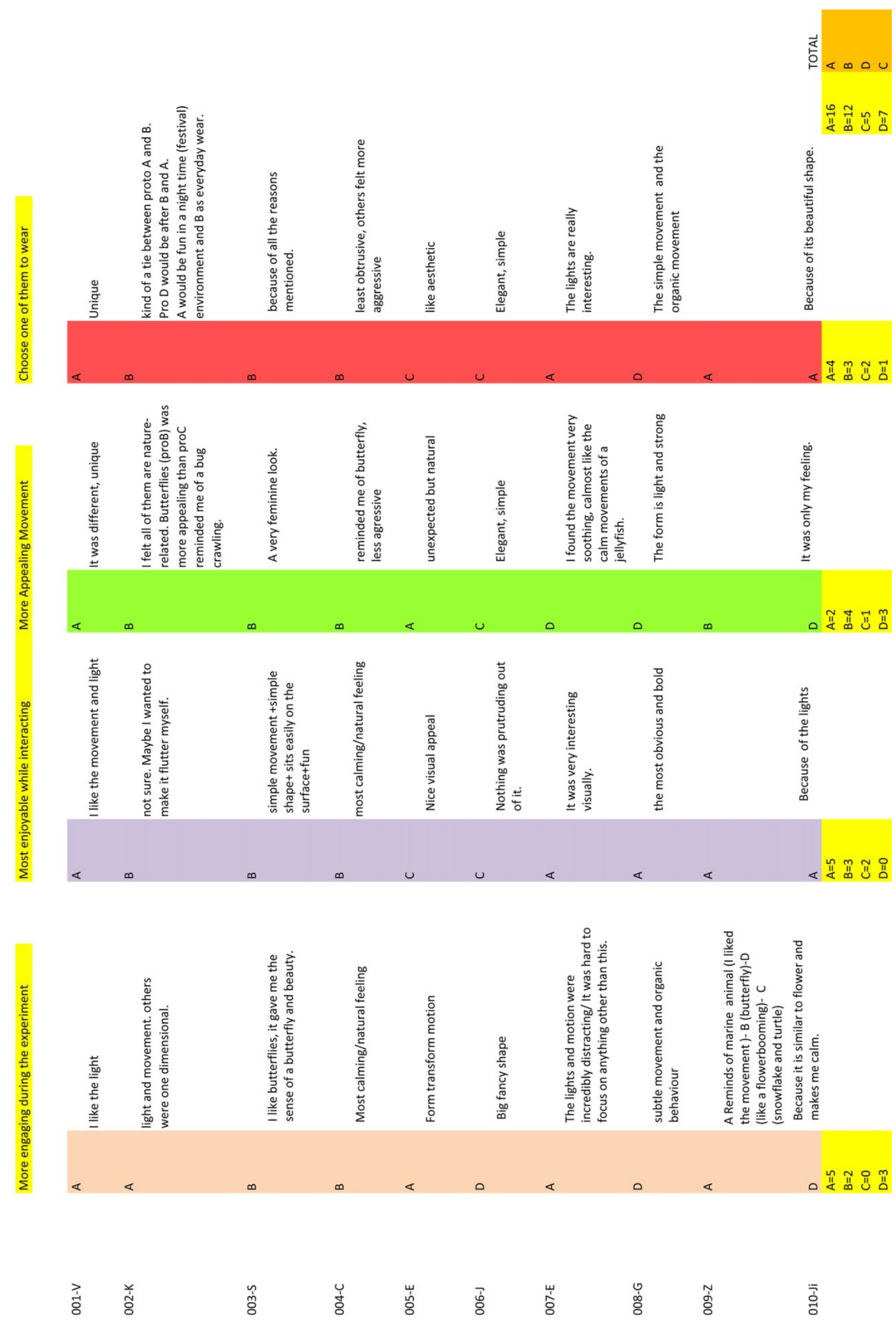


\title{
APPENDIX P
}

\section{Ethics Approval Form}

\section{단 Carleton \\ Canada's Capital University}

\author{
Carleton University Research Office \\ Research Ethics Board \\ 1325 Dunton Tower \\ 1125 Colonel By Drive \\ Ottawa, ON K1S 5B6 Canada \\ Tel: 613-520-2517 \\ ethics@carleton.ca
}

\section{Ethics Clearance Form - New Clearance}

This is to certify that the Carleton University Research Ethics Board has examined the application for ethical clearance. The REB found the research project to meet appropriate ethical standards as outlined in the Tri-Council Policy Statement: Ethical Conduct for Research Involving Human, 2nd edition, and the Carleton University Policies and Procedures for the Ethical Conduct of Research.

Date of Clearance: November 21, 2013

Researcher: Neda Fayazi (Student - MA student)

Department: Faculty of Engineering and DesignIIndustrial Design (School of) University: Carleton University

Research Supervisor (if applicable): Lois Franke

Project Number: 100788

Alternate File Number (if applicable):

Project Title: Investigating interactive biophilic wearable objects

Clearance Expires: May 31, 2014

\section{All researchers are governed by the following conditions:}

Annual Status Report: You are required to submit an Annual Status Report to either renew clearance or close the file. Failure to submit the Annual Status Report will result in the immediate suspension of the project. Funded projects will have accounts suspended until the report is submitted and approved.

Changes to the project: Any changes to the project must be submitted to the Carleton University Research Ethics Board for approval. All changes must be approved prior to the continuance of the research.

Adverse events: Should a participant suffer adversely from their participation in the project you are required to report the matter to the Carleton University Research Ethics Board. You must submit a written record of the event and indicate what steps you have taken to resolve the situation.

Suspension or termination of clearance: Failure to conduct the research in accordance with the principles of the Tri-Council Policy Statement: Ethical Conduct for Research Involving Humans, 2nd edition and the Carleton University Policies and Procedures for the Ethical Conduct of Research may result in the suspension or termination of the research project.

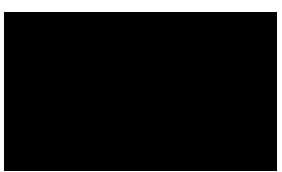

Andy Adler

Chair, Carleton University Research Ethics Board

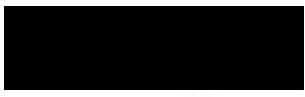

Louise Heslop

Vice-Chair, Carleton University Research Ethics Board 